ADSON ROCHA DO CARMO

\title{
KPI como base para modelagem de requisitos não funcionais em processos de negócio
}

São Paulo

2016 
ADSON ROCHA DO CARMO

\section{KPI como base para modelagem de requisitos não funcionais em processos de negócio}

Dissertação apresentada à Escola de Artes, Ciências e Humanidades da Universidade de São Paulo para obtenção do título de Mestre em Ciências pelo Programa de Pós-graduação em Sistemas de Informação.

Área de concentração: Metodologia e Técnicas da Computação

Versão corrigida contendo as alterações solicitadas pela comissão julgadora em 21 de novembro de 2016. A versão original encontra-se em acervo reservado na Biblioteca da EACH-USP e na Biblioteca Digital de Teses e Dissertações da USP (BDTD), de acordo com a Resolução CoPGr 6018, de 13 de outubro de 2011.

Orientador: Prof. Dr. Marcelo Fantinato

São Paulo

2016 
Autorizo a reprodução e divulgação total ou parcial deste trabalho, por qualquer meio convencional ou eletrônico, para fins de estudo e pesquisa, desde que citada a fonte.

CATALOGAÇÃO-NA-PUBLICAÇÃO

(Universidade de São Paulo. Escola de Artes, Ciências e Humanidades. Biblioteca)

Carmo, Adson Rocha do

KPI como base para modelagem de requisitos não funcionais em processos de negócio / Adson Rocha do Carmo ; orientador, Marcelo Fantinato. - São Paulo, 2016 $150 \mathrm{f}$ : : il.

Dissertação (Mestrado em Ciências) - Programa de Pós-

Graduação em Sistemas de Informação, Escola de Artes, Ciências e Humanidades, Universidade de São Paulo Versão corrigida

1. Negócios - Processos. 2. Negócios - Gerenciamento. 3. Negócios - Modelagem. 4. Desempenho organizacional Indicadores. 5. Engenharia de software. 6. Sistemas de informação. I. Fantinato, Marcelo, orient. II. Título

CDD 22.ed.- 610.0285 
Dissertação de autoria de Adson do Carmo, sob o título "KPI como base para modelagem de requisitos não funcionais em processos de negócio", apresentada à Escola de Artes, Ciências e Humanidades da Universidade de São Paulo, para obtenção do título de Mestre em Ciências pelo Programa de Pós-graduação em Sistemas de Informação, na área de concentração Metodologia e Técnicas da Computação, aprovada em 21 de novembro de 2016 pela comissão julgadora constituída pelos doutores:

Prof. Dr. Marcelo Fantinato

Prof. Dr.

Presidente

Escala de Artes, Ciências e Humanidades - Universidade de São Paulo

Profa. Dra. Lucinéia Heloisa Thom

Prof. Dr.

Universidade Federal do Rio Grande do Sul

Prof. Dr. Mauro de Mesquita Spinola

Prof. Dr.

Escola Politécnica - Universidade de São Paulo

Prof. Dr. Edmir Parada Vasques Prado

Prof. Dr.

Escala de Artes, Ciências e Humanidades - Universidade de São Paulo 
A Deus, aos meus familiares e amigos. 


\section{Agradecimentos}

Agradeço a Deus pela oportunidade de cursar este mestrado pela Universidade de São Paulo. É um desejo realizado. Agradeço aos meus familiares pelo apoio, principalmente à minha esposa, Kelly do Carmo, pela compreensão e empatia com os meus objetivos. Agradeço aos amigos e colegas de trabalho pela compreensão e incentivo, em especial Leonardo Simões e Laudison dos Anjos. Agradeço ao Prof. Dr. Marcelo Fantinato pela paciência e ao estimulo do meu desenvolvimento acadêmico. 


\section{Resumo}

CARMO, Adson Rocha. KPI como base para modelagem de requisitos não

funcionais em processos de negócio. 2016. 149 f. Dissertação (Mestrado em Ciências)

- Escola de Artes, Ciências e Humanidades, Universidade de São Paulo, São Paulo, 2016.

No cenário atual, nota-se a constante busca das organizações para que se mantenham competitivas no mercado. Para apoiar a organização, tanto no nível operacional quanto no nível não operacional, a Tecnologia da Informação (TI) é usada. Com intuito de apoiar as estratégias, as organizações usam a Gestão de Processos de Negócio (BPM Business Process Management) para identificar, definir e evoluir seus processos de negócio. Usando estes recursos, o framework Strategic Alignment with BPM (StrAli-BPM) foi desenvolvido para contribuir na melhoria do alinhamento entre os níveis estratégicos e operacionais da organização, por meio do tratamento dos requisitos não funcionais nos processos de negócio. Este projeto de pesquisa propõe estender o framework StrAli-BPM com a criação de um novo componente para fazer a extração de informações de metas estratégicas organizacionais a serem usadas na modelagem de requisitos não funcionais de processos de negócio. Para auxiliar na melhoria do alinhamento estratégico, a versão antiga do framework StrAli-BPM usa os Acordos em Nível de Negócio (BLA - Business Level Agreement) para tratar os requisitos não funcionais. Além de tratar os requisitos não funcionais por meio de BLAs, a versão antiga do framework StrAli-BPM define que o BLA deve dar origem aos Acordos em Nível de Serviço (SLA - Service Level Agreement), ou seja, os SLAs devem ser derivados dos BLAs. No entanto, esta versão antiga não define quais informações das metas estratégicas organizacionais devem ser usadas para compor BLAs. O novo componente proposto neste projeto de pesquisa, chamado Indicador Chave de Desempenho para Acordo em Nível de Negócio (KPI2BLA - Key Performance Indicator to Business Level Agreements), se propõe a identificar quais informações relevantes das metas estratégicas organizacionais devem ser usadas na criação dos requisitos não funcionais, que, posteriormente, devem servir para criação de BLAs.

Palavras-chaves: Gestão de processo de negócio, BPM, modelo de processo de negócio, BPMN, indicadores chave de desempenho, KPI. 


\begin{abstract}
CARMO, Adson Rocha. KPI as basis for modeling non-functional requirements in business processes. 2016. 149 f. Dissertação (Mestrado em Ciências) - Escola de Artes, Ciências e Humanidades, Universidade de São Paulo, São Paulo, 2016.

In the present scenario, there is the constant search for organizations to remain competitive in the market. And to support the organization, both at the operational level and in the non-operational level, the Information Technology (IT) is used. In order to support the strategies organizations use the Business Process Management (BPM) to identify, define and evolve their business processes. Using these features, the framework Strategic Alignment with BPM (StrAli-BPM) is designed to contribute to improving the strategic alignment between the strategic and operational levels of the organization, through the treatment of non-functional requirements in the business process. This research project proposes to extend the StrAli-BPM framework with the creation of a new component to the extraction of organizational strategic goals information to be used in the modeling of non-functional requirements of business processes. To assist in improving the strategic alignment, the old version of StrAli-BPM framework uses the Agreements in Business Level (BLA) to treat the non-functional requirements. In addition to treating non-functional requirements through BLAs, the old version of StrAli-BPM framework defines the BLA should lead to agreements on service level (SLA), it's mean, the SLAs should be derived from BLAs. However, this old version does not define what information the organizational strategic goals should be used to compose BLAs. The new component proposed in this research project, called Key Performance Indicator to Agreement on Business Level (KPI2BLA) aims to identify relevant information from organizational strategic goals should be used in the creation of requirements nonfunctional, which later must be used to create BLAs.
\end{abstract}

Keywords: Business Process Management, BPM, business process model and notation, BPMN, key performance indicator, KPI. 


\section{Lista de figuras}

Figura 1 - Área de atuação do subprojeto . . . . . . . . . . . . . . . . . 19

Figura 2 - Alinhamento estratégico entre o negócio e a TI . . . . . . . . . . . 24

Figura 3 - Atendimentos realizados por status . . . . . . . . . . . 27

Figura 4 - Metamodelo para monitoramento de negócio orientado a serviço . . . . 28

Figura 5 - Metamodelo de especificação do contexto da abordagem AMDiRE . . . 29

Figura 6 - Metamodelo de KPI . . . . . . . . . . . . . . . . . . . . 29

Figura 7 - Ciclo de vida BPM . . . . . . . . . . . . . . . 31

Figura 8 - Processo de negócio do exemplo ilustrativo envolvendo os principais elementos de BPMN . . . . . . . . . . . . . . . . 35

Figura 9 - Representação genérica dos conceitos envolvidos . . . . . . . . . . . 39

Figura 10 - Exemplos de métricas de QoS, QoE e QoBiz . . . . . . . . . . . . . 41

Figura 11 - Estrutura do acordo de serviço web . . . . . . . . . . . . . . . . 42

Figura 12 - Relação entre BLA e SLAs . . . . . . . . . . . . . . . . . . . . . . 43

Figura 13 - Framework de mapeamentos e derivações propostos . . . . . . . . . . . 46

Figura 14 - Metamodelo BLA@BPMN . . . . . . . . . . . . . . . . . . 47

Figura 15 - Exemplo ilustrativo do uso de BLA . . . . . . . . . . . . . . . 48

Figura 16 - Processo de seleção de estudos primários selecionados na revisão sistemática realizada . . . . . . . . . . . . . . . . 58

Figura 17 - Distribuição dos estudos primários por ano de publicação . . . . . . . . 66

Figura 18 - Técnicas de modelagem de metas estratégicas organizacionais identificadas nos estudos primários . . . . . . . . . . . . . . . . . 67

Figura 19 - Técnicas de modelagem de processos de negócio identificadas nos estudos primários . . . . . . . . . . . . . . . . . 6 67

Figura 20 - Número de estudos primários que apresentam abordagens automatizadas e não automatizadas . . . . . . . . . . . . . . . . . . . . . 68

Figura 21 - Ferramentas usadas na automação das técnicas identificadas nos estudos primários . . . . . . . . . . . . . . . .

Figura 22 - Framework StrAli-BPM estendido com o uso de metas estratégicas organizacionais via KPI . . . . . . . . . . . . . . . . 70

Figura 23 - Metamodelo proposto de indicadores chave de desempenho . . . . . . . 72 
Figura 24 - Relação entre as entidades da abordagem KPI2BLA e a entidade "Goal" do metamodelo BPMN . . . . . . . . . . . . . . . . 75

Figura 25 - Relação entre as entidades do componente KPI2BLA e a entidade "Penalty", "Reward" e "Compensation" do metamodelo BLA@BPMN 76

Figura 26 - Relação entre a entidade "BLA" e "KPI" do metamodelo BLA@BPMN com as entidades da abordagem KPI2BLA . . . . . . . . . 76

Figura 27 - Fluxo de passos para a extração de informações relevantes do KPI para

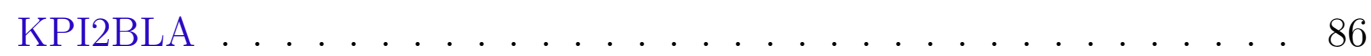

Figura 28 - Tela de criação de KPI . . . . . . . . . . . . . . . . . . . . 87

Figura 29 - Tela de criação de KPI - detalhes tolerância e etc. . . . . . . . . . . . . 87

Figura 30 - Tela de criação de KPI - detalhes bonificação e penalidade . . . . . . . 88

Figura 31 - BLA baseado no KPI criado . . . . . . . . . . . . . . . . . . . . 89

Figura 32 - XML criado a partir do BLA . . . . . . . . . . . . . . . 89 


\section{Lista de tabelas}

Tabela 1 - Seis principais fatores facilitadores e inibidores do alinhamento estratégico entre o negócio e a $\mathrm{TI} \ldots$. . . . . . . . . . . . . . 23

Tabela 2 - Categorias da notação BPMN . . . . . . . . . . . . . . . . 34

Tabela 3 - BLA de acordo com a abordagem StrAli-BPM . . . . . . . . . . . . . 49

Tabela 4 - Exemplo ilustrativo de BLA para contratação de crédito . . . . . . . . 50

Tabela 5 - String de busca básica . . . . . . . . . . . . . 55

Tabela 6 - String de busca Scopus . . . . . . . . . . . . . . . 55

Tabela 7 - String de busca Web of Science . . . . . . . . . . . . 56

Tabela 8 - Lista final de estudos primários selecionados na revisão sistemática . . 65

Tabela 9 - Template proposto para definição de KPI . . . . . . . . . . . . 78

Tabela 10 - Exemplo ilustrativo do template proposto para o KPI da meta estratégica organizacional . . . . . . . . . . . . . . 83

Tabela 11 - Validação das informações retiradas do KPI da meta estratégica organizacional via o preenchimento do template de BLA . . . . . . . . . . . . 84

Tabela 12 - Número de participantes e respostas ao questionário . . . . . . . . . 98

Tabela 13 - Experiência como profissional ou estagiário . . . . . . . . . . . . 98

Tabela 14 - Experiência dos participantes por faixa três em três anos . . . . . . . . 99

Tabela 15 - Áreas de experiência dos participantes . . . . . . . . . . . . . . . . 99

Tabela 16 - Nível de escolaridade . . . . . . . . . . . . . . . . 100

Tabela 17 - Área de graduação dos alunos da Pós-graduação . . . . . . . . . . . . . 100

Tabela 18 - Experiência prévia em BPM . . . . . . . . . . . . . . . . 101

Tabela 19 - Experiência prévia em BPMN . . . . . . . . . . . . . . . . 101

Tabela 20 - Experiência prévia em requisitos não funcionais . . . . . . . . . . . . . 102

Tabela 21 - Experiência prévia em SLA (Service Level Agreement) e QoS (Quality of Service)' . . . . . . . . . . . . . . . . 102

Tabela 22 - Experiência prévia em planejamento/plano estratégico e metas estratégicas organizacionais . . . . . . . . . . . . . . 103

Tabela 23 - Experiência prévia em KPI . . . . . . . . . . . . . . . 103

Tabela 24 - Facilidade em modelar BLA usando as abordagens . . . . . . . . . . . 104

Tabela 25 - Viabilidade em modelar BLA usando as abordagens . . . . . . . . . . . 104

Tabela 26 - Benefícios em modelar BLA usando as abordagens . . . . . . . . . . 105 
Tabela 27 - Recomendação da abordagem . . . . . . . . . . . . . . . . . . . 106 


\section{Lista de abreviaturas e siglas}

B2B Negócio para Negócio (Business to Business)

BLA Acordo em Nível de Negócio (Business Level Agreement)

BPM Gestão de Processos de Negócio (Business Process Management)

BPMI Iniciativa em Gestão de Processos de Negócio (Business Process Management Initiative)

BPMN Notação de Modelagem de Processo de Negócio (Business Process Model Notation)

EPC Correntes de Processo de Evento (Event Process Chains)

IDEF Métodos de Definição Integrada (Integrated Definition Methods)

KPI Indicador Chave de Desempenho (Key Performance Indicator)

QoS Qualidade de Serviço (Quality of Service)

RAD Diagramas de Papel Atividade (Role Activity Diagrams)

REA Agente de Evento de Recurso (Resource Event Agent)

SLA Acordo em Nível de Serviços (Service Level Agreement)

SOA Arquitetura Orientada a Serviço (Service Oriented Architecture)

StrAli-BPM Alinhamento Estratégico com BPM (Strategic Alignment with BPM)

TI Tecnologia da Informação (Information Technology)

UML Linguagem de Modelagem Unificada (Unified Modeling Language)

WS-BPEL Linguagem de Execução de Processos de Negócio de Serviço Web (Web Service Business Process Execution Language) 


\section{Sumário}

$1 \quad$ Introdução $\ldots \ldots \ldots \ldots \ldots \ldots \ldots \ldots$

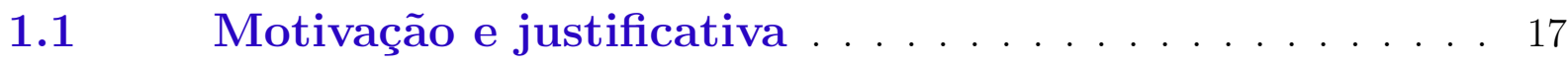

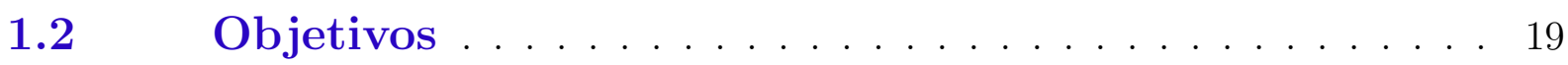

$1.3 \quad$ Estrutura da proposta $\ldots \ldots \ldots \ldots \ldots \ldots$

2 Fundamentação teórica . . . . . . . . . . . . 22

$2.1 \quad$ Alinhamento estratégico . . . . . . . . . . . . 22

2.1.1 Indicadores Chave de Desempenho . . . . . . . . . . . . 25

2.2 Gestão de Processos de Negócio . . . . . . . . . . . . . 28

2.2.1 Modelagem de processos de negócio . . . . . . . . . . . . 32

2.2.2 Implementação de processo de negócio . . . . . . . . . . . 36

2.3 Requisitos não funcionais . . . . . . . . . . . . . 37

2.3.1 Requisitos não funcionais em BPM no Nível de Serviços 40

2.3.2 Requisitos não funcionais em Acordos em Nível de Negócio 42

2.4 Metas estratégicas organizacionais . . . . . . . . . 44

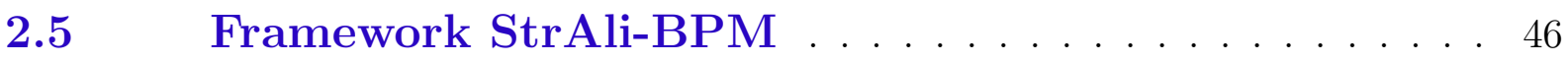

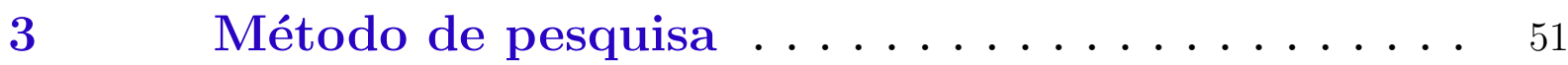

$3.1 \quad$ Planejamento da revisão sistemática . . . . . . . . . . 53

3.1.1 Necessidade para uma revisão sistemática . . . . . . . . . . 53

3.1.2 Questões de pesquisa da revisão sistemática . . . . . . . . 53

3.1.3 Protocolo da revisão sistemática . . . . . . . . . . . . . . 54

3.1.3.1 Fontes de dados e estratégia de pesquisa . . . . . . . . . . . . . 54

3.1.3.2 Estratégia de seleção dos estudos primários . . . . . . . . . . . . 55

3.2 Condução da revisão sistemática . . . . . . . . . . . 57

4 Trabalhos relacionados . . . . . . . . . . . 59

$4.1 \quad$ Estudos primários . . . . . . . . . . . . . . 59

4.2 Características e lacunas das abordagens dos estudos primários ...................... 63 
5 Proposta de extensão para a abordagem StrAliBPM ..................... 69

5.1 Visão geral da extensão proposta . . . . . . . . 69

5.2 Modelo para elaboração de KPIs relacionados às metas estratégicas organizacionais . . . . . . . . 71

5.3 Mapeamento entre o metamodela abordagem KPI2BLA e o metamodelo BLA@BPMN . . . . . . . . . . . . . . . 73

5.4 Template derivado do componente KPI2BLA $\ldots \ldots 77$

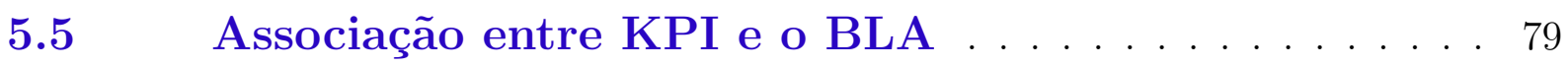

5.6 Exemplo ilustrativo de uso da extensão proposta . . . 80

5.6.1 Descrição do cenário usado no exemplo . . . . . . . 80

5.6.2 Contextualização do problema . . . . . . . . . 81

5.6.3 Exemplos dos artefatos elaborados seguindo a extensão proposta .................... 81

$5.7 \quad$ Prototipação $\ldots \ldots \ldots \ldots \ldots \ldots \ldots \ldots \ldots . . \ldots 5$

$6 \quad$ Avaliação da abordagem . . . . . . . . . . . 90

6.1 Planejamento da avaliação da abordagem . . . . . . 90

6.2 Resultados da avaliação da abordagem . . . . . . . 95

6.2.1 Resultados qualitativos da criação do BLA . . . . . . . 95

6.2.2 Resultados quantitativos das respostas do questionário . 97

6.2.3 Análise dos resultados da avaliação . . . . . . . . . 108

6.2.3.1 Aspectos sobre riscos da validade da abordagem e experiência prévia dos alunos . . . . . . . . . . . . 108

6.2.3.2 A análise feita sobre as respostas das perguntas da quarta parte do questionário . . . . . . . . . . . . . . . 109

6.2.3.3 Análise entre o perfil, experiência dos participantes do questionário e as respostas das perguntas da quarta parte do questionário . . . 112

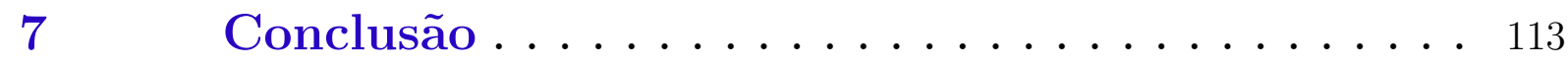

7.1 Trabalhos futuros . . . . . . . . . . . . . . 114 
Referências $^{1} \ldots \ldots \ldots \ldots \ldots \ldots$

APÊNDICES 


\section{Introdução}

Visando o alinhamento estratégico, Sousa e Leite (2014) afirmam que é necessário compreender a importância dos requisitos não funcionais oriundos das metas estratégicas organizacionais. Segundo Xavier Alencar (2010) e Florio, Salles e Fantinato (2012), a identificação dos requisitos não funcionais depende do tratamento das metas estratégicas organizacionais. Assim, tratar requisitos não funcionais se refere à busca dos interesses organizacionais.

Indicadores Chave de Desempenho (KPI - Key Performance Indicator) estão ligados às metas estratégicas organizacionais (LEVIN, 2012). Via KPI, é possível verificar se a organização está tomando medidas para alcançar suas metas estratégicas organizacionais. A partir da comparação entre uma meta estratégica e os KPIs - derivados destas metas estratégicas, caso os indicadores expressem valores fora da variação esperada pela meta estratégica, é necessário aplicar ações corretivas para direcionar a organização ao caminho desejado.

Gestão de Processos de Negócio (BPM - Business Process Management) tem sido usada no alcance do alinhamento estratégico entre negócio e TI. BPM é a ciência responsável por supervisionar como o trabalho é executado na organização em busca de resultados positivos, visando adquirir vantagem competitiva (DUMAS et al., 2013). BPM trata de gerenciar cadeias inteiras de eventos, atividades e decisões que trazem valor à organização e aos clientes - os chamados "processos de negócio".

Para apoiar o alinhamento estratégico, Salles (2014) propõe a modelagem de processos de negócio via uma extensão da Notação e Modelo de Processos de Negócio (BPMN - Business Process Model and Notation) dentro de um framework chamado StrAli-BPM (Strategic Aligment with BPM). Esse framework permite o uso de Acordos em Nível de Negócio (BLA - Business Level Agreements) na modelagem de requisitos não funcionais associados a modelos de processo de negócio. O framework StrAli-BPM contém dois componentes: o BLA@BPMN e BLA2SLA, sendo que o primeiro visa inserir o BLA no contexto da gestão de processos de negócio e o segundo visa converter o BLA em Acordos em Nível de Serviço (SLA - Service Level Agreements). Porém, StrAli-BPM não define quais informações devem compor os requisitos não funcionais na forma de BLAs, mas apenas como estruturá-las. Há somente a hipótese de que tais informações devem ser provenientes de metas estratégicas organizacionais. De acordo com Florio, Salles e 
Fantinato (2012), BLAs são restrições não funcionais em nível de modelo de processo, similar às restrições realizadas por SLA em nível de implementação de processos via serviços.

É proposto neste trabalho de mestrado, a inclusão de uma nova camada ao framework StrAli-BPM. Esta nova camada contem um novo componente chamado KPI para Acordo em Nível de Negócio (KPI2BLA - KPI to Business Level Agreements). Assim como existe uma relação entre o BLA e SLA, do componente BLA2SLA do StrAli-BPM anterior, que busca refletir o negócio e o nível operacional. Da mesma forma, existe uma relação entre as metas estratégicas organizacionais e o negócio. Tal relação, entre o negocio e as metas estratégicas organizacionais, é representada neste trabalho por meio da abordagem KPI2BLA, que atua no nível estratégico.

\subsection{Motivação e justificativa}

De acordo com Weske (2007), BPM tem papel fundamental na aplicação de conceitos e instrumentos que, em associação com a TI, tendem a melhorar os processos de negócio nas organizações. No ponto de vista de BPM, sua aplicação permite o alinhamento estratégico com maior facilidade. Essa facilidade ocorre pelo gerenciamento e aperfeiçoamento das soluções tecnológicas por meio de processos de negócio que agregam valor às organizações. Com intuito de contribuir ainda mais por parte da BPM, os processos de negócio devem levar em consideração não somente os requisitos funcionais, mas também os requisitos não funcionais (PRESSMAN; MAXIM, 2014). No entanto, Aghdasi e Malihi (2010) afirmam que extrair requisitos não funcionais dos processos organizacionais é uma tarefa difícil e que, mesmo assim, ambos requisitos devem ser observados para otimizar os processos.

Existe uma forte relação entre qualidade e requisitos não funcionais, sendo que, via esta relação pode-se obter restrições e eficiência aos processos de negócio, dando um diferencial ao produto ou serviço entregue. Alguns exemplos são a confiabilidade, desempenho e escalabilidade; esses exemplos mencionados interferem diretamente na capacidade funcional de um processo de negócio da organização. É comum as organizações buscarem atender por completo os requisitos funcionais, pois, logicamente, diz respeito às principais frentes de entrega. No entanto, prezar na qualidade e/ou desempenho, favorece no alcance de melhores produtos ou serviços. E quando se trata de qualidade ou desempenho faz-se menção a requisitos não funcionais. Esses requisitos são difíceis de se especificar e 
medir apenas usando linguagens de modelagem de processos de negócio existentes (SALLES, 2014).

Porém, em BPM, a fase de modelagem ainda não oferece apoio adequado ao tratamento de requisitos não funcionais (FLORIO; SALLES; FANTINATO, 2012), afastando-se do ideal que seria existir apoio em todo o ciclo de vida de BPM. Os ciclos são: modelagem do processo de negócio, implementação, execução e monitoramento (AALST, 2013). A falta de cobertura no ciclo de vida dificulta o alinhamento estratégico entre negócio e TI. Apenas a fase de implementação já conta com tratamento de requisitos não funcionais por meio do uso de SLA e Qualidade de Serviço (QoS).

Além de SLA e QoS, que auxiliam no tratamento de requisitos não funcionais, Bratanis, Dranidis e Simons (2010) inspiraram-se no que já existe no mundo real dos negócios para definir um outro tipo de acordo, o Acordo em Nível de Negócio (BLA). Uma definição simples é que o BLA é um contrato entre o servidor e o consumidor do serviço que descreve as características funcionais e não funcionais acordadas em um serviço web. Detalhando a definição, o BLA é um acordo de qualidade principal ou "Pai" em tempo de modelagem, que é suportado por um conjunto de SLAs relacionados aos serviços web que foram definidos como consequência das atividades do modelo do processo usado.

Fazendo uma relação entre os três conceitos citados anteriormente (SLA, QoS e BLA), entende-se que SLA define QoS (foco em serviços web) e é avaliado baseado em critérios técnicos. Diferentemente do BLA, que é avaliado por meio dos resultados organizacionais obtidos e tem o propósito de auxiliar no cumprimento dos requisitos estratégicos organizacionais. Também deve ser possível extrair informações do BLA para criar um conjunto de SLAs e, por consequência, alcançar as metas estratégicas organizacionais. Percebendo-se esta lacuna gerada pela falta de tratamento dos requisitos não funcionais em boa parte dos processos de negócio, Salles (2014) propôs uma abordagem chamada Strategic Alignment with BPM (StrAli-BPM). Fez-se necessária esta nova abordagem, por conta da carência de representação de requisitos não funcionais por parte das linguagens mais conceituadas para modelagem de processos de negócio, como BPMN. Por consequência, dificulta o tratamento dos requisitos não funcionais durante a implementação do processo de negócio, e o alinhamento estratégico entre negócio e TI.

Devido a esta nova abordagem, apresentada por estre trabalho, fez-se necessário formalizar quatro perfis que estão diretamente relacionados as tarefas que são executadas nesta abordagem. $\mathrm{O}$ analista estratégico, o analista de negócio, o analista de processo e o 
Figura 1 - Área de atuação do subprojeto

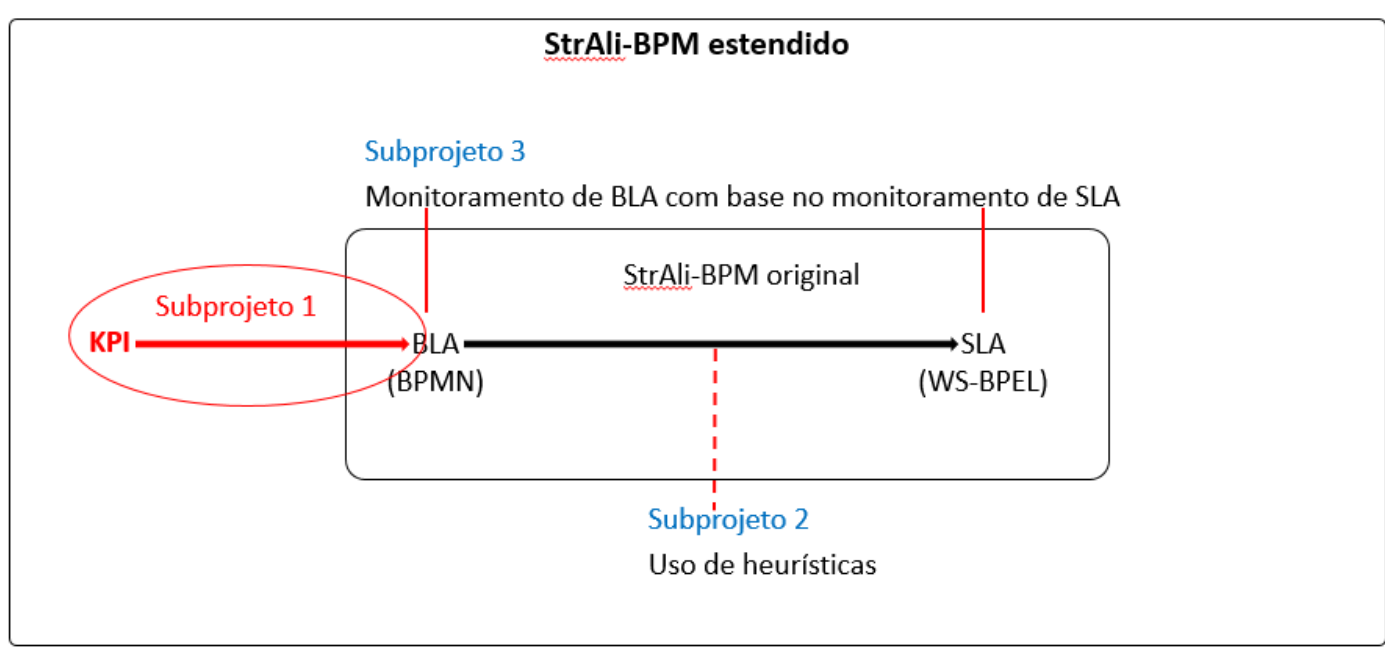

Fonte: Adson Rocha do Carmo, 2016

implementador de processos. O analista estratégico é quem define as metas estratégicas da organização ou então está ciente das metas estratégicas. O analista de negócio atua interpretando as metas estratégicas e as transformando em KPI. O analista de negócio também valida o BLA no modelo de processo de negócio e insere informação extra ao KPI. O analista de processos deve extrair as informações úteis do KPI, em seguida, modelar BLA baseado em KPI. Por último, o implementador de processos define o(s) SLA(s) com base no(s) BLA(s).

É importante esclarecer que este trabalho de mestrado está contido em um projeto maior, intitulado "Extensão do Framework StrAli-BPM: Fomento ao Alinhamento Estratégico entre negócio e TI baseado em BPM". Esta pesquisa é dividida em três partes, sendo, a primeira, responsabilidade deste trabalho de mestrado, que visa sanar uma lacuna encontrada em alto nível organizacional, entre as metas estratégicas organizacionais e o negócio. O segundo trabalho, busca sanar uma lacuna existente entre a área de negócio e a operacional de TI. O terceiro trabalho busca monitorar os resultados dos dois primeiros. A figura 1 ilustra os subprojetos que compõem o projeto de pesquisa e destaca em vermelho o subprojeto conduzido por este trabalho de pesquisa.

\subsection{Objetivos}

Dentro do contexto motivacional apresentado anteriormente, este trabalho de mestrado visa propor uma extensão chamada KPI2BLA do framework StrAli-BPM com 
o objetivo de contribuir com a busca do alinhamento estratégico entre o negócio e a TI em alto nível. Por meio desta extensão, buscar melhorias no processo de definição dos BLAs por parte dos analistas de negócio, via extração dos requisitos não funcionais das metas estratégicas organizacionais encontradas nos KPIs. E em seguida, os BLAs devem ser passados para área de TI, que, por sua vez, deve derivar os SLAs dos BLAs.

Mesmo que o intuito deste trabalho seja auxiliar na criação de BLA, não faz parte do escopo deste trabalho definir em qual subprocesso o BLA está associado. Mas sim disponibilizar a informação necessária para oferecer apoio a criação do BLA de forma a refletir corretamente as metas estratégicas organizacionais.

Neste contexto, o conceito de KPI deve ser usado na abordagem visando auxilar a coleta dos requisitos não funcionais das metas estratégicas organizacionais. Levando em consideração que esse conceito é bastante difundido no mercado e aceito nas organizações para medição e gestão de desempenho por meio de indicadores, o uso do KPI deve agregar valor e confiança.

Uma consequência resultante deste trabalho é o auxilio à comunicação mais eficiente e mais assertiva entre o negócio e a TI, no contexto de alto nível da organização, aonde as metas estratégicas organizacionais são definidas. Devido este auxílio na comunicação entre o negócio e a TI, a TI deverá estar alinhada às metas organizacionais, assim, poderá dar mais apoio aos objetivos organizacionais possibilitando alcançá-los oferecendo um diferencial em relação ao mercado e um posicionamento estratégico mais rápido. Outra consequência deste trabalho é desenvolver um protótipo de ferramenta para avaliar a abordagem proposta.

Visando tornar mais clara a lacuna mencionada, a abordagem proposta e sua aplicabilidade, este trabalho faz uso de um exemplo fictício, mas que reflete a realidade de algumas empresas. Neste exemplo, é apresentado um problema e a solução aplicada. Aproveitando o cenário, este estudo, identifica a meta estratégica, seus requisitos não funcionais por meio dos KPIs criados para controlar a estratégia de solução do problema, e aplica o componente KPI2BLA, do framework StrAli-BPM, exemplificando e correlacionado o exemplo com a abordagem do início ao fim do processo de negócio.

Para atingir os objetivos mencionados anteriormente, os objetivos específicos apresentados na subseção a seguir servem como direcionadores ao alcance do objetivo principal citado nos parágrafos acima. 
Com intuito de descrever como os resultados serão alcançados, é necessário enumerar os objetivos específicos deste trabalho de mestrado, como pode ser visto na lista a seguir:

1. Desenvolver uma abordagem que busque sanar a lacuna apontada neste estudo.

2. Construir um metamodelo que busca visa obter as informações necessárias para representar um indicador de desempenho do tipo KPI.

3. Construir um template que busca expressar o metamodelo criado no item 2.

4. Usar exemplos reais e ilustrativos para exemplificar a aplicabilidade da abordagem proposta nos itens 1 e 3 .

5. Avaliar a abordagem KPI2BLA usando os resultados obtidos pelo uso do protótipo computacional desenvolvido.

\subsection{Estrutura da proposta}

Este documento está dividido nos seguintes itens: Capítulo 2, contextualizando o tema em estudo por meio de fundamentação teórica; Capítulo 3, dispondo a metodologia para a realização da pesquisa; Capítulo 4, trabalhos relacionados ao estudo em questão; Capítulo 5, proposta de extensão da abordagem StrAli-BPM; Capítulo 6, avaliação da abordagem proposta; Capítulo 7, apresenta as considerações finais desta proposta; Referências Bibliográficas; Apêndice A, dispondo artigo submetido ao SBSI 2016, que contém uma revisão sistemática sobre o tema. Apêndice B, questionário submetido aos alunos para coletar informações sobre o processo de criação de BLA a partir do KPI e das metas estratégicas. Apêndice C, protótipo de ferramenta usado para apoiar a avaliação da abordagem. 


\section{Fundamentação teórica}

Neste capítulo, estão apresentados os principais conceitos que servem de base e direcionamento da abordagem apresentada na proposta de pesquisa. O primeiro conceito explanado é o KPI, usado para auxiliar na busca e controle das metas estratégicas organizacionais. Seguido pela Gestão de Processos de Negócio que contém outros três sub assuntos, a Modelagem de processos de negócio, Business Process Management Notation (BPMN), Implementação de processo de negócio e Execução de processos de negócio. Requisitos não funcionais, contendo Requisitos não funcionais em BPM no nível de serviço e Acordo em nível de negócio como sub-seções. A penúltima seção trata sobre Monitoramento de Atividade de Negócio. Por fim, a última seção deste capítulo é intitulada de framework StrAli-BPM.

\subsection{Alinhamento estratégico}

Segundo Bloomfield et al. (1997), o advento da era industrializada, o crescimento na implementação de tecnologias da informação e comunicação resultou em mudanças em diversos setores. Na economia, instituições públicas e privadas, e entre os limites organizacionais, o aparecimento de sistemas de informação computacional foi consolidado intensamente. Por consequência do cenário descrito anteriormente, surgiu a necessidade do planejamento estratégico no uso dos sistemas de informação alinhado com a organização e suas necessidades de Negócio.

Henderson e Venkatraman (1999), acredita que a dificuldade que as empresas tinham em identificar o valor dos investimentos em TI, em parte justificava a lacuna entre o negócio e as estratégias de TI das organizações. Há algumas décadas as organizações tendiam a pensar que a TI era apenas para oferecer apoio às funções da empresa e não como essencial para ao negócio organizacional. Com a evolução da TI e a globalização, os países abriram as portas para o mercado internacional dando maior possibilidade de novos mercados, no entanto, aumentando também os concorrentes. A TI deixou de ser apenas um "back office" - apoio de serviços, e passou a ter um papel estratégico com potencial não somente de apoio às estratégias organizacionais, mas indo além, permitindo às empresas evoluirem para novas estratégias de mercado (HENDERSON; VENKATRAMAN, 1999). 
Por meio de estudos feitos em empresas e dados obtidos de executivos da área de TI e negócio, Luftman, Papp e Brier (1999) identificaram fatores facilitadores e inibidores (Enablers and Inhibitors) na busca do alinhamento estratégico entre TI e negócio. Resultados extraídos apontaram que algumas atividades podem auxiliar no alcance do estado de alinhamento, em contrapartida, outras atividades causam barreiras ao alinhamento. E para evitar as barreiras e estimular os fatores facilitadores, constatou-se necessária a ajuda de gestores experientes, bom relacionamento no trabalho, forte liderança, priorização apropriada, confiança e comunicação efetiva. Por fim, um ótimo entendimento do ambiente de negócio. Na tabela 1 são apresentados os principais fatores facilitadores e inibidores identificados no estudo.

Tabela 1 - Seis principais fatores facilitadores e inibidores do alinhamento estratégico entre o negócio e a TI

\begin{tabular}{ll}
\hline Facilitadores & Inibidores \\
\hline apoio executivo sênior de TI & $\begin{array}{l}\text { Ausência de bom relacionamento TI e } \\
\text { Negócio }\end{array}$ \\
$\begin{array}{l}\text { TI envolvida em desenvolvimento es- } \\
\text { tratégico }\end{array}$ & Ná priorização da TI \\
TI compreende o Negócio & TI não entende do Negócio \\
Parceria entre Negócio e TI & Executivos sênior não auxiliam a TI \\
Projetos de TI bem priorizados & TI demonstra ausência de liderança \\
TI demonstra liderança &
\end{tabular}

Fonte: Traduzido de Luftman, Papp e Brier (1999)

Certamente, não somente buscar eliminar os fatores inibidores de alinhamento estratégico, mas promover o alinhamento estratégico de todas as áreas e setores da organização com TI se tornou fundamental para obter as vantagens competitivas das organizações (GALAS; PONTE, 2006).

Segundo Brodbeck e Hoppen (2003), o alinhamento estratégico é importante e deve ser um processo unificado na organização, diferentemente do comportamento anterior que o tratava isoladamente como uma dimensão única da área de negócio ou para área de TI. A partir disto, a perspectiva passou a ser de gerenciamento das estratégias do negócio, usando a tecnologia como instrumento essencial ao sucesso dos negócios.

De acordo com Henderson e Venkatraman (1999), o conceito de Alinhamento Estratégico é pautado em duas vertentes fundamentais, como ilustrado na Figura 2. A primeira, baseada em desempenho econômico, está diretamente relacionada a habilidade de gerenciamento para criar uma adequação estratégia entre a posição da organização 
Figura 2 - Alinhamento estratégico entre o negócio e a TI

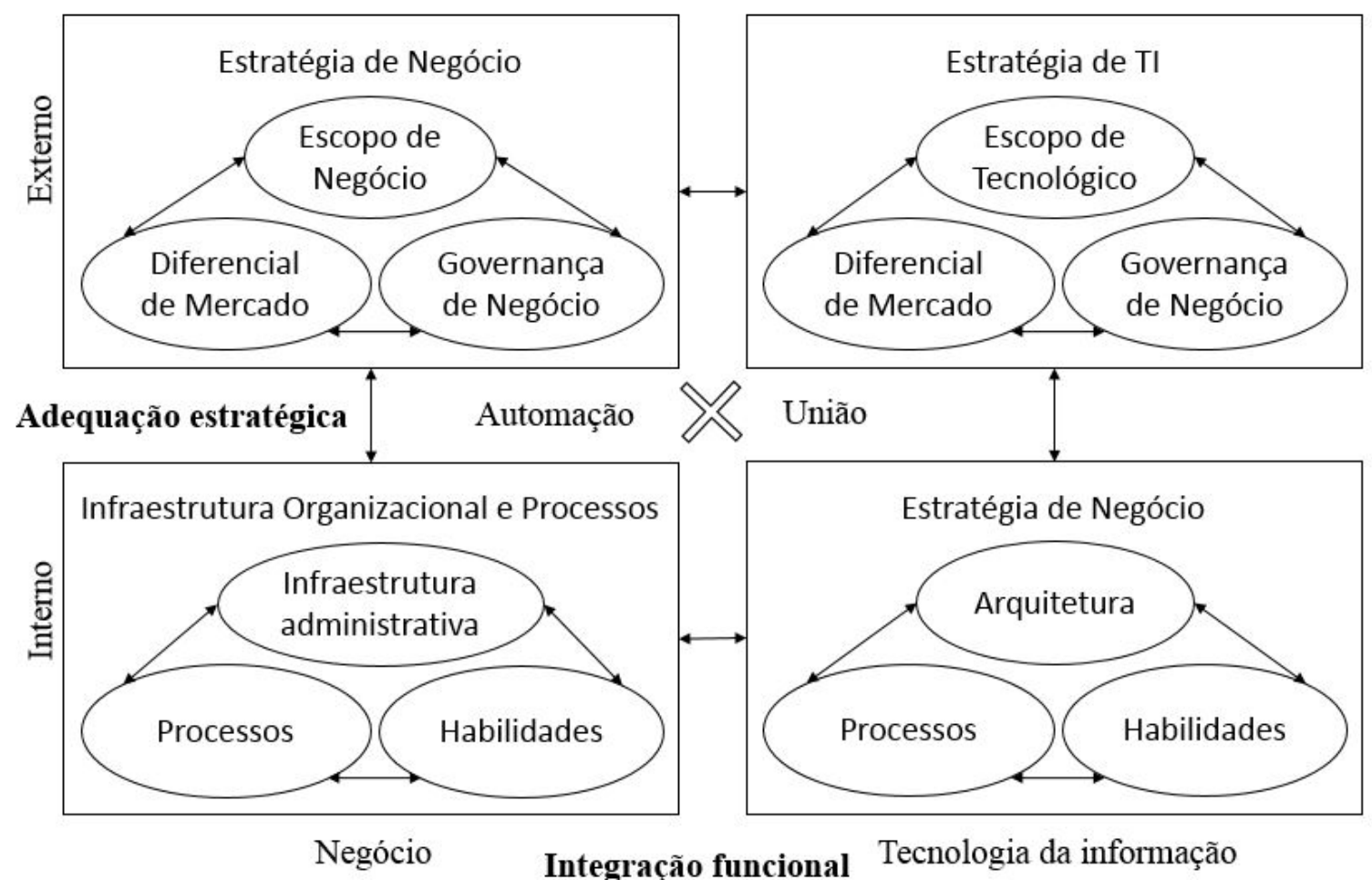

Fonte: Traduzido de Henderson e Venkatraman (1999)

no mercado e um projeto de estrutura administrativa apropriada para auxiliar na sua execução. Ou seja, adequação estratégica e integração funcional, intitulado pelos autores como Modelo de Alinhamento Estratégico. Para reconhecer as necessidades estratégicas, os autores consideram o domínio interno e o externo, sendo o domínio externo a área que o negócio está inserido e as decisões estratégicas tomadas sobre o mercado/produto para obter diferencial competitivo. Por outro lado, o domínio interno diz respeito às escolhas feitas sobre a estrutura administrativa e escolhas relacionadas aos processos críticos de negócio (entrega de produtos, qualidade total etc.).

Os estudos feitos por Brodbeck e Hoppen (2003) concluem que uma das maiores contribuições da pesquisa é a evolução do modelo proposto por Henderson e Venkatraman (1999). Essa contribuição foi dada devido ao auxílio na etapa de implementação do processo de planejamento e fornecendo elementos para a sua implementação. O ponto principal desse modelo induz à promoção de alinhamento estratégico contínuo na organização. Sendo assim, o alinhamento não deve ser tratado de forma isolada, mas integrada entre a área de negócio e a área de TI. Essa integração entre a área de negócio e a área de TI gera uma nova perspectiva de gerenciamento das estratégias do negócio, pois usa a tecnologia como pilar fundamental para alcançar as metas estratégicas organizacionais da empresa. 


\subsubsection{Indicadores Chave de Desempenho}

Segundo Spitzer (2007), mensurar ou medir está associado à punição ou recompensa. Certamente, no contexto organizacional, a ausência da mensuração pode acarretar na punição (a perda de clientes, por exemplo) ou na recompensa (melhoria nas vendas).

Um exemplo ilustrativo sobre medição no contexto organizacional é que gerir um negócio sem efetiva medição é como pilotar um avião em meio a tempestade e sem instrumentos. Por isso, o Indicadores Chave de Desempenho (KPI - Key Performance Indicator) é uma técnica fundamental, pois serve de instrumentos para nortear as empresas, tal qual, em um avião os instrumentos de voo auxiliam a pilotagem segura. Spitzer (2007) cita problemas obtidos pela falta de mensuração, como exibidos abaixo:

- as estratégias organizacionais não são bem executadas, pois os gestores e funcionários não conhecem, ou não compreendem bem o que significa a estratégia em seu trabalho;

- impossibilidade de gerência sobre o desempenho operacional, em função da gestão atuar frequentemente com suposições a respeito da estratégia;

- conflitos, prioridades vagas e contraditórias resultam no não alcance das metas, pois as metas necessitam de medição corretas para serem alcançadas;

- os problemas são camuflados, impedindo ações corretivas mais assertivas.

Uma Revisão Sistemática da Literatura (RSL) foi desenvolvida (apresentada na seção de Apêndice desta dissertação de mestrado), e, por meio desta RSL, identificou-se o uso do KPI como uma das principais técnicas para auxiliar as organizações no controle das metas organizacionais. Segundo Parmenter (2015), KPI são aqueles indicadores que focam nos aspectos de desempenho da organização que são os mais importantes para o sucesso atual e futuro da organização. Porém, muitas organizações estão trabalhando com mensuração de forma errada. Elas acreditam que muitas organizações consideram que todas as medidas de desempenho são KPIs. No entanto, seus estudos concluíram que existem quatro tipos de medida de qualidade, sendo que esses quatro tipos são divididos em dois grupos - indicadores de resultados (IRs) e indicadores de desempenho (IDs).

Os IRs misturam entradas de diversas áreas, essa informação é válida para analisar os resultados das equipes. Em contrapartida, não ajuda a resolver problemas de gestão pela dificuldade em identificar qual área foi responsável pelo bom ou mau desempenho. Agora, no caso dos IDs, são medidas que são aplicadas a uma equipe específica ou conjunto 
de equipes que trabalham juntas em busca do mesmo propósito. Assim, um desempenho bom ou mau é responsabilidade do time (PARMENTER, 2015).

Cabeza et al. (2015), explica que KPI é uma medida de desempenho que avalia o sucesso de uma atividade específica. De modo que o sucesso pode ser tanto um resultado de uma meta operacional (por exemplo, nenhum defeito no produto, satisfação do cliente) quanto o progresso rumo aos objetivos estratégicos. Nota-se forte relevância no uso de KPIs, principalmente quando se trata de alcançar metas estratégicas organizacionais de negócio da empresa.

Levin (2012) afirma que o KPI deve ser medido contra uma meta específica. Isto é, o KPI está estritamente ligado ás metas estratégicas organizacionais, até porque, por meio do KPI será possível constatar se a organização está tomando as medidas corretas para alcançar as metas. A partir desta comparação - entre o KPI e a meta, caso o indicador expresse valores fora do intervalo da meta -, faz-se necessário análise e ação corretiva para direcionar a organização no caminho desejado, de acordo com as metas.

Os KPIs são medidas quantificáveis, que refletem os principais objetivos da organização. Na medida que os objetivos organizacionais mudam, os KPIs devem acompanhar essa mudança para manter o foco organizacional. Um exemplo de KPI pode ser dado da seguinte forma: "ser a empresa mais rentável em nossa indústria". Neste caso, o KPI seria medir o lucro e medidas fiscais relacionadas ao negócio. Percebe-se que, no contexto de alinhamento estratégico das metas organizacionais, o KPI é uma técnica que apoia e auxilia a empresa no acompanhamento do processo de busca das metas.

Segundo Kolár (2009), na visão do negócio, KPIs são concebidos na fase de definição das metas organizacionais. Em seguida, é necessário verificar, usando KPI, se os resultados desejados foram alcançados ou não. Baseado neste conceito, que o KPI está diretamente associado aos interesses organizacionais - que são as metas organizacionais, uma conclusão é que o uso de KPI tende a ser um apoiador para o alcance das metas estratégicas organizacionais.

Um exemplo que pode representar um KPI é o ilustrado na figura 3, intitulado de "Atendimentos realizados por status". O objetivo deste KPI é controlar o percentual de atendimento dos pacientes com status engaged, ou seja, que estão comprometidos com o acompanhamento do hospital.

Com propósito de obter uma formalização das informações necessárias para criação de KPIs, pesquisou-se por metamodelos para tal propósito. 
Figura 3 - Atendimentos realizados por status

\section{Cobertura de atendimentos}

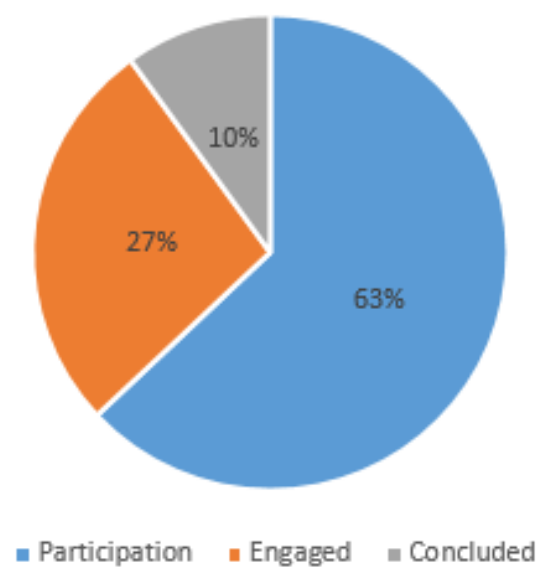

Fonte: Adson Rocha do Carmo, 2016

No estudo de Karagiannis, Ronaghi e Fill (2007) é apresentado o metamodelo ilustrado na figura 4, que exibe elementos e os relacionamentos entre eles. Nesse metamodelo, os elementos em cinza estão relacionados com os interesses deste trabalho de mestrado. A figura 4 ilustra três elementos que estão relacionados com o contexto deste trabalho "Strategic Level", "Tactical Level" e "Operational Level", porém, no escopo deste trabalho de mestrado, apenas os níveis "Strategic" e "Tactical" são de interesse. Ainda na mesma figura é ilustrado os elementos "Goal" e "KPI", sendo que o "Goal" ilustra as metas oriundas dos elementos "Strategic Level", "Tactical Level" e "Operational Level" e, por sua vez, as metas podem ter um ou vários KPIs com propósito de controlar a(s) meta(s). Uma limitação deste metamodelo é o fato de não detalhar os atributos que devem estar contidos nos elementos.

Outro estudo que apresenta um metamodelo envolvendo KPI é o de Fernández e Penzenstadler (2015) ilustrado na figura 5, que traz informações importantes ao escopo deste trabalho de mestrado, como os elementos ilustrados no grupo chamado de "Constraincts and Roles" e "Objectives and Goals". O primeiro grupo, "Constraincts and Roles", contém os elementos que ilustram a definição das regras e restrições que podem estar presentes no KPI. O segundo grupo, "Objectives and Goals", contém os elementos que ilustram a definição das metas e seus relacionamentos com outros elementos. Desses dois grupos, os elementos que contribuem para o escopo deste trabalho são: "Restriction, Constraint, Rule, Influence, InfluenteTypes, Influences e Goal". 
Figura 4 - Metamodelo para monitoramento de negócio orientado a serviço

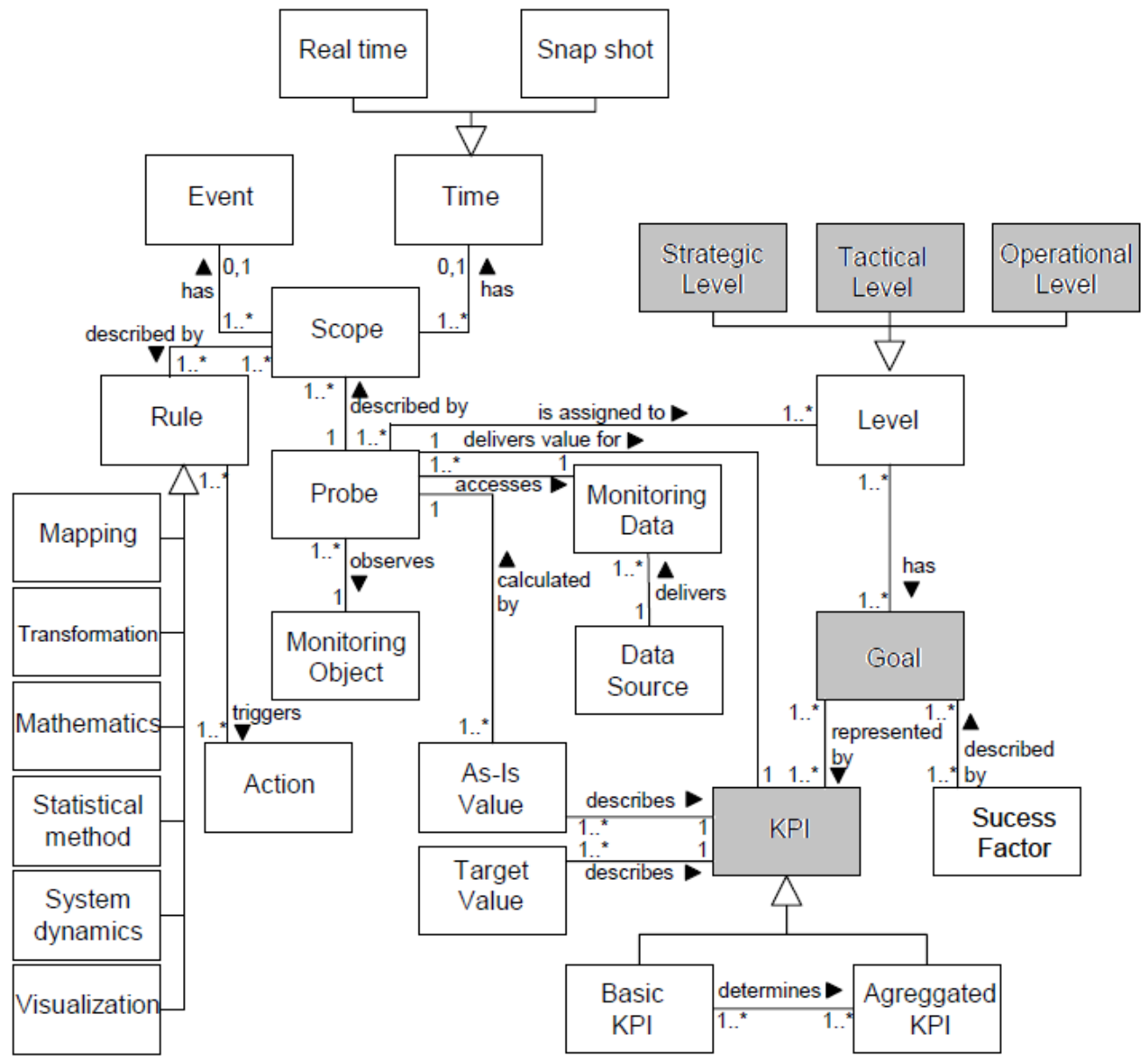

Fonte: Karagiannis, Ronaghi e Fill (2007)

O estudo de Pierantonio et al. (2015) apresenta um metamodelo, ilustrado na figura 6, que tem uma característica simples em termos de número de elementos e relacionamentos, porém positivamente detalha os atributos dos elementos.

\subsection{Gestão de Processos de Negócio}

Inicialmente, faz-se necessário explanar os conceitos e características da Gestão de Processos de Negócio (BPM - Business Process Management). Sendo assim, este estudo usará definições das principais fontes sobre o assunto. Segundo BALDAM et al. (2007), o BPM diz respeito a descoberta, projeto e entrega de processos de negócio. Como extensão, o BPM inclui o controle executivo, administrativo e supervisor desses processos. Os autores usam o modelo proposto por Scheer e Schneider (1998), que define os diferentes processos encontrados na organização. São eles: 
Figura 5 - Metamodelo de especificação do contexto da abordagem AMDiRE

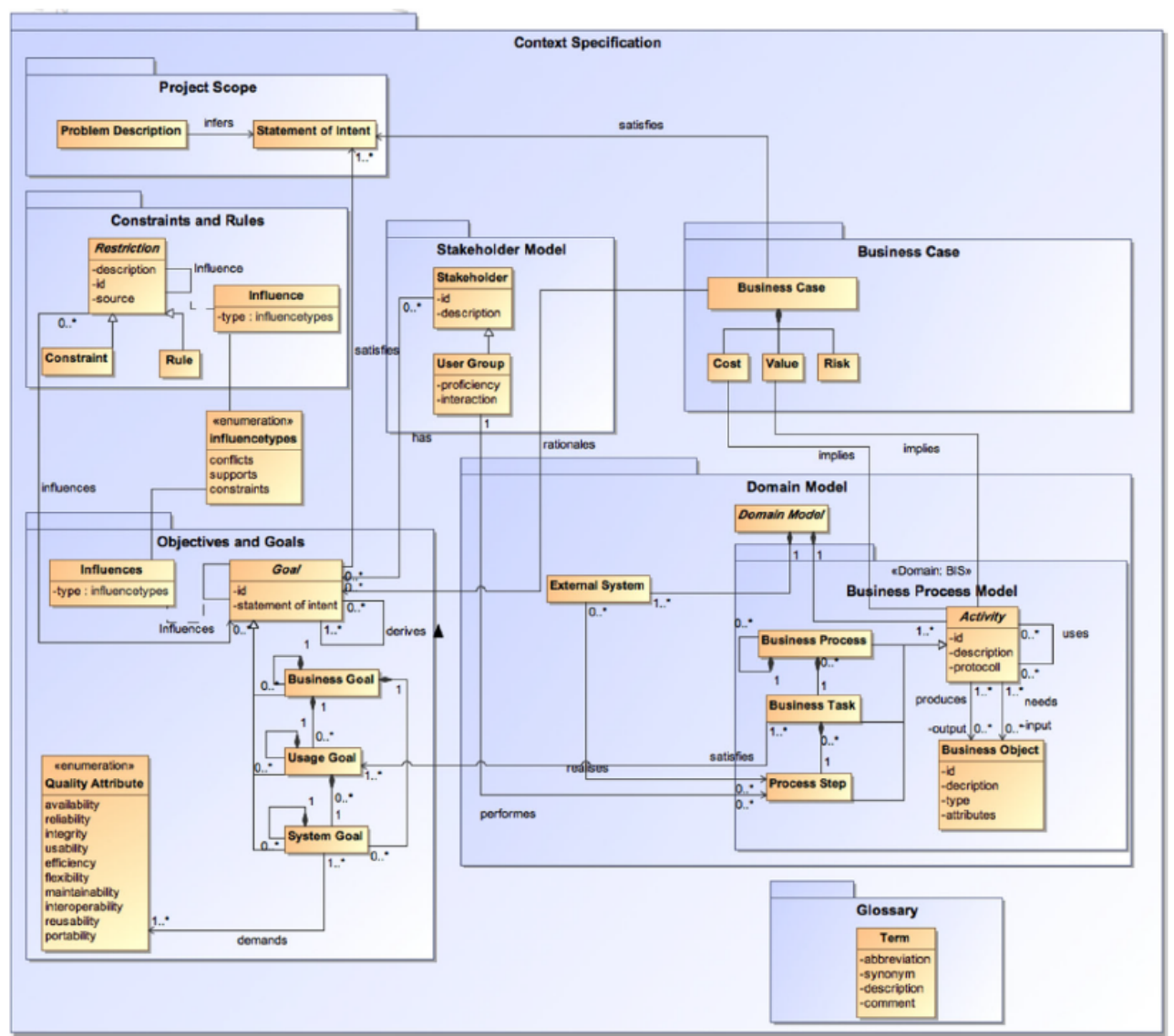

Fonte: Fernández e Penzenstadler (2015)

Figura 6 - Metamodelo de KPI

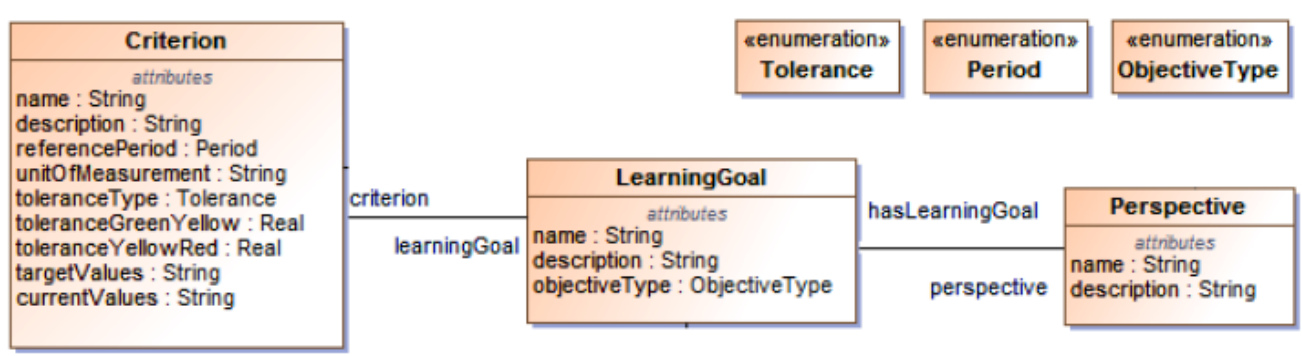

Fonte: Pierantonio et al. (2015)

- Processos de governança: trata de processos como gerenciamento de conformidades, gerenciamento de riscos, Business Intelligence, processos de BPM, desenvolvimento de estratégia, desenvolvimento de negócios e arquitetura empresarial.

- Processos de gerenciamento (apoio e controle): está relacionado às atividades corriqueiras de gerenciamento da organização, como gestão financeira, controladoria, gestão da informação, o BPM, gestão da qualidade.

- Processos operacionais: voltada a desenvolver a atividade final da empresa. Por exemplo: Customer Relation Management CRM, logística, gestão de material. 
Segundo Dumas et al. (2013), BPM é a arte e ciência de supervisionar como o trabalho é executado na organização em busca de resultados positivos com objetivo de adquirir vantagens das oportunidades. Os autores citam também que o BPM não é uma técnica para melhorar a forma de fazer algo, mas sim, trata de gerenciar cadeias inteiras de eventos, atividades e decisões que trazem valor à organização e aos clientes. Ou seja, essas ferramentas mencionadas como estimuladoras na obtenção de valor à organização e aos clientes é definida como processos.

Outra maneira de entender o BPM, segundo Jeston e Nelis (2014), primeiramente é entender que BPM não é igual a uma ferramenta tecnológica ou iniciativa para processo de negócio. Porém, segundo as experiências obtidas pelos autores no BPM, existe uma melhora significante no processo que pode ser obtida sem tecnologia. O objetivo é desmistificar o BPM como visto por alguns. Eles conceituam o BPM como uma realização dos objetivos organizacionais, por intermédio da melhoria, gerenciamento e controle dos processos de negócio vitais à companhia.

Em contrapartida, Der (2004) afirma que a combinação dos conhecimentos vindos da TI e da ciência de gestão quando aplicados ao processo de negócio operacional se configuram como BPM. Esta visão faz uma relação direta da TI com o Processo, o que difere do conceito anteriormente citado por (JESTON; NELIS, 2014). Contudo, este trabalho não tem o objetivo de aprofundar-se nesta discussão. Mas explanar os conceitos atuas sobre o BPM.

O BPM agrega métodos, técnicas, e ferramentas para auxiliar projetos, contratos, gestão e análise de processo de negócio funcional. Considera-se o BPM como uma extensão do sistema de gestão de fluxo (Workflow Management - WFM). No entanto, o BPM tem um ciclo de vida dividido em quatro partes, detalhadas a seguir e ilustradas na figura 7 (AALST, 2013):

- (Re)Desenho: Nessa fase é onde ocorre a modelagem do processo por intermédio da identificação do seu estado atual, como ele é ("as-is"). Em seguida, propor como o processo deve ser ("to-be"). É nessa fase que se entende como a organização lida com o negócio no sentido operacional. A partir de então, é proposto um modelo ideal. Essa fase pode ocorrer mais de uma vez, por motivos de ajustes no processo.

- Implementação/Configuração: Nesse momento, o modelo é aplicado na organização via sistemas de apoio. Caso já estejam em execução, o processo tende a ser rápido. 
Figura 7 - Ciclo de vida BPM

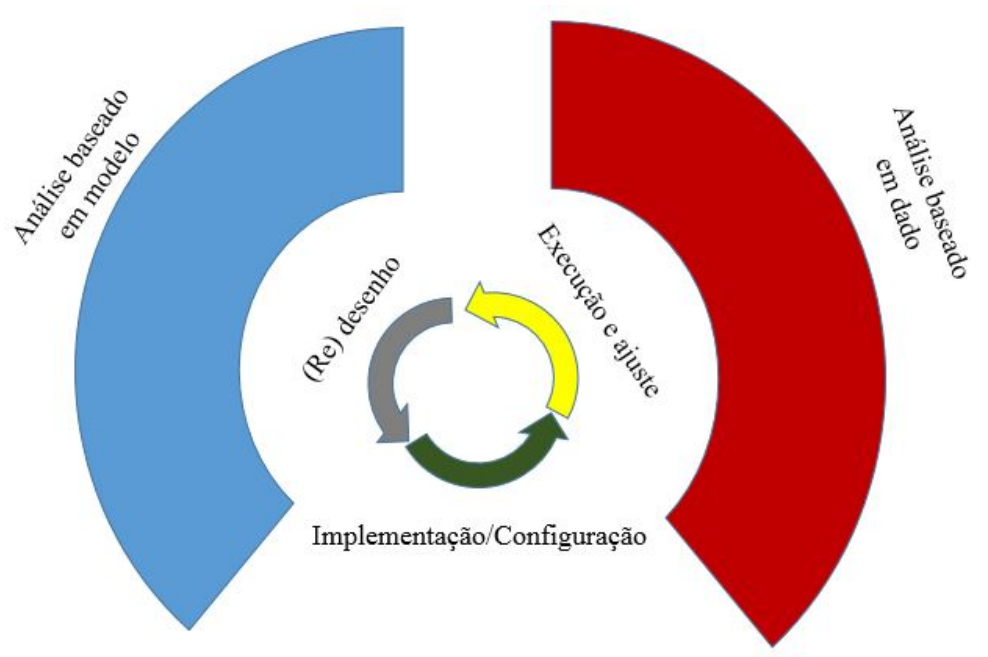

Fonte: Traduzido de Aalst (2013)

Por outro lado, se o modelo é informal e traz mudanças drásticas, a etapa Pode levar maior tempo.

- Execução e ajuste: Nesse momento, o processo é acordado e, caso necessário, ajustado. Porém esses ajustes não são em termos de redesenho do projeto e nem ocorre inclusão de novo software, somente controles já predefinidos são usados para adequar ou reconfigurar o processo.

- Análise baseada em modelo e dados: Nesse momento, diversos eventos ocorrem com os sistemas em execução e geram informações que ajudam a identificar gargalos, desvios ou erros no modelo do processo. Essas informações servem de entrada para a fase de redesenho, pois, com a identificação de problemas oriundos dessas informações, é possível redesenhar de forma assertiva.

As organizações entenderam a necessidade de nova visão da integração da TI com os processos de negócio, por isso as ferramentas de TI que apoiam o BPM devem melhorar a agilidade no negócio e de seu controle e monitoramento, eliminando redundâncias e incrementando a automação; fornecer caminho direto entre o projeto do processo e sua implementação; apoiar modelagens top-down e bottom-up, via cadeia de valor, relacionando as pessoas ativas no processo de negócio, levando em consideração os sistemas, as informações e os equipamentos; ser uma base de compartilhamento de processos entre aplicações e pessoas, seja interno ou externo à organização, de forma análoga ao compartilhamento de dados em sistemas de banco de dados; por fim, apoiar processos que herdam integrações e colaboração (BALDAM et al., 2007). 
A maturidade adquirida no uso da TI, por parte da organização, contribuiu na busca do diferencial estratégico, e, ajuda diretamente na mudança dos processos de trabalho (BALDAM et al., 2007). Após a maturidade no uso da TI, houve o advento de SOA (Arquitetura Orientada a Serviço) - que contribui com a integração das aplicações envolvidas no processo de busca do diferencial estratégico. O BPM ganhou espaço privilegiado no cenário corporativo e no meio acadêmico, contudo, o cenário anterior ao SOA já contava com soluções de middleware, tais como ODBC, JDBC, Java RMI e CORBA, que auxiliavam na integração em nível de execução dos processos de negócio (SALLES, 2014), porém com pouco foco no alinhamento estratégico.

Uma correta implementação de BPM (respeitando todos os seus ciclos e características) faz com que as organizações obtenham benefícios que estimulam o aumento das chances de alcance das metas estratégicas organizacionais. Alguns dos benefícios são: integrar pessoas, tecnologia, equipamentos e facilidade com propósito de ajudar na compatibilidade dos mesmos no processo; responder rapidamente aos estímulos ou mudanças do ambiente externo à organização; possibilitar a criação de novos negócios rapidamente; ampliar a capacidade de monitoramento dos indicadores de desempenho, assim eliminar gargalos, auxiliando as tarefas estão sendo executadas; integrar profissionais da empresa de diferentes unidades e setores; identificar atividades desnecessárias ao negócio; aumentar a produtividade via análise de tempo e custos operados nos processos; alcançar as metas estratégicas organizacionais com clareza, tanto interna como externa à empresa.

Por fim, a aplicação da gestão do processo de negócio organizacional tem sido essencial à organização, por conta dos benefícios obtidos e principalmente no auxílio do alinhamento estratégico.

\subsubsection{Modelagem de processos de negócio}

Para apoiar a gestão de processo de negócio organizacional, usa-se também de modelagem de processos de negócio.

No contexto empresarial, com sua competitividade e mudanças constantes, exige que as empresas modifiquem suas metas de negócio com uma certa frequência para manterem-se bem posicionadas. Devido a essas mudanças, as organizações que usam o BPM modelam seus processos com apoio de ferramentas tecnológicas que permitem acompanhar a criação de processos de negócio, edição de processos de negócio já existentes ou remoção de 
processos de negócio desnecessários. Para apoiar o BPM, algumas ferramentas permitem a descrição das metas de negócio, como, por exemplo: Notação e Modelo de Processos de Negócio (BPMN - Business Process Model and Notation) e Linguagem de Modelagem Unificada (UML - Unifield Modeling Language) (RUOKONEN; PAJUNEN; SYSTÄ, 2009).

Pourshahid et al. (2009), acrescenta que a Modelagem de Processo de Negócio é a documentação gráfica e exibição dos processos de negócio. No entanto, as ferramentas de modelagem devem auxiliar a modelagem não apenas dos processos de negócio, mas, também, das metas organizacionais. Para isso os autores propõem o uso da Notação de Requisito de Usuário (URN - User Requirement Notation), como sendo uma notação que suporta esses dois pontos - processos e metas organizacionais.

Com a necessidade da modelagem dos processos de negócio com algumas ferramentas já citadas para descrição dos processos, é importante pontuar que o BPMN é a notação mais difundida no mercado, de acordo com o Grupo de Gestão de Objeto (OMG - Object Management Group) (2008). Logo em seguida, nota-se o uso do UML e URN. Além dos exemplos citados anteriormente, as seguintes técnicas também são usadas: IDEF (Integrated Definition Methods), EPC (Event Process Chains), RAD (Role Activity Diagrams), REA (Resource Event Agent), Redes de Petri e Gráficos de Gantt (AGHDASI; MALIHI, 2010).

A Iniciativa de Gestão do Processos de Negócio (BPMI - Business Process Management Initiative) desenvolveu um padrão conhecido como BPMN, que tem como principal objetivo prover uma notação que seja de fácil leitura e entendimento dos usuários de negócio, das informações vindas dos analistas de negócio que modela o desenho dos processos. Em seguida, os desenhos dos processos são implementados via sistemas que automatizam os processos, de modo, que permita aos gestores gerenciar e monitorar estes processos.

Hoje o BPMN está na versão 2.0, que contempla uma gama maior de símbolos que auxiliam na modelagem detalhada do modelo de processo de negócio. Esses símbolos são classificados como fluxos de objetos, conexão de objetos, piscinas e raias, e artefatos. As categorias citadas totalizam quatro, sendo que os elementos básicos permitem e suportam modelagem de fluxo de sequência, regras, atividades, eventos e hierarquia de processos (WHITE, 2004). Na tabela 2, são ilustradas essas quatro categorias e seus elementos.

Tratando-se da categoria de Objetos de Fluxo, ela envolve eventos, desvios e atividades na sua estrutura. Um exemplo de evento é algo que acontece instantaneamente, por ter sido solicitado. O desvio é caracterizado por permitir representar escolhas possíveis 
Tabela 2 - Categorias da notação BPMN

\begin{tabular}{ll}
\hline Categoria & Elemento \\
\hline Objetos de Fluxo & Evento, Atividade e Desvio (Gateway) \\
$\begin{array}{l}\text { Objetos de Co- } \\
\text { nexão }\end{array}$ & Fluxo de Sequência, Fluxo de Mensagem e Associação \\
Artefatos & Objeto de Dados, Grupo e Anotação \\
Swimlanes & Piscina e Raia \\
\hline
\end{tabular}

Fonte: Salles et al. (2013)

dentro do processo de negócio. A atividade representa uma unidade de trabalho com uma duração, por exemplo, uma atividade que exerce uma solicitação. Por fim, tanto evento quanto atividade estão logicamente relacionados no contexto de processo (DUMAS et al., 2013). Na figura 8, é ilustrado um fluxo envolvendo eventos e atividades do programa criado de forma fictícia para auxiliar no entendimento.

Ainda de acordo com Dumas et al. (2013), Salles et al. (2013), na categoria dos Objetos de Conexão - que tem o objetivo de unir os demais elementos da notação entre si, encontra-se o Fluxo de Sequência, o Fluxo de Mensagem, e ao Fluxo de Associação, de modo que, o Fluxo de Sequência deve ser usado entre Objetos de fluxo contidos dentro da mesma piscina. Já o Fluxo de Mensagem tem objetivo de unir Objetos de Fluxo entre diferentes piscinas ou processos de negócio. Por último, a Associação dever ser usada com propósito de relacionar Artefatos a Objetos de Fluxos, e, por ventura, ligar a outros artefatos.

Artefato ou Artefatos de Informação e tudo aquilo que é necessário para executar uma atividade, por exemplo um documento de negócio ou um arquivo. Por outro lado, pode ser tudo aquilo que é gerado a partir da execução de uma atividade. Um exemplo clássico é um processo de vendas em que o cliente inicia o processo com o pedido e a primeira atividade seria a verificação do estoque para poder seguir o processo. No momento da verificação do estoque, a atividade acessa um artefato que contém informações de disponibilidade de produtos (neste caso seria um banco de dados). Como artefato, encontra-se os objetos de dados que podem estar dentro ou fora da atividade e podem ser representados por artefatos físicos como arquivo ou e-mail. Ainda dentro da categoria de artefato, encontra-se o grupo que reúne todos os elementos representados no seu interior. Finalizando, a anotação que contém comentários sobre os elementos a ele associados (DUMAS et al., 2013). 
Figura 8 - Processo de negócio do exemplo ilustrativo envolvendo os principais elementos de BPMN

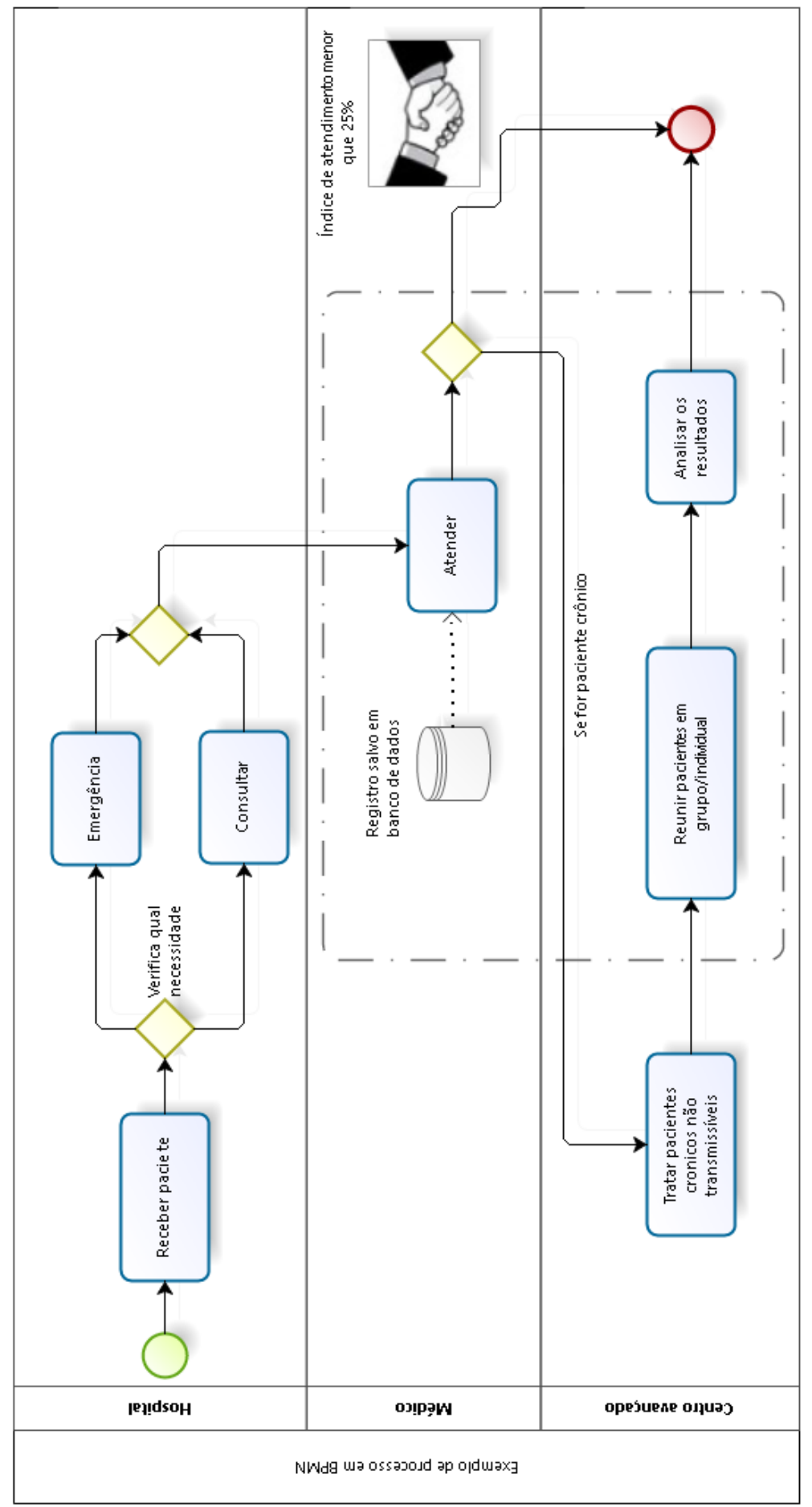

Fonte: Adson Rocha do Carmo, 2016 
Swimlanes representa tanto uma piscina quanto uma raia. As Swimlanes não são usadas em uma coreografia - é a interação ou comunicação entre os elementos do modelo. Isto é, não existe comunicação entre uma raia e um elemento do modelo. Em contrapartida, piscinas podem ser usadas como diagramas de coreografia quando está inserido no contexto de um diagrama de colaboração (OMG, 2011). Piscinas representam os participantes dos processos, já as raias representam os papéis.

Para ilustrar os conceitos apresentados nos parágrafos anteriores, é exibida a figura 8 contendo um desenho abstrato de um processo de negócio usando o BPMN. Embora o BPMN seja uma linguagem difundida no mercado por atender às principais necessidades da modelagem, Bocciarelli e D'Ambrogio (2014) pondera que o BPMN não suporta o tratamento de requisitos não funcionais dos processos de negócio e também não oferece apoio a atividades de medição de desempenho. Por consequência disso, nota-se então uma lacuna que será explorada em seções futuras neste trabalho.

\subsubsection{Implementação de processo de negócio}

Uma alternativa para implementação de sistemas com uma filosofia que envolve a disponibilidade de componentes úteis a um processo de negócio é a Arquitetura Orientada a Serviços (SOA - Service Oriented Architecture), pois sua proposta é disponibilizar aplicativos ou rotinas independentes, mais precisamente, serviços dispostos na maioria das vezes na internet ou intranet baseados em padrão aberto.

Segundo Sousa e Leite (2014), na atualidade o SOA é considerado um dos paradigmas mais promissores na área de computação distribuída por induzir a interoperabilidade e o fraco acoplamento entre os elementos essenciais de software, ou seja, os serviços. Papazoglou (2003) afirma que serviços são componentes abertos, auto-descritivos que suportam a composição de baixo custo de aplicações distribuídas.

BALDAM et al. (2007) esclarece que as grandes empresas fabricantes de software estão investindo alto em SOA buscando evoluí-lo e, por intermédio desta evolução, ampliar oportunidades como:

- Aumento das possibilidades de comercialização de seus produtos de forma diferenciada. Porque as empresas passariam a oferecer serviços com menor custo e mais 
acessíveis aos clientes, pois permite que o cliente adquira apenas um ou alguns serviços, ao invés de uma licença de todo um software.

- Integração entre diferentes plataformas e sistemas variados com ERP's, Workflow's, CRM etc., com maior possibilidade.

A respeito da execução de processos de negócio, o advento do SOA como um paradigma voltado à integração entre sistemas e os limites organizacionais estimulou o uso dos serviços web que se comunicam entre si usando padrão baseado em uma Linguagem de Marcação Extensível (XML - eXtensible Markup Language). Esse XML é expresso pelo Protocolo Simples de Acesso a Objetos (SOAP - Simple Object Access Protocol) e outros protocolos. Neste ponto, o cenário descrito tem objetivo de expressar o modelo do processo de negócio por meio do BPMN. Sendo assim, surgiu a necessidade de transformar a abstração criada em BPMN, em um nível operacional, ou seja, mais próximo à execução do negócio (LAPADULA; PUGLIESE; TIEZZI, 2012; OUYANG et al., 2007).

Os web services já permitiam que as empresas disponibilizassem seus serviços na internet, dessa forma, integrando e dando acessibilidade na comunicação com clientes. Por outro lado, com a criação de aplicações complexas de Negócio para Negócio (B2B - Business to Business) e integração automatizada de processo de negócio por meio da necessidade da organização, fez-se necessário funcionalidades como interação assíncrona, concorrência, coordenação de fluxos e transações de negócio. E como apoio a essa necessidade surgiu a Linguagem de Execução de Processos de Negócio de Serviço Web (WS-BPEL - Web Service Business Process Execution Language), que, atualmente, é a linguagem mais popular para modelar processo de negócio em serviço (LAPADULA; PUGLIESE; TIEZZI, 2012).

O WS-BPEL é baseado em XML e é recomendada pela W3C. Sendo assim, a linguagem mais comum para declaração formal e execução, devido a maioria dos processos de negócio ser orquestrado (SALLES, 2014).

\subsection{Requisitos não funcionais}

O objetivo desta seção é apresentar os conceitos relacionados aos requisitos não funcionais de processos de negócio. Tais informações devem ser abordadas via os requisitos não funcionais e QoS. Em seguida, apresentados os requisitos do tipo Acordo, composto 
por SLA e BLA, que buscam formalizar e auxiliar o cumprimento dos requisitos não funcionais.

Para melhor compreender o conceito de requisitos não funcionais, é importante primeiro expor as definições de requisitos. No contexto da engenharia de software, os requisitos são características relacionadas ao produto ou serviço, de modo que os requisitos funcionais expressam o comportamento obtido entre a interação dos componentes e seu ambiente. Diferentemente, os requisitos não funcionais dizem respeito a características associadas a desempenho, qualidade e satisfação. Um exemplo aconece no trabalho de Kotonya e Sommerville (1996).

Complementando as características dos requisitos não funcionais (NFR), é dito que eles obrigam restrições no produto desenvolvido - requisitos do produto. Restrições no processo de desenvolvimento - requisitos de processo. E, por fim, restrições externas que devem ser encontradas no produto - requisitos externos (SOMMERVILLE; KOTONYA, 1998).

Sommerville e Kotonya (1998) explicam que requisitos não funcionais são identificados a partir das necessidades dos usuários, levando em consideração parâmetros de tempo de execução, orçamento e criticidade do processo/serviço. Caso a identificação dos requisitos seja equivocada poderá resultar na entrega de sistemas de informação ineficazes.

Estudos sobre NFR apontam que a identificação dos mesmos é equivalente a tratar as metas de negócio da organização. Tanto é que o NFR framework associa NFR a metas. No entanto, só por intermédio de uma árvore de decisão é definido quais NFR serão realmente tratados como metas (XAVIER ALENCAR, 2010; SALLES, 2014).

No contexto deste trabalho, utiliza-se de alguns requisitos não funcionais que são usados por Fernández e Penzenstadler (2015) no metamodelo da figura 5. Esse requisitos não funcionais são usados no prótotipo computacional, desenvolvido como parte deste trabalho, para definir o atributo de qualidade que se busca alcançar por meio da métrica usada. Os requisitos não funcionais estão listados a seguir:

- Availability

- Reliability

- Integrity

- Usability

- Efficiency

- Flexibility 
Figura 9 - Representação genérica dos conceitos envolvidos

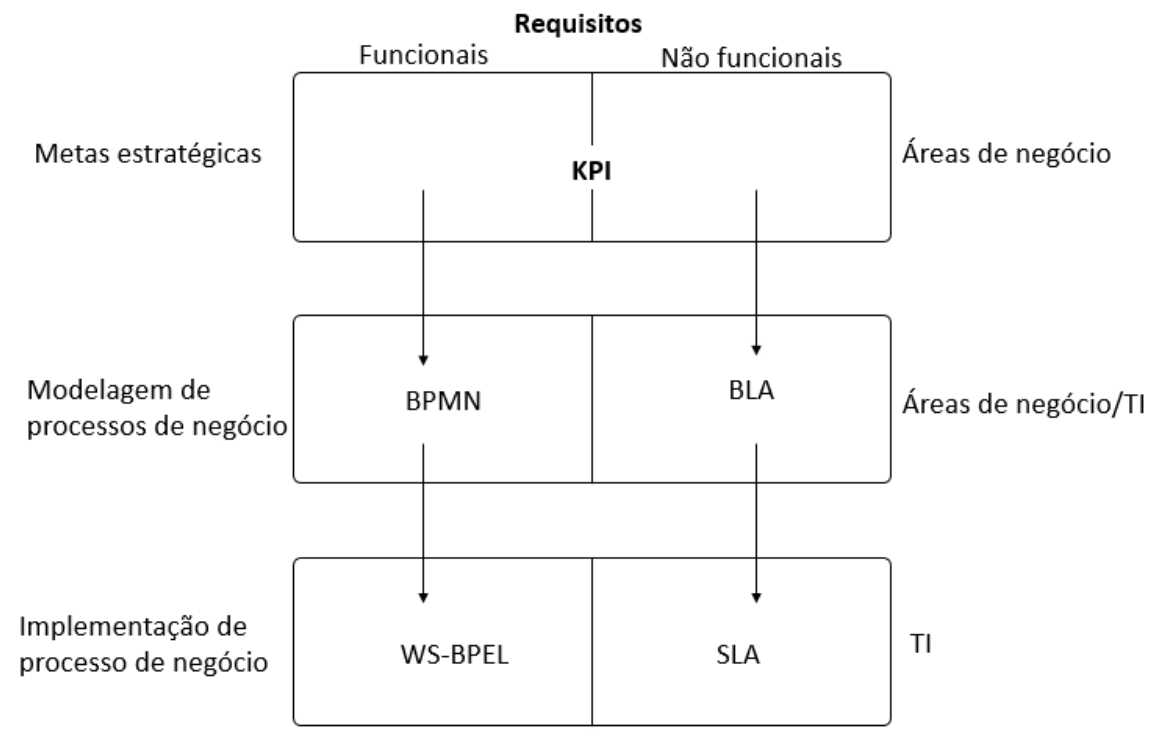

Fonte: Adson Rocha do Carmo, 2016

- Maintainability

- Interoperability

- Reusability

- Portability

- Effectiveness

Visando contextualizar o uso dos requisitos não funcionais com sua aplicação nos respectivos níveis (entende-se aqui como nível Meta estratégica, Modelo de processo de negócio e Implementação de processo de negócio) organizacionais, a figura 9 ilustra os níveis e o método ou técnica usada para tratar tais requisitos. Este estudo considera que os problemas podem permear por três níveis diferentes, porém, em cada nível, existe um método ou uma técnica para tratar os requisitos, seja ele funcional ou não. Por exemplo: ainda na figura 9, no nível de Modelagem de processos de negócio/Área de negócio, quando se trata de requisito funcional, o BPMN é usado. Entretanto, quando se trata de requisito não funcional, o BLA é usado. Uma exceção nesta figura é o nível representado pelas Metas estratégicas e Área de negócio, pois o KPI pode ser usado para tratar tanto o requisito funcional quanto o não funcional.

Enfim, Salles et al. (2013) argumenta que os requisitos não funcionais tendem a ser informalmente relatados pelos usuários ou envolvidos no processo. Dessa forma, ocasionando maior dificuldade no alcance do cumprimento dos requisitos. Este problema ocorre, tanto na engenharia de software quanto em BPM, principalmente em contextos 
complexos de negócio no caso de BPM. Por outro lado, para contornar esta dificuldade exposta, o SLA e BLA devem ser considerados como pilares fundamentais na solução de TI.

\subsubsection{Requisitos não funcionais em BPM no Nível de Serviços}

Devido à percepção do mercado na importância do tratamento dos requisitos não funcionais, no contexto de processos e alinhamento estratégico organizacional, a atenção foi aumentada e estimulou as organizações a adotarem técnicas para melhorar a qualidade dos produtos ou serviços. Por isso, fez-se necessário confeccionar um contrato entre os prestadores e os clientes para formalizar responsabilidades mútuas relacionada à qualidade por meio de especificações técnicas (SKENE; LAMANNA; EMMERICH, 2004).

As especificações técnicas mencionadas no parágrafo anterior dizem respeito à Especificação de Nível de Serviço (SLS). Ou seja, um conjunto de parâmetros e seus valores assim unificados que definem os serviços oferecidos e acordado entre as partes (FAWAZ et al., 2004). O conceito é mantido pela The Internet Engineering Task Force (IETF, 2015), instituição responsável por melhorar a qualidade da internet.

A partir da criação de SLS, adquiri-se, ao final, um contrato denominado como contrato de Acordo de Nível de Serviço (SLA), segundo a IETF (2015). O SLA tem o objetivo de formalizar acordo entre prestador e cliente, no contexto de prestação de serviço. No SLA são definidas políticas e regras para contribuir com aspectos de qualidade do serviço como: desempenho, disponibilidade e responsabilidade. Dessa forma, um SLA contém um ou vários SLS, trazendo as especificações detalhadas dos serviços.

Para alcançar o sucesso do contrato e manter ou aumentar a qualidade, o SLA usa políticas de custo e penalidade para controlar a busca da qualidade do serviço disponível. Para isso, usa-se a Qualidade de Serviço (QoS) (IETF, 2015). Não somente o QoS, também dois outros conceitos são necessários para auxiliar o SLA na medição da experiência do usuário e na medição do negócio: a Qualidade do Negócio (QoBiz) e a Qualidade de Experiência (QoE).

De acordo com Moorsel (2001), QoBiz é o ato de medir os resultados do negócio, em termos de ganhos ou perdas. Já o QoE é o ato de medir a qualidade na experiência do usuário. Para exemplificar, pode-se fazer uma analogia com um serviço de compra na internet, que o usuário pode acessar e fazer o pedido do produto desejado. O QoBiz 
Figura 10 - Exemplos de métricas de QoS, QoE e QoBiz

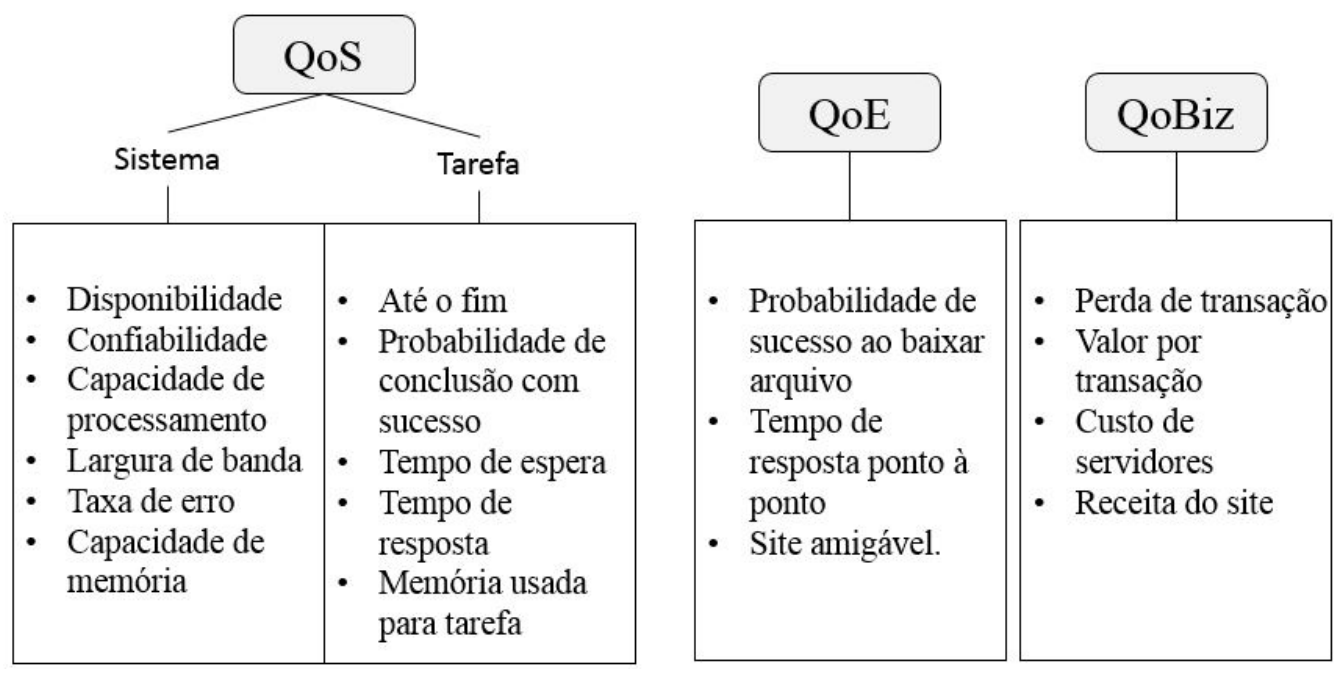

Fonte: Traduzido de Moorsel (2001)

mediria o retorno obtido por intermédio deste serviço, por outro lado, o QoE obteria informações sobre a experiência do usuário no processo de compras, como a usabilidade do sistema web. Alguns exemplos são ilustrados na figura 10.

Tornou-se então necessária a implementação dos conceitos (QoBis, QoE e QoS) citados, assim a Web Services Policy Working Group (VEDAMUTHu; HOndO; YALÇINALP, 2007) desenvolveu o WS-Policy Framework, que faz parte do W3C Service Activity, com objetivo de auxiliar na descrição da política dos serviços web. Mais precisamente auxiliar na especificação das capacidades, requisitos e características gerais da entidade dos sistemas baseados em serviços web. Este framework usa XML para representar as propriedades propostas.

Outro recurso usado no apoio a execução da qualidade dos serviços é o WS-Security, um protocolo proposto por (ATKINSON et al., 2002), profissionais da IBM e Microsoft, com a finalidade de descrever mensagens SOAP para prover qualidade de proteção por meio da integridade e confidencialidade da mensagem, também única autenticação da mensagem. Desta forma, por exemplo, atendendo o item Confiabilidade ilustrado na figura 10 no tópico "QoS" e subtitulo "Sistema".

Tratando dos requisitos não funcionais do processo de negócio, no contexto do SOA, e implementação dessas características traduzidos em serviços web, a W3C recomenda o uso das linguagens WS-Agreement e WS-Policy.

O WS-Agreement consiste em representar o acordo definido entre as partes, detalhando os objetivos do nível de serviço para expressar os requisitos de serviço. O 
Figura 11 - Estrutura do acordo de serviço web

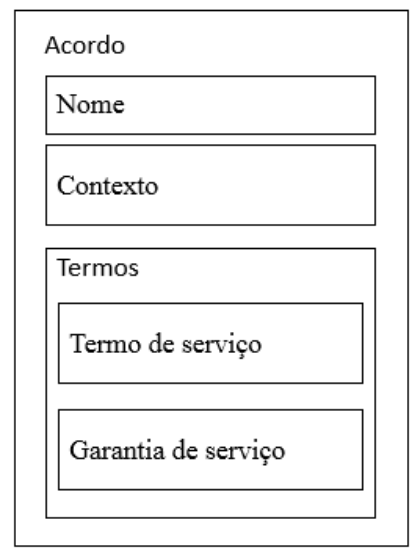

Fonte: Traduzido de Andrieux et al. (2007)

WS-Agreement tem uma estrutura que contempla o nome, o contexto, o termo que contém - termo de serviço e garantia de serviço. Tal estrutura é representada na figura 11 (ANDRIEUX et al., 2007).

Por fim, no contexto de BPM o SLA tem papel fundamental no auxílio do alcance das metas estratégicas organizacionais, principalmente as metas com características não funcionais devido ao fato do SLA usar o QoS, QoE e QoBiz para garantir o cumprimento dos serviços ao cliente. E por o SLA se tratar de uma técnica que está no nível da execução do processo, ou seja, diretamente associada aos interesses do cliente, seus resultados devem ser acompanhados de forma criteriosa. Segundo Melo et al. (2014), o SLA pode ser usado para manejar o relacionamento entre o negócio e a TI, garantindo que as atividades modeladas sejam cumpridas, atendendo, assim, os interesses de negócio da organização.

\subsubsection{Requisitos não funcionais em Acordos em Nível de Negócio}

De acordo com Melo et al. (2014), BLA é uma abordagem que despontou no cenário recentemente e busca lidar com acordos relacionados ao processo de Negócio com perspectiva de obter resultados desejados, definidos nas metas organizacionais. Segundo Bratanis, Dranidis e Simons (2010), o BLA é uma representação do mundo real no tocante a representação de acordos entre dois parceiros de negócio, que usarão os serviços web para executar seus processos de negócio.

O BLA pode ser incorporado a ferramentas de modelagem de processos, por meio da inclusão do elemento BLA como é possível ser feito hoje no Bizagi - É uma ferramenta para modelar BPM. 
Figura 12 - Relação entre BLA e SLAs

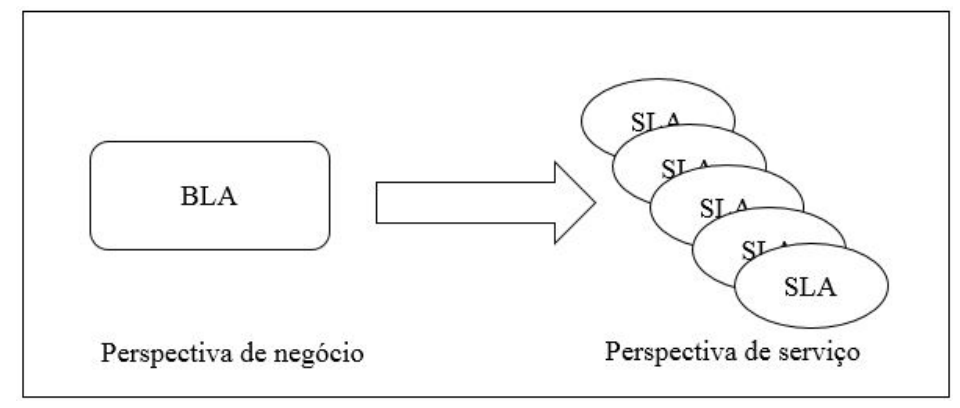

Fonte: Salles (2014)

Salles (2014) propôs um template de BLA, ilustrada na tabela 3, contendo os atributos e descrições que compõem o BLA.

Ainda segundo Bratanis, Dranidis e Simons (2010), o BLA pode ser usado para descrever as características funcionais e não funcionais de um serviço $W e b$ de uma maneira automatizada. Além disso, de acordo com Salles et al. (2013), o BLA pode ser considerado similar ao SLA, em termos de nível de negócio, no entanto, o BLA está mais voltado à representação dos requisitos não funcionais e, em seguida, visa mapear estas características via SLAs. Uma forma de compreender melhor o BLA é entendendo que o BLA pode ser representado por um conjunto de SLAs. Por outro lado, as características de um SLA podem ser encontradas em um BLA (BRATANIS; DRANIDIS; SIMONS, 2010).

Certamente, o BLA tem sido usado como uma composição de SLAs, haja visto que SLAs estão presentes no dia a dia da TI, principalmente quando se trata de gerenciamento de serviços. Porém, para auxiliar no alinhamento estratégico organizacional, o desejado é o de que os SLAs sejam extraídos do BLA (deve ocorrer uma inversão na ordem de execução em que antes era do SLA para BLA), como ilustrado na figura 12 (SALLES, 2014).

Buscando esclarecer o funcionamento de um BLA, Salles (2014) usa um exemplo, ilustrado na tabela 4, com as informações que podem estar contidas no BLA. Este exemplo demonstra uma necessidade organizacional que é "melhorar a satisfação dos clientes", e tal necessidade está relacionada com requisitos não funcionais por lidar com a melhoria da satisfação, pois envolve a qualidade do serviço prestado ao cliente. E quando se trata de qualidade - atributos como desempenho, tempo de resposta etc., provavelmente deve-se tratar os requisitos não funcionais.

O exemplo da tabela 4 trata de uma regra para contratação de crédito e diz que o período de vigência é entre 18 de fevereiro de 2013 até 29 de agosto de 2014. E envolve um contrato entre cliente e fornecedor, sendo o cliente o solicitante do crédito e o fornecedor o 
a instituição financeira. É definido um tempo de seis horas para duração do processamento desde a solicitação até a entrega do crédito caso aprovado ou resposta de não liberação do crédito caso negado. Em situação de não cumprimento do tempo de processamento existem dois tipo de multa. Em contrapartida, é possível obter bonificação, caso as regras do contrato sejam atendidas corretamente durante o período vigente Salles (2014).

Enfim, o BLA deve ser uma representação de alto nível, ou seja, acordo que reflitam os requisitos não funcionais das metas da organização. E, por intermédio do BLA, os SLA devem ser extraídos, dessa forma, auxiliando que os objetivos da organização sejam o principal direcionador do alinhamento estratégico.

\subsection{Metas estratégicas organizacionais}

As informações relevantes das metas estratégicas organizacionais são aquelas que servem como base para criação dos indicadores, que, por sua vez, servem para auxiliar na busca do alcance das metas estratégicas.

As metas estratégicas organizacionais podem ser expressas por requisitos funcionais ou não funcionais. Porém, esta abordagem se limita a tratar os requisitos não funcionais, pois geralmente as metas estratégicas organizacionais estão associadas a fatores como qualidade e desempenho (KOTONYA; SOMMERVILLE, 1996). Pode-se concluir que, se a meta estratégica organizacional apresenta uma ou várias das características citadas, esta meta contém caráter não funcional. Assim, a forma de identificar se existe ou não requisitos não funcionais nas metas estratégicas organizacionais é verificando a presença dessas características.

Há indício de que existem informações nas metas organizacionais que oferecem apoio aos requisitos não funcionais, e é por meio da identificação de palavras que fazem referência a características como desempenho ou qualidade e etc. Por exemplo os verbos aumentar, reduzir, melhorar, que podem estar fazendo menção a características não funcionais.

Além de identificar as informações das metas estratégicas organizacionais que oferecem apoio aos requisitos não funcionais é necessário identificar algum padrão nas metas estratégicas organizacionais. Para ilustrar foram coletados alguns exemplos, listados a seguir: 
- "Aumentar Market Share passando da participação atual de 15\% em 2016, para 25\% em 2017."

- "Manter índice de satisfação dos clientes acima de 95\% nas medições semestrais."

- "Melhorar a qualidade dos serviços de telefonia em 12\% dentro de dois anos."

- "Reduzir em 90\% a percentual da taxa de mortalidade da UTI Neo natal em seis meses."

- "Melhorar em 40\% a qualidade do atendimento dos pacientes com doenças crônicas não transmissíveis nos próximos três anos."

- "Alcançar o primeiro lugar em audiência entre as emissoras de TV por assinatura até 2020."

É possível identificar alguns padrões entre os exemplos de metas estratégicas organizacionais citadas na lista acima.

O primeiro padrão identificado é o verbo que inicia cada meta. As três metas começam com os verbos "aumentar, manter, melhorar", dando indícios do propósito desejado sobre o sujeito das frases (aumentar Market Share, manter índice de satisfação, melhorar o serviço). O segundo padrão identificado é a presença de valores numéricos expressados por valores absolutos ou percentuais. Nos exemplos das metas estratégicas organizacionais, foram encontrados os seguintes valores em percentual: 15\%, 95\%, 12\%. O terceiro padrão encontrado é a definição de prazo ou período de tempo para alcançar os valores desejados relacionados ao verbo encontrado na meta. Por exemplo: Aumentar Market Share entre 2016 até 2017, ou Melhorar a qualidade em dois anos.

Após analisar os três padrões encontrados nos exemplos de metas estratégicas organizacionais, uma hipótese pode ser levantada: uma meta estratégica organizacional pode ser composta por um verbo, seguida do sujeito, valores numéricos (absolutos ou percentuais), e, por fim, período de tempo para alcançar os valores determinados. A partir desta hipótese, torna-se possível concluir que toda informação contida na meta estratégica organizacional que esteja relacionada com esses padrões identificados, poder vir a ser classificados como informações relevantes que devem compor KPIs organizacionais. 
Figura 13 - Framework de mapeamentos e derivações propostos

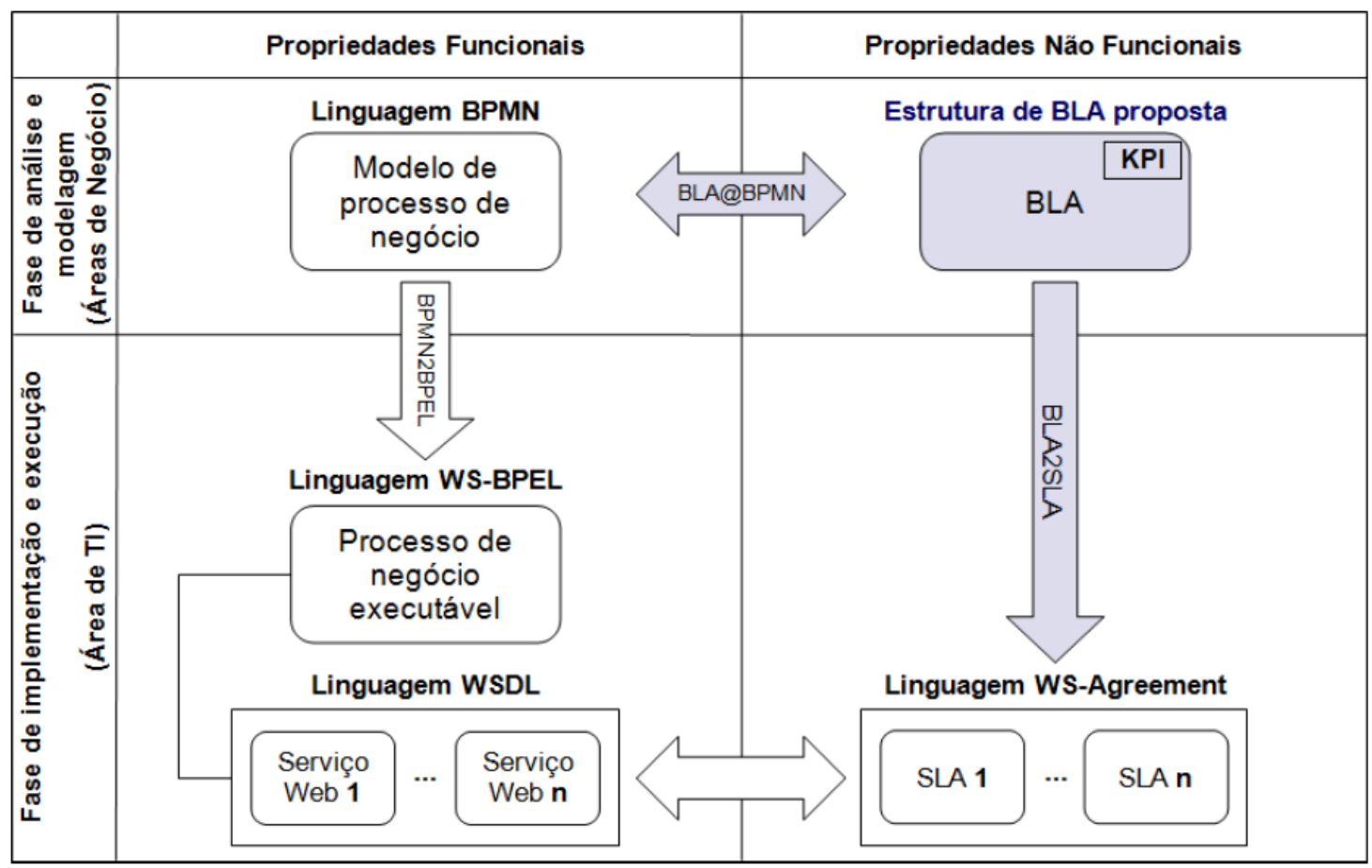

Fonte: Salles (2014)

\subsection{Framework StrAli-BPM}

Com o intuito de semi automatizar o processo de definição de BLAs baseada em metas organizacionais via a inserção da informação pelos analistas de negócio e, em seguida, derivar os BLAs de forma semiautomática, em SLAs. Salles (2014) propôs um Framework, que é uma extensão de BPM chamado StrAli-BPM, que busca sanar a lacuna que existe nas abordagens de BPM em termos de requisitos não funcionais, entre a modelagem de processos de negócio e sua implementação e realização via SOC.

De acordo com Salles (2014), permitir que o BLA seja criado por um analista da área de negócio garante que o SLA deve ser um reflexo das metas estratégicas organizacionais. Diferenciando do cenário até então visto, em que os BLAs eram criados a partir dos SLAs. A figura 13 ilustra os elementos existentes no clico de vida de processos de negócio, sendo que, os elementos em cinza representam os elementos propostos pela abordagem StrAli-BPM.

Devido à necessidade de identificar e formalizar os elementos do contexto organizacional que oferecem apoio á criação de BLA, Salles (2014) propôs um metamodelo que ilustra os relacionamentos entre os elementos que compõem a estrutura de BLA. Os 
elementos de cor cinza são os elementos que estão diretamente ligados ao BLA. Por outro lado, os outros elementos (de cor branca) atuam de forma indireta no apoio ao BLA.

Figura 14 - Metamodelo BLA@BPMN

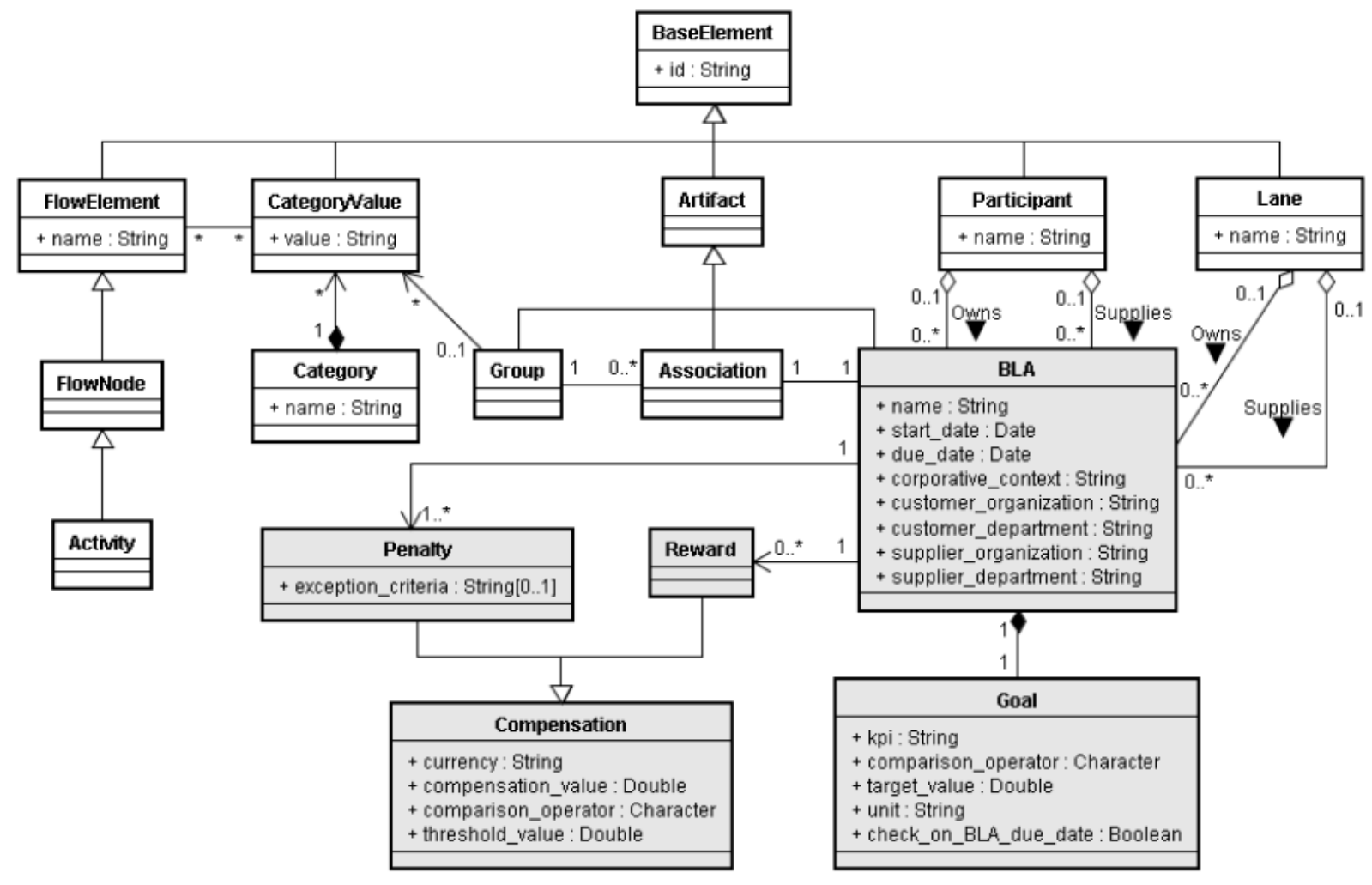

Fonte: Salles (2014)

As fases iniciais (análise e desenho) são de responsabilidade dos analistas de negócio, e, nessas fases, a extensão proposta de BPMN considerou a relação entre atividades do processo modelado chamada de BLA@BPMN, usando-se de representação gráfica para referenciar o BLA e o armazenamento de seus atributos. Além disso, o ato de extrair SLAs dos BLAs é representado pela expressão BLA2SLA, que é implementado nas duas fases finais, que são de implementação e execução (usando o WS-BPEL/WSDL como linguagens).

Com o propósito de estender o BPMN para inclusão de BLA, a abordagem usa o BizAgi como ferramenta para implementação do BPMN, pois ela, além de outras ferramentas, permite a inclusão de artefatos. No caso, o BLA é representado como um elemento do BPMN 2.0. Na figura 15, é possível visualizar um exemplo contendo o artefato de BLA ilustrado no contexto de negócio da empresa privada, especificamente no programa apresentado aqui como exemplo. Neste exemplo, o BLA envolve um conjunto de elementos 
que, quando suas condições são satisfeitas, de acordo com as regras definidas entre as entidades (entende-se como entidade neste exemplo a empresa de saúde e o médico), atinge o objetivo esperado do BLA.

Figura 15 - Exemplo ilustrativo do uso de BLA

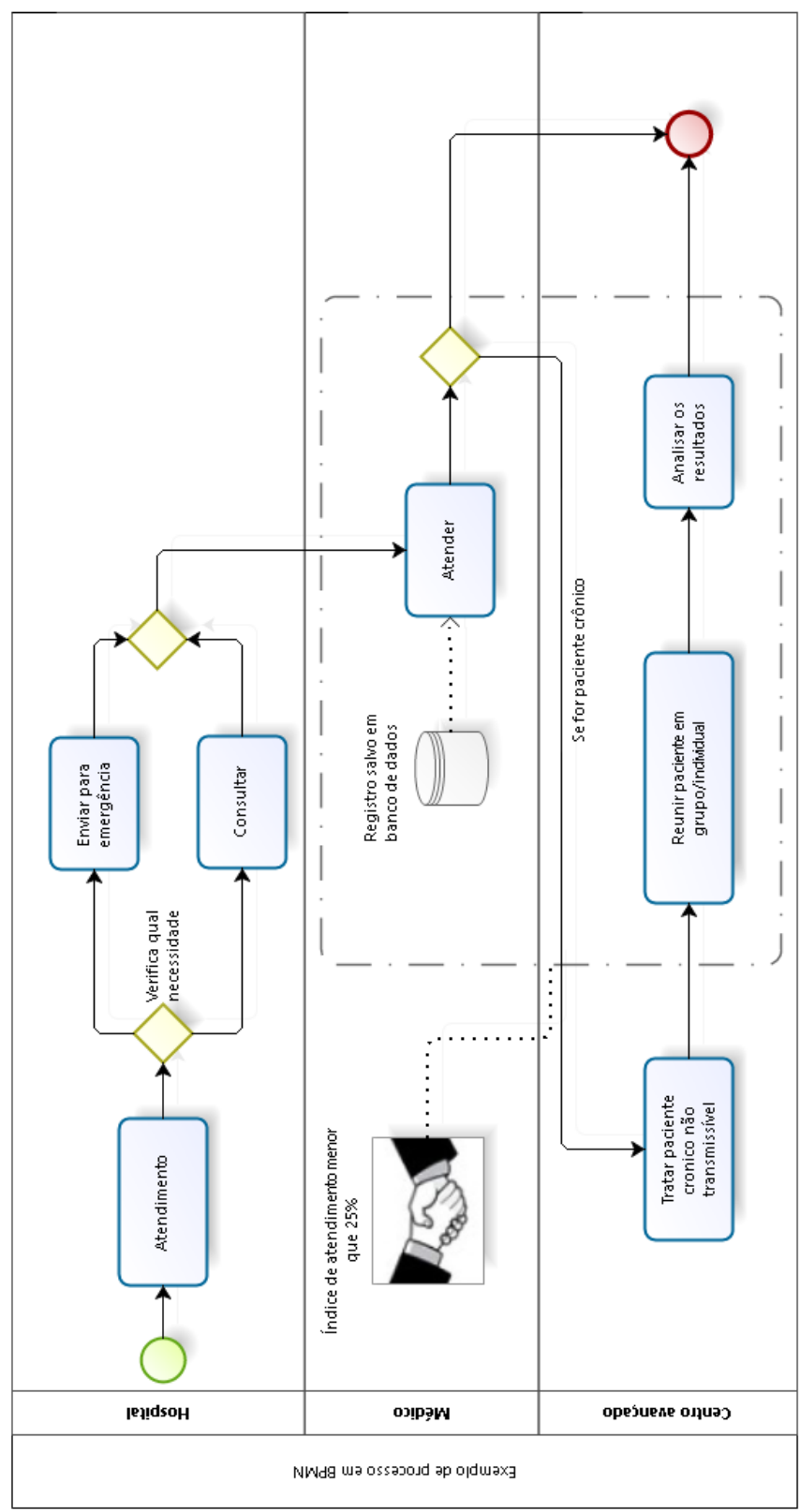

Fonte: Adson Rocha do Carmo, 2016 
Tabela 3 - BLA de acordo com a abordagem StrAli-BPM

\begin{tabular}{|c|c|c|}
\hline Atributo & Descrição & Qtd. \\
\hline Identificador & $\begin{array}{l}\text { Nome definido para o artefato BLA durante a modelagem } \\
\text { em BPMN }\end{array}$ & 1 \\
\hline Data de início & Data de inicio do período de vigência do BLA & 1 \\
\hline Data de término & Data de termino do período de vigência do BLA & 1 \\
\hline Contexto corporativo & $\begin{array}{l}\text { Cenário organizacional e/ou econômico e propósito pelo qual } \\
\text { se firmou o BLA }\end{array}$ & 1 \\
\hline Organização proprietária & $\begin{array}{l}\text { Nome da organização proprietária do BLA, responsável pelo } \\
\text { monitoramento dos futuros SLAs }\end{array}$ & 1 \\
\hline $\begin{array}{l}\text { Departamento pro- } \\
\text { prietário }\end{array}$ & $\begin{array}{l}\text { Nome do departamento (obrigatoriamente pertencente à } \\
\text { "Organização proprietária") responsável pelo pagamento de } \\
\text { bonificações e pelo recebimento de indenizações }\end{array}$ & 1 \\
\hline Organização fornecedora & $\begin{array}{l}\text { Nome da organização responsável pelo cumprimento das } \\
\text { metas do BLA }\end{array}$ & 1 \\
\hline Departamento fornecedor & $\begin{array}{l}\text { Nome do departamento (obrigatoriamente pertencente à } \\
\text { "Organização fornecedora") responsável pelo recebimento de } \\
\text { bonificações e pelo pagamento de multas }\end{array}$ & 1 \\
\hline Meta & $\begin{array}{l}\text { Meta do BLA considerando qual o KPI envolvido, seu valor } \\
\text { alvo e regra de medição do desempenho }\end{array}$ & 1 \\
\hline$-\mathrm{KPI}$ & $\begin{array}{l}\text { Descrição do KPI, que pode representar tanto um requisito } \\
\text { não funcional especifico quanto um requisito funcional de } \\
\text { mais alto nível }\end{array}$ & 1 \\
\hline $\begin{array}{l}\text { - Operador de com- } \\
\text { paração }\end{array}$ & $\begin{array}{l}\text { Operador que define a desigualdade entre o "KPI" e seu } \\
\text { "Valor alvo" }\end{array}$ & 1 \\
\hline - Valor alvo & Valor da "Meta" que se deseja alcançar, como desejável & 1 \\
\hline - Unidade & Descrição da unidade de medida do "Valor alvo" & 1 \\
\hline $\begin{array}{l}\text { - Verificação no término } \\
\text { do BLA }\end{array}$ & $\begin{array}{l}\text { Booleano que indica: "Verdadeiro": a verificação da "Meta" } \\
\text { deve ocorrer somente na "Data de término" do BLA; "Falso": } \\
\text { a verificação da "Meta" deve ocorrer a cada execução do } \\
\text { processo }\end{array}$ & 1 \\
\hline Multa & $\begin{array}{l}\text { Aplicação de indenização para o "Departamento proprietário" } \\
\text { caso a "Meta" não seja atingida }\end{array}$ & $1 . .^{*}$ \\
\hline - Moeda & Unidade monetária referente ao "Valor da compensação" & 1 \\
\hline - Valor de compensação & Valor da "Multa" a ser pago se necessário & 1 \\
\hline $\begin{array}{l}\text { - Operador de com- } \\
\text { paração }\end{array}$ & Operado de desigualdade para o "Valor limiar" da "Multa" & 1 \\
\hline - Valor limiar & $\begin{array}{l}\text { Valor na mesma unidade do "Valor alvo" da "Meta", a partir } \\
\text { do qual a "Multa" é disparada (considerando o intervalo } \\
\text { determinado pelo presente "Operador de comparação") }\end{array}$ & 1 \\
\hline - Critérios de exceção & $\begin{array}{l}\text { Descrição de possíveis condições excepcionais que anulem a } \\
\text { necessidade de pagamento da "Multa" }\end{array}$ & $0 . .1$ \\
\hline Bonificação & $\begin{array}{l}\text { Aplicação de bonificação opcional para o "Departamento } \\
\text { fornecedor" caso a "Meta" seja superada }\end{array}$ & $0 . .^{*}$ \\
\hline - Moeda & Unidade monetária referente ao "Valor da compensação" & 1 \\
\hline - Valor de compensação & Valor da "Multa" a ser pago se necessário & 1 \\
\hline $\begin{array}{l}\text { - Operador de com- } \\
\text { paração }\end{array}$ & Operado de desigualdade para o "Valor limiar" da "Multa" & 1 \\
\hline - Valor limiar & $\begin{array}{l}\text { Valor na mesma unidade do "Valor alvo" da "Meta", a partir } \\
\text { do qual a "Bonificação" é disparada (considerando o intervalo } \\
\text { determinado pelo presente "Operador de comparação") }\end{array}$ & 1 \\
\hline
\end{tabular}


Tabela 4 - Exemplo ilustrativo de BLA para contratação de crédito

\begin{tabular}{ll}
\hline Atributo & Valor \\
\hline Identificador & Criação de contratos em até 6 horas \\
Data de inicio & 18 de fevereiro de 2013 \\
Data de término & 29 de agosto de 2014 \\
Contexto corporativo & Em 2013, o foco da organização deve ser na melhoria da \\
& satisfação dos clientes \\
Organização proprietária & Instituição financeira \\
Departamento proprietário & Departamento de Gestão Comercial \\
Organização fornecedora & Instituição financeira \\
Departamento fornecedor & Departamento de Tecnologia \\
Meta & \\
- KPI & Tempo de Processamento \\
- Operador de comparação & $\leq$ \\
- Valor alvo & 6.00 \\
- Unidade & Horas \\
- Verificação no término do BLA & Falso \\
Multa & R $\$$ \\
- Moeda & $15.000,00$ \\
- Valor de compensação & $\geq$ \\
- Operador de comparação & 9,00 \\
- Valor limiar & R $\$$ \\
Multa 2 & $40.000,00$ \\
- Moeda & $\geq$ \\
- Valor de compensação & 24,00 \\
- Operador de comparação & A multa é anulada se houver indisponibilidade da aplicação \\
- Valor limiar & durante a execução do processo \\
- Critérios de exceção & $R \$$ \\
Bonificação & $10.000,00$ \\
- Moeda & $<$ \\
- Valor de compensação & Operador de comparação \\
- Valor limiar & \\
\hline
\end{tabular}

Fonte: Salles (2014) 


\section{Método de pesquisa}

Este capítulo destina-se a descrever o método aplicado no trabalho, usando-se das estratégias metodológicas com intuito de alcançar os objetivos propostos neste trabalho nos conformes de uma pesquisa científica.

- Gênero "pesquisa empírica": por tratar-se de um estudo que se propõe a compreender o senso comum a respeito do assunto proposto por este trabalho. Além de não se apoiar em teorias este trabalho busca tirar conclusões a partir da vivencia e experiência dos participantes que foram submetidos ao processo de avaliação desta abordagem.

- Natureza "aplicada": após a identificação de uma lacuna, este estudo propõe-se desenvolver uma abordagem que tem como estratégia criar um protótipo para sanar a lacuna apontada neste trabalho.

- Objetivo "explicativo": devido a necessidade de identificar os fatores do cenário atual das práticas de BPM relacionadas às características não funcionais das metas estratégicas organizacionais que contribuem ou determinam a criação de BLAs. Então, a partir dessa identificação, propor uma abordagem para contribuir com o avanço da busca do alinhamento estratégico entre o negócio e a TI.

- Abordagem "qualitativa": Por possuir um pequeno número de ideias preconcebidas e enfatizar na interpretação dos eventos mais do que a interpretação do pesquisador e analisar as informações narradas de forma organizada, no entanto, intuitiva. Como analise de qualidade, este estudo visualizará ao final da execução da abordagem proposta, se o BLA reflete as metas organizacionais.

No contexto dos procedimentos técnicos, o estudo apresenta o "Design Science" como característica de pesquisa. Segundo Alan et al. (2004), "Design Science", na área de Sistemas de Informação (SI), é a criação e evolução de artefatos tecnológicos para resolver problemas organizacionais identificados. Não somente a criação de artefato pela identificação de uma lacuna e propor uma solução que atende as necessidades do negócio, mas também tem o respaldo cientifico tanto como referência para a construção da solução como para tratar os resultados obtidos com a pesquisa (ALAN et al., 2004). 
Segundo Alan et al. (2004), a pesquisa em "Design Science" mantém o foco no desenvolvimento de artefatos com propósito de melhorar o desempenho do negócio, isso é possível por conta da criação de uma ponte entre a ciência e a ação prática.

O principal indício que esta pesquisa configura-se como "Design Science", levando em consideração a relação citada entre pesquisas na área de SI, é pelo fato da necessidade de criação de um artefato como parte da solução proposta da abordagem (ALAN et al., 2004). Por outro lado, a criação do artefato não é a finalidade desta pesquisa, mas sim a criação de uma abordagem.

Como instrumentos de coletas de dados, este estudo usou o questionário. Pois por meio dele, é possível identificar o nível de conhecimento prévio dos participantes a respeito dos conceitos relacionados a abordagem e compreender se na visão dos participantes a abordagem auxilia ou não no processo de modelagem de requisitos não funcionais dos KPIs.

A Técnica de análise de dados usada é a análise qualitativa, por meio da análise de conteúdo, buscando compreender se a abordagem proposta alcança os objetivos propostos e se efetivamente proporciona melhoria no controle dos processos de negócio organizacional no contexto de gestão de processos.

Os passos metodológicos neste trabalho de mestrado apresentam as seguintes etapas previstas: uma revisão bibliográfica por meio de livros que contenham os principais conceitos usados neste estudo; RSL, para identificar o estudo da arte contido nos trabalhos recentemente publicados, por exemplo, os periódicos, outras revisões sistemáticas da literatura e artigos; detalhamento da extensão que será proposta; desenvolvimento da abordagem; prototipação e avaliação dos resultados alcançados.

A respeito da fundamentação teórica deste estudo, o escopo definido explorou os seguintes assuntos: o Alinhamento Estratégico, e o KPI e BSC como ferramentas de apoio; a Gestão de Processo de Negócio, Modelagem de Processo de Negócio usando o BPMN como linguagem, Implementação de processos de negócio e Execução de processos de negócio; os Requisitos Não Funcionais e os Requisitos não funcionais em BPM no nível de serviço e Acordo em nível de negócio; o framework StrAli-BPM, pois, a partir dele, será proposta uma extensão. 


\subsection{Planejamento da revisão sistemática}

Uma revisão sistemática da literatura (também chamada apenas de "revisão sistemática") refere-se à identificação, a evolução e a interpretação de todos os trabalhos de pesquisa relevantes disponíveis que atendam às questões de um protocolo de pesquisa (KEELE, 2007). Estudos individuais que contribuem para uma revisão sistemática são denominados estudos primários; uma revisão sistemática é uma forma de estudo secundário. Uma revisão sistemática difere de uma revisão tradicional (ou seja, uma revisão simples da literatura) e revisões com comentários realizados por especialistas da área (chamados de surveys) por ser uma abordagem transparente, científica e replicável, usada para evitar vieses (BIOLCHINI et al., 2005).

Para conduzir esta revisão sistemática, as diretrizes propostas por Kitchenham (KEELE, 2007) foram usadas. Uma revisão sistemática inclui alguns passos que podem ser agrupados dentro de três fases: (i) planejamento; (ii) condução; e, (iii) resultados.

O planejamento inclui os seguintes principais passos (KEELE, 2007): (i) identificação da necessidade para a revisão sistemática; (ii) questões de pesquisa; e, (iii) desenvolvimento do protocolo. Esses passos são descritos a seguir.

\subsubsection{Necessidade para uma revisão sistemática}

Esta revisão sistemática se justifica uma vez que não foi identificado nenhum trabalho sistemático prévio que tenha sido realizado neste contexto e que apresenta resultados claros sobre trabalhos de pesquisa realizados no âmbito do interesse do grupo de pesquisa em que os autores se insere; ou seja, a extração de informação a partir de metas estratégicas organizacionais para servir de fonte na modelagem de requisitos não funcionais durante a modelagem de processos de negócio. Acredita-se que essa mesma informação pode ser de interesse e útil para outros pesquisadores.

\subsubsection{Questões de pesquisa da revisão sistemática}

Assumindo a necessidade desta revisão sistemática, três questões de pesquisa foram formuladas para direcionar esse estudo. As questões formuladas deveriam delimitar apenas a artigos que apresentassem abordagens relacionadas com a "definição de requisitos não 
funcionais, durante a modelagem de processos de negócio, com base em alguma técnica usada para o tratamento de metas estratégicas organizacionais, tais como KPI ou BSC". De forma mais específica, as três questões de pesquisa definidas são as seguintes:

- Q1. Quais são as técnicas usadas para tratamento de metas estratégicas organizacionais nas abordagens identificadas? Essas técnicas são, por exemplo, KPI ou BSC?

- Q2. Quais são as técnicas usadas para a modelagem de processos de negócio nas abordagens identificadas? Essas técnicas são, por exemplo, BPMN ou Diagramas de Atividades da UML?

- Q3. Quais abordagens identificadas são automatizadas? Que ferramentas têm sido usadas na automação?

\subsubsection{Protocolo da revisão sistemática}

Segundo Kitchenham (KEELE, 2007), um protocolo especifica os métodos a serem usados para realizar uma revisão sistemática específica. Um protocolo bem definido é essencial para reduzir a possibilidade de pesquisas ambíguas, pois ele descreve como pesquisar e selecionar estudos primários relevantes e analisar os dados extraídos para responder as questões de pesquisas propostas, de forma sistemática. O protocolo aqui definido, seguindo a estratégia prevista por Kitchenham (KEELE, 2007), é composto por: (i) fonte de dados; (ii) estratégia de pesquisa; (iii) estratégia de seleção dos estudos primários; (iv) método de extração; e, (v) sumarização dos dados. Esses itens são descritos nas próximas seções.

\subsubsection{Fontes de dados e estratégia de pesquisa}

As fontes de dados selecionadas são Scopus e Web of Science. Em conjunto, ambas oferecem acesso aos artigos publicados e indexados pelas principais editoras internacionais da área em questão, incluindo: IEEE, ACM e Springer.

Para estratégia de pesquisa, uma string de busca foi criada para expressar os objetivos desta revisão sistemática e filtrar artigos que pudessem responder às questões de pesquisa. Na Tabela 5, está apresentada a string de busca básica que reflete os interesses 
das questões de pesquisa e sem a influência das sintaxes das ferramentas de busca usadas. A lógica usada na busca visa pesquisar artigos que tratem de: (i) modelagem de processos de negócio, de forma geral ou BPMN, de forma específica; e, (ii) metas estratégicas organizacionais, incluindo diversos possíveis sinônimos ou técnicas específicas, tais como KPI or BSC. Devido a peculiaridades dos motores de busca das fontes de dados usadas (Scopus e Web of Science), duas strings específicas foram criadas para atender o perfil de busca de cada uma (cf. Tabelas 6 e 7).

Tabela 5 - String de busca básica

("business process model" OR "BPMN") AND ("organizational requirement" OR "strategic goal" OR "strategic plan" OR "business requirement" OR "business constraint" OR "business goal" OR "business plan" OR "Key Performance Indicator" OR KPI OR "Balanced Scorecard" OR $\mathrm{BSC})$

Fonte: Adson Rocha do Carmo, 2016

Tabela 6 - String de busca Scopus

(TITLE-ABS-KEY(("business process model*" OR "BPMN") AND (("organizational requirement*" OR "organizational constraint*" OR "organizational goal*" OR "organizational plan*") OR ("organisational requirement*" OR "organisational constraint*" OR "organisational goal*" OR "organisational plan*") OR ("corporate requirement*" OR "corporate constraint*" OR "corporate goal*" OR "corporate plan*") OR ("enterprise requirement*" OR "enterprise constraint*" OR "enterprise goal*" OR "enterprise plan*") OR ("company requirement*" OR "company constraint*" OR "company goal*" OR "company plan*") OR ("strategic requirement*" OR "strategic constraint*" OR "strategic goal*" OR "strategic plan*") OR ("business requirement*" OR "business constraint*" OR "business goal*" OR "business plan*") OR ("Key Performance Indicator*" OR "KPI*" OR "Balanced Scorecard" OR "BSC")))) AND PUBYEAR i 1999 AND (LIMITTO(LANGUAGE, "English")) AND (LIMIT-TO(DOCTYPE, "cp") OR LIMIT-TO(DOCTYPE, "ar") OR LIMIT-TO(DOCTYPE, "ip")) AND (LIMIT-TO(SUBJAREA, "COMP") OR LIMITTO(SUBJAREA, "ENGI") OR LIMIT-TO(SUBJAREA, "BUSI") OR LIMIT-TO(SUBJAREA, "ECON"))

Fonte: Adson Rocha do Carmo, 2016

\subsubsection{Estratégia de seleção dos estudos primários}

Um conjunto de Critérios de Inclusão (CI) e de Critérios de Exclusão (CE) foram especificados para garantir que somente artigos relacionados ao contexto definido neste protocolo fossem selecionados como estudos primários da revisão sistemática. Os critérios definidos são apresentados a seguir. 
Tabela 7 - String de busca Web of Science

$\mathrm{TS}=(($ "business process model*" OR BPMN) AND (("organizational requirement*" OR "organizational constraint*" OR "organizational goal*" OR "organizational plan*") OR ("organisational requirement*" OR "organisational constraint*" OR "organisational goal*" OR "organisational plan*") OR ("corporate requirement*" OR "corporate constraint*" OR "corporate goal*" OR "corporate plan*" ) OR ("enterprise requirement*" OR "enterprise constraint*" OR "enterprise goal*" OR "enterprise plan*") OR ("company requirement*" OR "company constraint*" OR "company goal*" OR "company plan*") OR ("strategic requirement*" OR "strategic constraint*" OR "strategic goal*" OR "strategic plan*") OR ("business requirement*" OR "business constraint*" OR "business goal*" OR "business plan*") OR ("Key Performance Indicator*" OR KPI* OR "Balanced Scorecard" OR BSC)) ) AND (SU="COMP*" OR SU="ENGI*" OR SU="BUSI*" OR SU="ECON*")

Fonte: Adson Rocha do Carmo, 2016

- CI-1: artigo diretamente relacionado à metas estratégicas organizacionais, tais como BSC ou KPI.

- CI-2: artigo diretamente relacionado à modelagem de processos de negócio, tais como BPMN ou UML.

- CI-3: artigo apresentando abordagem que trata requisitos não funcionais na modelagem de processos de negócio baseada em metas estratégicas organizacionais.

\section{Critérios de exclusão:}

- CE-1: artigo publicado antes do ano 2000.

- CE-2: artigo não disponível eletronicamente na web.

- CE-3: artigo não relacionado primariamente à área de sistemas de informação, ciência da computação ou administração de empresas.

- CE-4: não se refere a artigo científico revisado por pares, tais como: relatórios técnicos, livros e capítulos de livro, prefácios de anais, e editoriais de periódicos.

- CE-5: artigo escrito em língua diferente do inglês.

Cada resultado retornado nos motores de busca, para ser considerado um estudo primário para esta revisão sistemática deveria passar por cada um dos CI e não ser eliminado por nenhum dos CE. Alguns desses critérios de exclusão já puderam ser tratados nas strings de busca específicas criadas para os motores de busca usados, conforme apresentadas nas Tabelas 6 e 7. Assim, vários artigos já puderam ser excluídos automaticamente, não precisando passar pela checagem manual. 


\subsection{Condução da revisão sistemática}

A condução foi feita pela identificação e seleção de estudos primários, bem como avaliação de sua qualidade.

A identificação, seleção e avaliação de qualidade dos estudos primários foram baseadas na estratégia de Kitchenham (KEELE, 2007), que consiste em três passos, exibido na Figura 16 e descritos a seguir.

\section{- Passo 1. Identificação dos estudos primários relevantes nas bases de dados:} para obter os estudos primários, as strings de busca foram submetidas às bases escolhidas. Como resultado, foram obtidos 244 registros no Scopus e 114 na Web of Science. Descontando os repetidos, obteve-se ao final 268 registros.

- Passo 2. Aplicação dos critérios de inclusão e de exclusão (manualmente): cada estudo selecionado nas ferramentas de busca foi submetido aos critérios de inclusão e de exclusão. Para isso, realizou-se uma leitura do título do artigo, assim como de seu resumo e introdução na busca de indícios que levassem a conclusão de que o estudo atende ou não os objetivos desta revisão sistemática. Considerando o baixo número de estudos primários encontrados, o critério de inclusão CI-3 foi relaxado para que trabalhos obtidos nas buscas das fontes de dados e que atendem completamente os CI-1 e CI-2 sirvam de contribuição a esta RSL, por meio da identificação das técnicas aplicadas. Sendo assim, os trabalhos que respondem ao CI-1 e CI-2 são chamados aqui de estudos primários parciais.

- Passo 3. Avaliação da qualidade dos estudos primários: segundo Kitchenham (KEELE, 2007), é fundamental avaliar a qualidade dos estudos primários por vários motivos: disponibilizar detalhes dos critérios de inclusão e de exclusão; ponderar a importância de estudos individuais quando os resultados estão sendo sintetizados; orientar a interpretação dos resultados; e determinar a força das inferências. Kitchenham (KEELE, 2007) também informa a inexistência de um padrão para medir a qualidade de estudos e sugere como exemplo o uso de conceitos de CRD Guidelines e Cochrane Reviewers' Handbook, que sugerem a qualidade como medida em que o estudo minimiza a lacuna apontada e maximiza a validade interna e externa. Para análise de qualidade, neste estudo aqui apresentado, considerou-se: 
estudos com experimentos; evidencias de estudos de caso controlado. Ao final deste passo, obteve-se 11 estudos primários, resumidos na Tabela 8.

Figura 16 - Processo de seleção de estudos primários selecionados na revisão sistemática realizada

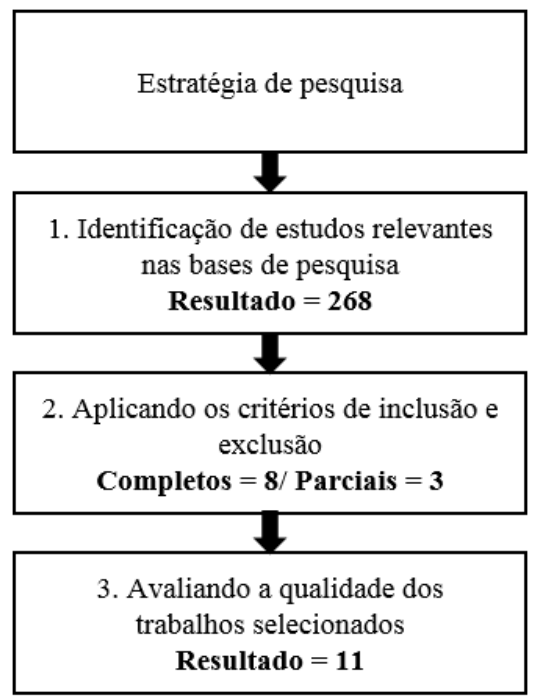

Fonte: Adson Rocha do Carmo, 2016 


\section{Trabalhos relacionados}

Neste capitulo, é apresentado os estudos que demonstram preocupação em tratar os requisitos não funcionais dos processos de negócio, usando técnicas para auxiliar nesta tarefa. Contudo, nenhum deles se propôs a fazer este tratamento no nível estratégico ou tático, que seria na camada das metas estratégicas organizacionais, e, proporcionar um método semiautomatizado para auxiliar na extração das informações das metas estratégicas organizacionais e modelar os requisitos não funcionais dessas informações.

\subsection{Estudos primários}

Na abordagem "Semantic Web Service Discovery for Business", os autores Markovic e Karrenbrock (2007) visam manter o alinhamento estratégico usando tecnologia baseada em semântica para representar metas estratégicas organizacionais. Essa semântica está pautada em serviços web e usa a Web Service Modeling Ontology (WSMO). Para especificação do modelo de processo de negócio, é usada BPMN. O processo de negócio é automatizado por meio da ferramenta Maestro de modelagem de processos de negócio da SAP Research. WSMO é usada para modelar as metas estratégicas organizacionais. A pesquisa tem um foco em especificação de preferências do usuário considerando tanto os requisitos funcionais quanto os requisitos não funcionais, podemos assim definir tal comportamento como ponto positivo. Por outro lado, não é apresentado solução para acompanhamento das metas estratégicas organizacionais.

Pourshahid et al. (2009) em "Business Process Management with the User Requirements Notation" usam uma abordagem baseada em User Requirement Notation (URN), que usa Goal-Oriented Requirement Language (GRL) como técnica para modelagem das metas estratégicas organizacionais. Além disso, URN usa a técnica Use Case Maps (UCM) que atende tanto a modelagem de processos de negócio quanto a análise, a identificação e o levantamento de requisitos. Os autores modelam os requisitos não funcionais do processo de negócio usando KPI para ajudar na integração entre as fases que compõem a modelagem de processos de negócio. Para auxiliar na implementação de URN, a ferramenta jUCMNav é usada para automatizar o processo de negócio e gerar uma interface amigável. O ponto positivo dessa abordagem é o fato de unificar duas técnicas que atendem aos aspectos 
principais desta revisão sistemática. Um ponto negativo é o fato de não ter explorado URN/GRL no tratamento dos requisitos não funcionais.

Abeti, Ciancarini e Moretti (2009) apresentam WikReq, na abordagem "Wikibased Requirements Management for Business Process Reengineering" - baseada em uma plataforma chamada Semantic Mediawiki (SMW). Trata-se de uma ferramenta que gerencia tanto sistemas como requisitos organizacionais com o objetivo de reengenharia de processos de negócio. A modelagem das metas estratégicas organizacionais é realizada por meio do framework $\mathrm{Si}^{*}$, que é uma linguagem orientada a metas que permite a descrição de requisitos não funcionais. Para modelar os processos de negócio, BPMN e UML são usadas. A implementação desta abordagem é automatizada por uma interface gráfica que exporta os conjuntos de modelos para o Eclipse IDE, que são conectados a modelos de BPMN e casos de uso da UML, resultando em um conjunto de informações chamada Model Driven Engineer (MDE). Um ponto forte neste estudo está na facilidade de manipulação do framework $\mathrm{Si}^{*}$, pois não exige conhecimento teórico aprofundado em notação gráfica.

Aghdasi e Malihi (2010) propõem uma abordagem intitulada de "Rule Based Business Process Optimization", que usa KPI para avaliar a eficiência dos processos de negócio para garantir que as mudanças estejam alinhadas com as metas estratégicas organizacionais. Os autores apresentam um framework próprio para a modelagem de processos de negócio e para a modelagem das metas estratégicas organizacionais. Assim, nenhuma técnica amplamente conhecida, tal como BPMN, é usada. O ponto forte dessa abordagem é o constante uso de KPI, pois induz o acompanhamento dos indicadores oriundos das metas estratégicas organizacionais, permitindo assim aplicar ações de correção, caso os resultados dos requisitos não funcionais não sejam satisfatórios. Os requisitos não funcionais são trabalhados fortemente via KPI, que reflete as metas estratégicas organizacionais com objetivo de validar o modelo de processos de negócio. Esta abordagem não apresenta um mecanismo automatizado.

Na abordagem "Towards a Pattern-Based Framework for Goal-Driven Business Process Modeling", Behnam, Amyot e Mussbacher (2010) aplicam o User Requirement Notation URN para auxiliar na modelagem, tanto de metas estratégicas organizacionais quanto de processos de negócio. Goal-Oriented Requirement Language (GRL) permite a modelagem das metas estratégicas organizacionais, além de possibilitar a modelagem de requisitos não funcionais, facilitando, assim, a extração das necessidades das diferentes partes envolvidas. Use Case Maps (UCM) é usada como linguagem visual de modelagem de 
processos de negócio. O ponto positivo é devido ao uso do URN, que permite comunicação eficiente entre as técnicas. Além disso, a ferramenta jUCMNav é usada para a criação, análise e gerenciamento de URN, além de ter apoio para extensão de URN para a modelagem de KPI, embora tal recurso não seja explorado pelos autores.

Pourshahid et al. (2012) usam Use Case Maps (UCM) de User Requirement Notation URN, em "A systematic Review and Assessment of Aspect-oriented Methods Applied to Business Process Adaptation", para analisar, identificar e especificar os requisitos não funcionais assim como a modelagem de processos de negócio. Para obter as metas estratégicas organizacionais, Goal-Oriented Requirement Language (GRL) é usada, por ser uma técnica orientada a metas, tem a função de capturar as metas estratégicas organizacionais e organizar as informações para apoiar as partes interessadas em suas decisões. URN/GRL também apoia o tratamento de requisitos não funcionais. Além de modelar as metas estratégicas organizacionais com URN/GRL, esta abordagem associa o conceito de KPI para acompanhar o andamento dos objetivos organizacionais que foram extraídos via URN/GRL. URN contém GRL e UCM, que oferece vantagem de comunicação entre elas, em relação às outras técnicas citadas nesta RSL. Porém, o tratamento de requisitos não funcionais de GRL não é explorado, embora a técnica ofereça tal recurso.

Bocciarelli e D’Ambrogio (2014) usam o PyBPMN, versão estendida de BPMN, desenvolvida para permitir apoio ao tratamento de requisitos não funcionais. Os autores propuseram uma técnica de extração de requisitos não funcionais do tipo desempenho e confiabilidade do processo de negócio. O tratamento dos requisitos não funcionais do modelo de processos de negócio é um dos pontos positivos tratados neste estudo, devido a extensão do BPMN para atender a falta de tratamento de requisitos não funcionais na modelagem de processos de negócio. PyBPMN possibilita ao analista de negócio prever o comportamento do processo de negócio em termos de desempenho e confiabilidade. Além de permitir estimar o tempo de execução de cada tarefa do processo de negócio, possibilitando verificar se uma determinada atividade ou o processo de negócio, de forma geral, estará de acordo com as metas estratégicas organizacionais antes de sua implementação. Como ponto negativo, destaca-se o fato desta abordagem não usar nenhuma técnica para a modelagem das metas estratégicas organizacionais com intuito de servir como entrada para modelagem dos requisitos não funcionais dos processos de negócio. 
O estudo conduzido por Bisogno et al. (2016) apresenta em sua abordagem "Combining modelling and simulation approaches: How to measure performance of business processes", uma preocupação com a garantia da eficiência dos processos de negócio. Para isso, os autores compreendem que é necessário atender às metas estratégicas organizacionais. KPI é a técnica usada para controlar os requisitos não funcionais das metas estratégicas organizacionais. A abordagem usa BPMN para a modelagem de processos de negócio e Business Processes Simulations (BPSim) para efetuar simulações no modelo atual, buscando encontrar lacunas ou gargalos. O último passo é a análise via KPIs, apresentados na proposta, que usam critérios previamente definidos na abordagem. O ponto positivo da abordagem é a técnica de simulação, porque permite detectar falhas no processo de negócio e principalmente o desalinhamento com as metas estratégicas organizacionais. No entanto, o processo de extração das metas estratégicas organizacionais não é automatizado.

Segundo Letsholo, Chioasca e Zhao (2012) no trabalho "An Integration Framework for Multi-Perspective Business Process Modeling", o objetivo é propor um framework de integração com múltiplas técnicas para preencher as lacunas apontadas pelos autores. Para isso, diferentes técnicas de modelagem de requisitos funcionais e não funcionais são usadas, incluindo as seguintes técnicas orientadas a metas (framework i*, Keep All Objectives Satisfied [KAOS], e Tropos) e orientadas a dados (Modelo Entidade-Relacionamento, Diagrama de Fluxo de Dados, e Diagrama de Classes da UML). Para atender a modelagem de processos de negócio, são usados Business Process Model and Notation (BPMN), Integrated DEFinition (IDEEF3), Unified Modeling Language (UML), Redes de Petri (RP), Role Activity Diagram (RAD) e Event-driven Process Chains (EPC). Talvez a solução fosse construir um framework que agregasse apenas os pontos fortes das técnicas citadas no estudo, sem necessariamente usar todas as características das técnicas. Assim, não seria necessário o uso de várias técnicas, pois o excesso delas pode causar algum tipo confusão no processo de aplicação das mesmas; além de ser necessário adquirir um certo grau de conhecimento em cada técnica para manipular e aplicar cada uma delas corretamente.

Cortes-Cornax et al. (2012) usam Business Process Model and Notation (BPMN) e Keep All Objectives Satisfied (KAOS) baseados em Intentional Fragment (IF) no estudo "Intentional Fragments Bridging the Gap". KAOS é um framework usado para modelar requisitos não funcionais orientado a metas; BPMN é usada para a modelagem de processos de negócio. IF é uma técnica que busca comprovar a utilidade da meta estratégica organizacional fazendo uma relação intermediária entre KAOS e BPMN; ou seja, todo 
modelo de meta deve ter uma representatividade com IF e, assim, relacionar-se com um ou mais processos de negócio. Esse processo, por sua vez, deve satisfazer a meta estratégica organizacional. O objetivo da abordagem é modelar processos de negócio e manter separados os modelos de metas estratégicas organizacionais. Além disso, traçar ligações entre esses dois modelos para permitir aos analistas identificar a falta de atividades necessárias, sendo esses os pontos fortes identificados. O ponto negativo deste trabalho é a falta de acompanhamento das metas estratégicas organizacionais, seja com o uso de KPI ou qualquer outra técnica.

Na abordagem "Scenario-Driven Approach for Business Process Modeling", Ruokonen, Pajunen e Systä (2009) propuseram algo que gera Web Services Description Language (WSDL) e Web Services Business Process Execution Language (WS-BPEL) baseados na descrição de um modelo Unified Modeling Language(UML) usado para simplificar a modelagem de processos de negócio. A abordagem implementa uma ferramenta chamada Sketch, associada a um plug-in Eclipse. Busca-se identificar os requisitos funcionais de negócio e modelá-los usando uma notação de cenário simples, com base em um processo de negócio automatizado. O trabalho trata de metas estratégicas organizacionais, porém sem citar uma técnica específica para extraí-las ou modelá-las. O artigo dedica-se pouco a requisitos não funcionais e não há técnicas para acompanhar as metas estratégicas organizacionais.

\subsection{Características e lacunas das abordagens dos estudos primários}

Nesta seção é apresentado os trabalhos selecionados usando os recursos da seção de método de pesquisa.

No protocolo desta revisão sistemática foram definidas três questões para nortear a análise dos estudos. A primeira questão se refere a "Quais são as técnicas usadas para tratamento de metas estratégicas organizacionais nas abordagens identificadas? Essas técnicas são, por exemplo, KPI ou BSC?". Identificou-se KPI, URN/GRL, KAOS e framework $\mathrm{i}^{*}$ como as técnicas mais recorrentes; todas elas classificadas como orientadas a "metas". Não foi identificada nenhuma referência ao uso de BSC, em nenhum dos estudos primários identificados. Com respeito ao uso de KPI, verificou-se que ele está sendo aplicado em níveis organizacionais estratégicos em conjunto com requisitos não funcionais aplicáveis a esse nível. Por outro lado, URN/GRL, KAOS e framework i*, além de tratar os requisitos 
não funcionais, geram entradas a modelos de processos de negócio, o que os posicionam mais próximo a TI. Ainda em relação ao uso de técnicas de modelagem de metas estratégicas organizacionais, verificou-se o uso de URN/GRL em três estudos (BEHNAM; AMYOT; MUSSBACHER, 2010; POURSHAHID et al., 2012; POURSHAHID et al., 2009), tendo também o uso de URN/UCM de forma associada, que atende a modelagem de processos de negócio. Juntas, essas duas técnicas compõem a URN, de forma a permitir uma comunicação com maior eficiência entre os modelos de metas estratégicas organizacionais e de processos de negócio.

Em relação à segunda questão "Quais são as técnicas usadas para a modelagem de processos de negócio nas abordagens identificadas? Essas técnicas são, por exemplo, BPMN ou Diagramas de Atividades da UML?", foram identificados o uso de técnicas como BPMN, UML e URN/UCM. BPMN é a mais frequente, o que indica que ela possa oferecer mais benefícios em relação às demais para este contexto. Em geral, quando BPMN não foi usada em algum dos estudos primários, ela foi pelo menos citada como parâmetro inicial para extensão de abordagens já existentes. Por exemplo, ByBPMN (BOCCIARELLI; D’AMBRogio, 2014) se refere a uma extensão de BPMN com características voltadas ao tratamento de requisitos não funcionais, incluindo desempenho, confiabilidade e segurança.

Em relação à terceira questão "Quais abordagens identificadas são automatizadas? Que ferramentas têm sido usadas na automação", foram identificados sete trabalhos apresentando uma abordagem automatizada em algum grau, com auxílio de ferramentas como Eclipse IDE (EMF, MediniQVT, TAOM4E, jUCMNav) e Maestro da SAP. Os quatro trabalhos que não oferecem apoio automatizado em nenhum nível, citaram pretender tratar isso em trabalhos futuros. O uso de automação é importante neste contexto para evitar a ocorrência de falhas manuais, por intervenção humana, no processo de extração de requisitos não funcionais a partir das metas estratégicas organizacionais e a posterior modelagem de tais requisitos como parte dos processos de negócio. Em relação as ferramentas usadas para automação, três trabalhos usam ferramentas open source. Apenas um trabalho usa uma ferramenta proprietária - Maestro, da SAP.

Em relação a um possível padrão encontrado entre os estudos primários analisados, foi constatado a prevalência do uso de BPMN e KPI. Indícios que BPMN aparenta ser a melhor opção para a modelagem de processos de negócio. E KPI aparentar ser a técnica mais viável para modelagem de metas estratégicas organizacionais. 
Os onze estudos primários selecionados estão listados na tabela 8, abaixo. Dentre os dez, sete foram publicados em anais de conferência e três em periódicos.

Tabela 8 - Lista final de estudos primários selecionados na revisão sistemática

\begin{tabular}{|c|c|c|c|c|}
\hline Título & Ano & Ref. & Veículo & CI-3 \\
\hline $\begin{array}{l}\text { Semantic Web Service Discovery } \\
\text { for Business }\end{array}$ & 2007 & $\begin{array}{l}\text { Markovic e Kar- } \\
\text { renbrock (2007) }\end{array}$ & Conferência & Completo \\
\hline $\begin{array}{l}\text { Business Process Management } \\
\text { with the User Requirements No- } \\
\text { tation }\end{array}$ & 2009 & $\begin{array}{l}\text { Pourshahid et al. } \\
(2009)\end{array}$ & Periódico & Completo \\
\hline $\begin{array}{l}\text { Scenario-Driven Approach for } \\
\text { Business Process Modeling }\end{array}$ & 2009 & $\begin{array}{l}\text { Ruokonen, Pa- } \\
\text { junen e Systä } \\
(2009)\end{array}$ & Conferência & Parcial \\
\hline $\begin{array}{l}\text { Wiki-based Requirements Mana- } \\
\text { gement for Business Process Re- } \\
\text { engineering }\end{array}$ & 2009 & $\begin{array}{l}\text { Abeti, Cianca- } \\
\text { rini e Moretti } \\
(2009)\end{array}$ & Conferência & Completo \\
\hline $\begin{array}{l}\text { Rule Based Business Process Op- } \\
\text { timization }\end{array}$ & 2010 & $\begin{array}{l}\text { Aghdasi e Malihi } \\
\text { (2010) }\end{array}$ & Conferência & Completo \\
\hline $\begin{array}{l}\text { Towards a Pattern-Based Fra- } \\
\text { mework for Goal-Driven Business } \\
\text { Process Modeling }\end{array}$ & 2010 & $\begin{array}{l}\text { Behnam, Amyot } \\
\text { e Mussbacher } \\
(2010)\end{array}$ & Conferência & Completo \\
\hline $\begin{array}{l}\text { A systematic Review and Assess- } \\
\text { ment of Aspect-oriented Methods }\end{array}$ & 2012 & $\begin{array}{l}\text { Pourshahid et al. } \\
\text { (2012) }\end{array}$ & dico & Completo \\
\hline $\begin{array}{l}\text { Applied to Business Process } \\
\text { Adaptation }\end{array}$ & & & & \\
\hline $\begin{array}{l}\text { An Integration Framework for } \\
\text { Multi-Perspective Business Pro- } \\
\text { cess Modeling }\end{array}$ & 2012 & $\begin{array}{l}\text { Letsholo, Chi- } \\
\text { oasca e Zhao } \\
(2012)\end{array}$ & Conferência & Parcial \\
\hline $\begin{array}{l}\text { Intentional Fragments Bridging } \\
\text { the Gap }\end{array}$ & 2012 & $\begin{array}{l}\text { Cortes-Cornax et } \\
\text { al. }(2012)\end{array}$ & Conferência & Parcial \\
\hline $\begin{array}{l}\text { A Model-driven Method for } \\
\text { Enacting the Design-time QoS } \\
\text { Analysis of Business Processes }\end{array}$ & 2014 & $\begin{array}{l}\text { Bocciarelli e } \\
\text { D'Ambrogio } \\
(2014)\end{array}$ & Periódico & Completo \\
\hline $\begin{array}{l}\text { Combining Modelling and Simu- } \\
\text { lation Approaches: How to Me- } \\
\text { asure Performance of Business } \\
\text { Processes }\end{array}$ & 2016 & $\begin{array}{l}\text { Bisogno et al. } \\
(2016)\end{array}$ & Periódico & Completo \\
\hline
\end{tabular}

Fonte: Adson Rocha do Carmo, 2016

A Figura 17 apresenta a distribuição dos onze trabalhos em relação ao ano de publicação, com destaque para o período entre os anos 2009 e 2012 (ou seja, 65\% do total). A linha de tendência (do tipo linear) apresentada no gráfico, indica uma tendencia de crescimento no número de publicações nos próximos anos.

A partir dos onze estudos primários selecionados, oito técnicas para a modelagem de metas estratégicas organizacionais foram identificadas: KPI (BOCCIARELLI; D'AMBROGIO, 
Figura 17 - Distribuição dos estudos primários por ano de publicação

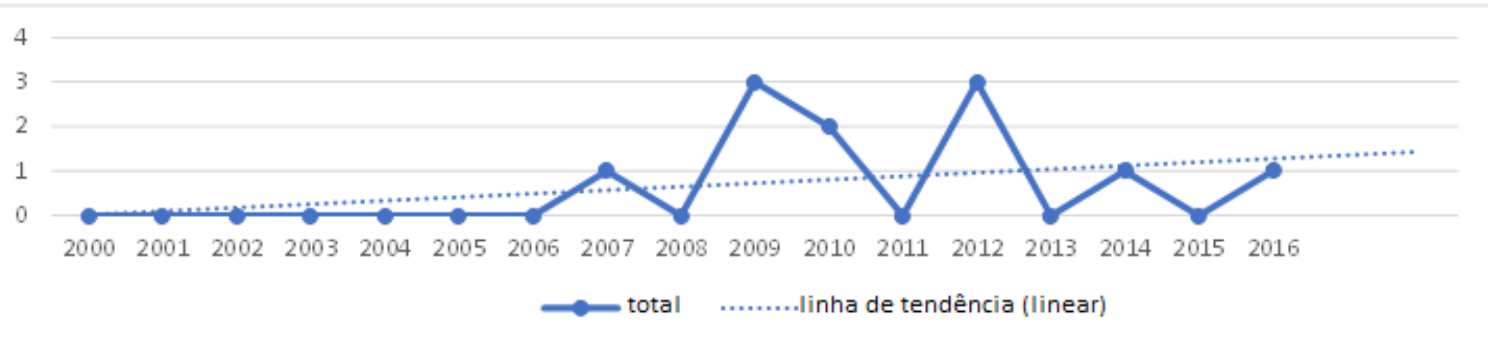

Fonte: Adson Rocha do Carmo, 2016

2011; POURSHAHID et al., 2009; AGHDASI; MALIHI, 2010; BISOGNO et al., 2016); User Requirement Notation (URN)/Goal-oriented Requirement Language (GRL) (POURSHAHID et al., 2012; POURSHAHID et al., 2009; BEHNAM; AMYOT; MUSSBACHER, 2010); Keep All Objectives Satisfied (KAOS) (LETSHOLO; CHIOASCA; ZHAO, 2012; CORTES-CORNAX et al., 2012); framework Si* (ABETI; CIANCARINI; MORETTI, 2009); Web Service Modeling Ontology (WSMO) (MARKOVIC; KARRENBROCK, 2007); Business Process Optimization Framework (BPOFW) (AGHDASI; MALIHI, 2010); framework i* (LETSHOLO; CHIOASCA; ZHAO, 2012); e Tropos (LETSHOlO; CHIOASCA; ZHAO, 2012). Os números de estudos primários identificados em que cada técnica é usada são apresentados na Figura 18. A técnica BSC não foi identificada em nenhum dos estudos primários. A técnica framework $\mathrm{Si}^{*}$ apresenta a característica peculiar para este contexto de possuir a capacidade de atender tanto a modelagem de metas estratégicas organizacionais quanto a modelagem de processos de negócio. Porém, ela só é usada na modelagem de metas estratégicas organizacionais.

Oito técnicas usadas para modelagem de processos de negócio foram identificadas: BPMN (BOCCIARELLI; D'AMBROGIO, 2014; LETSHOLO; CHIOASCA; ZHAO, 2012; CORTES-CORNAX et al., 2012; MARKOVIC; KARRENBROCK, 2007; ABETI; CIANCARINI; MORETTI, 2009; BISOGNO et al., 2016); Unified Modeling Language (UML) (RUOKONEN; PAJUNEN; SYSTÄ, 2009; ABETI; CIANCARINI; MORETTI, 2009); User Requirement Notation (URN)/Use Case Maps (UCM) (POURSHAHID et al., 2009; BEHNAM; AMYOT; MUSSBACHER, 2010); Integrated DEFinition (IDEEF3) (LETSHOLO; CHIOASCA; ZHAO, 2012); Diagramas de Atividade (LetSholo; CHIOASCA; ZHAO, 2012); Role Activity Diagram (RAD) (LETSHOlO; CHIOASCA; ZHAO, 2012); Event-driven Process Chains (EPC) (LETSHOLO; ChIOASCA; ZHAO, 2012); e Rede de Petri (PN) (LETSHOlO; CHIOASCA; ZHAO, 2012). Os 
Figura 18 - Técnicas de modelagem de metas estratégicas organizacionais identificadas nos estudos primários

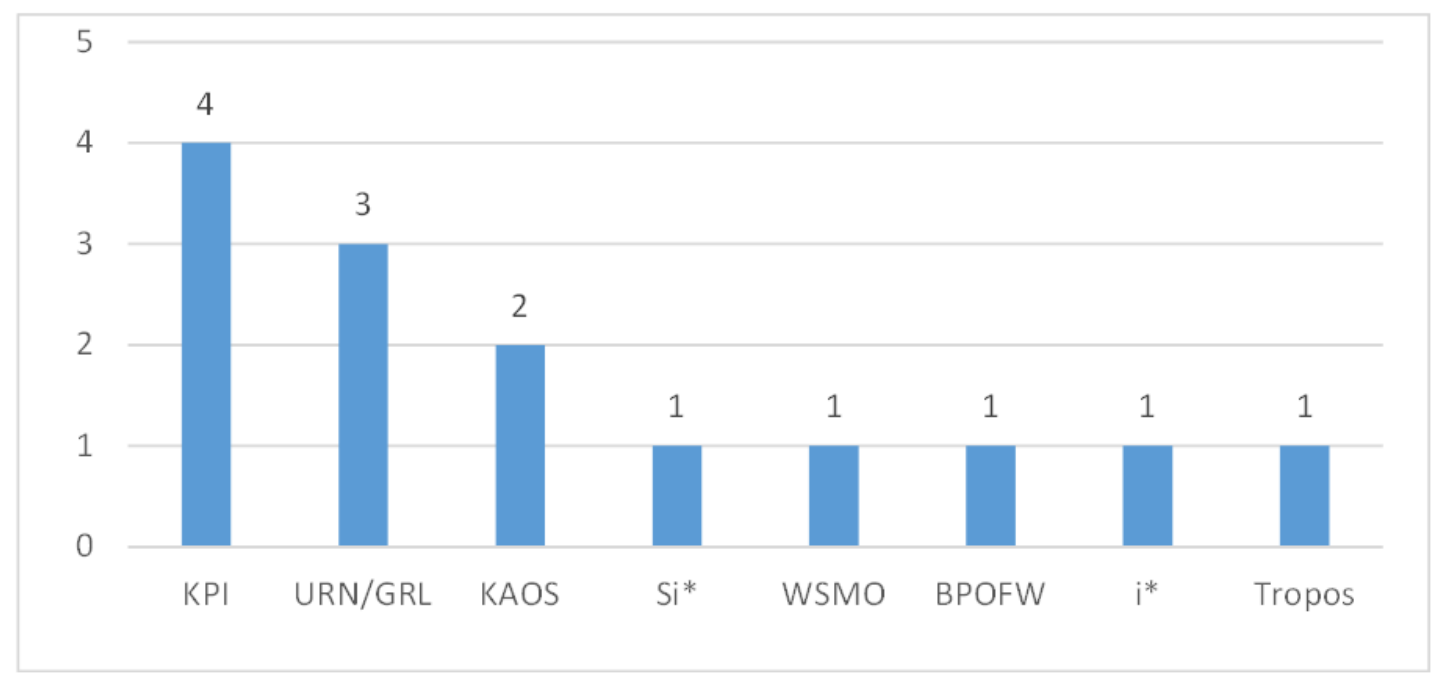

Fonte: Adson Rocha do Carmo, 2016

números de estudos primários identificados em que cada técnica usada são apresentados na Figura 19.

A abordagem URN se destaca entre as demais por englobar duas técnicas - GRL e UCM, a primeira aplicada na modelagem de metas estratégicas organizacionais e a segunda na modelagem de processos de negócio.

Figura 19 - Técnicas de modelagem de processos de negócio identificadas nos estudos primários

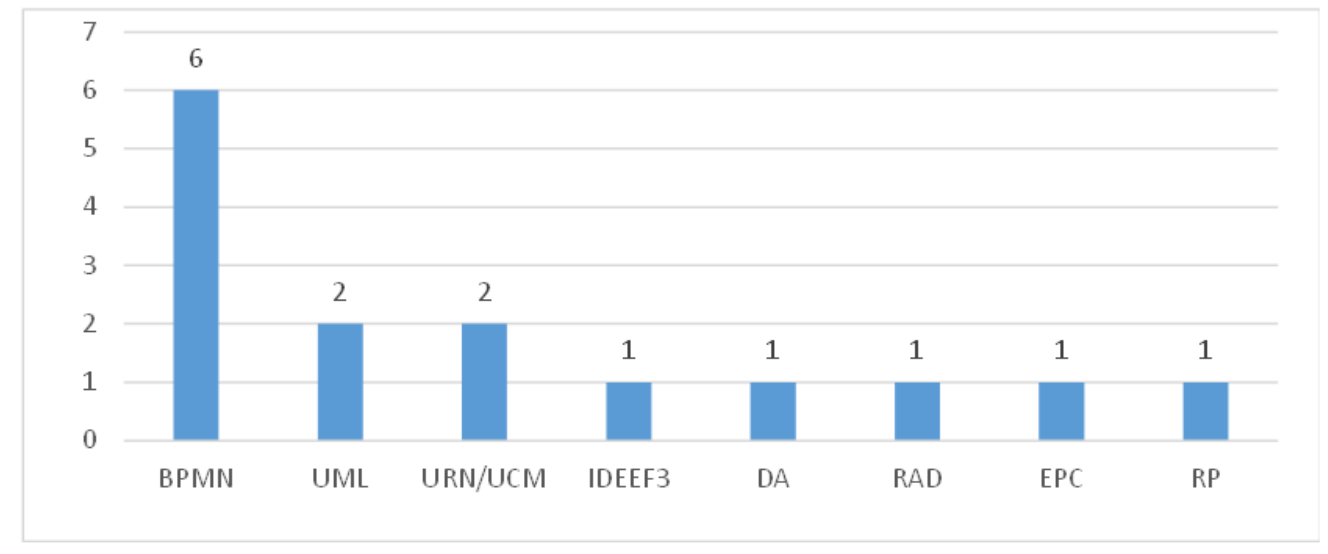

Fonte: Adson Rocha do Carmo, 2016

Sete abordagens apresentam algum grau de automação, como destacado na Figura 20. De acordo com a Figura 21, as ferramentas identificadas que tem sido usadas para automação são os seguintes plug-ins para o Eclipse - MediniQVT (BIOLCHINI et al., 2005), jUCMNav (BEHNAM; AMYOT; MUSSBACHER, 2010; POURSHAHID et al., 2012), Eclipse Modeling Framework (EMF) (ABETI; CIANCARINI; MORETTI, 2009; RUOKONEN; 
PAJUNEN; SYSTÄ, 2009) e Tool for Agent Oriented visual Modeling for the Eclipse plataform (TAOM4E) (ABETI; CIANCARINI; MORETTI, 2009) - e a ferramenta Maestro da SAP Research (MARKOVIC; KARRENBROCK, 2007).

Figura 20 - Número de estudos primários que apresentam abordagens automatizadas e não automatizadas

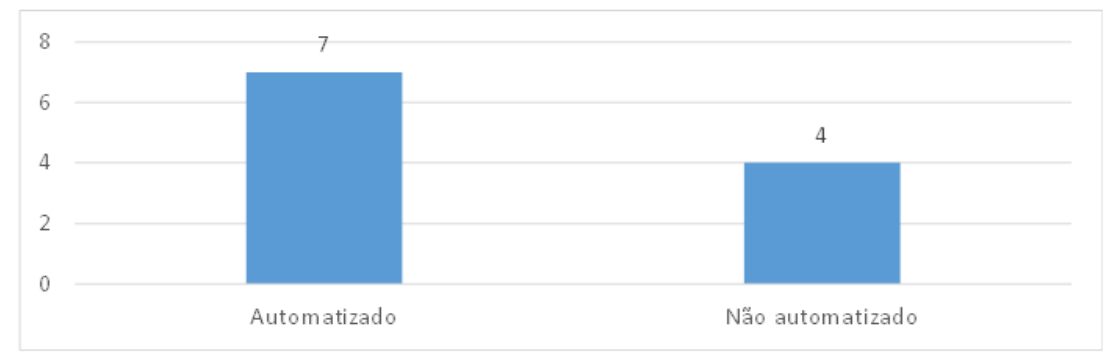

Fonte: Adson Rocha do Carmo, 2016

Figura 21 - Ferramentas usadas na automação das técnicas identificadas nos estudos primários

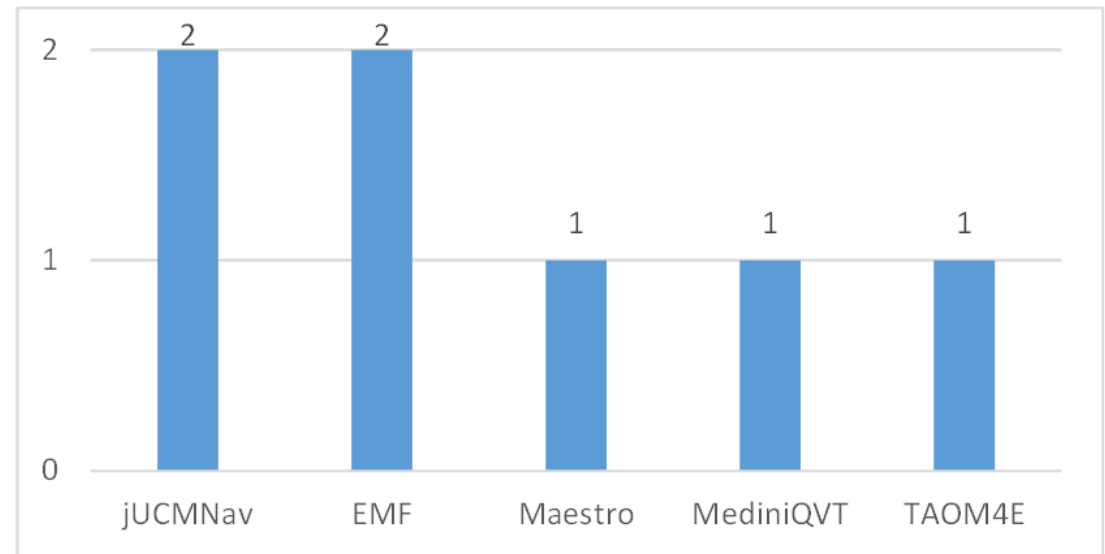

Fonte: Adson Rocha do Carmo, 2016 


\section{Proposta de extensão para a abordagem StrAli-BPM}

O KPI2BLA busca semiautomatizar a extração de informações relevantes das metas estratégicas organizacionais para a definição dos requisitos não funcionais dos processos de negócio na forma de BLA. Assim, este trabalho visa estender o framework StrAli-BPM para tratar tal limitação.

\subsection{Visão geral da extensão proposta}

A Figura 22 apresenta uma visão geral do framework StrAli-BPM original incluindo a abordagem KPI2BLA que é o cerne deste trabalho. Os novos elementos propostos são apresentados na cor cinza e estão associados a abordagem KPI2BLA, pois na abordagem KPI2BLA as relações entre o KPI e o BLA são estabelecidas. Do ponto de vista de requisitos não funcionais do processo de negócio, BLAs fazem a ligação entre o nível mais alto (estratégico e tático) da organização e a área de TI no nível mais baixo (operacional). BLAs também são responsáveis por auxiliar o alinhamento estratégico não só entre TI e áreas de negócio no nível operacional, mas entre o nível operacional e os níveis estratégicos e táticos da organização. Neste cenário, as metas organizacionais definidas em nível estratégico (e possivelmente refinadas pelo nível tático) são usadas como fonte de informações relevantes para a composição de BLAs. Embora as metas possam ser úteis também para o levantamento dos requisitos funcionais do processo de negócio, isso não é tratado no escopo deste trabalho.

As metas estratégicas organizacionais podem ser representadas no formato de KPI. Para a elaboração de tais KPIs relacionados as metas estratégicas organizacionais, um template apropriado é proposto, baseado em um metamodelo que representa os atributos de KPI. A definição desse metamodelo e template associado são necessários uma vez que não existem, na literatura, estruturas padronizadas para isso. A partir da estrutura proposta desse template, o conteúdo de metas estratégicas organizacionais é analisado para que informações relevantes à criação de BLAs sejam mapeadas para as áreas de negócio responsáveis pela modelagem do processo. A versão atual da estrutura do template é apresentada na tabela 9. Essa versão do template busca contemplar os principais atributos de KPI. 
Figura 22 - Framework StrAli-BPM estendido com o uso de metas estratégicas organizacionais via KPI

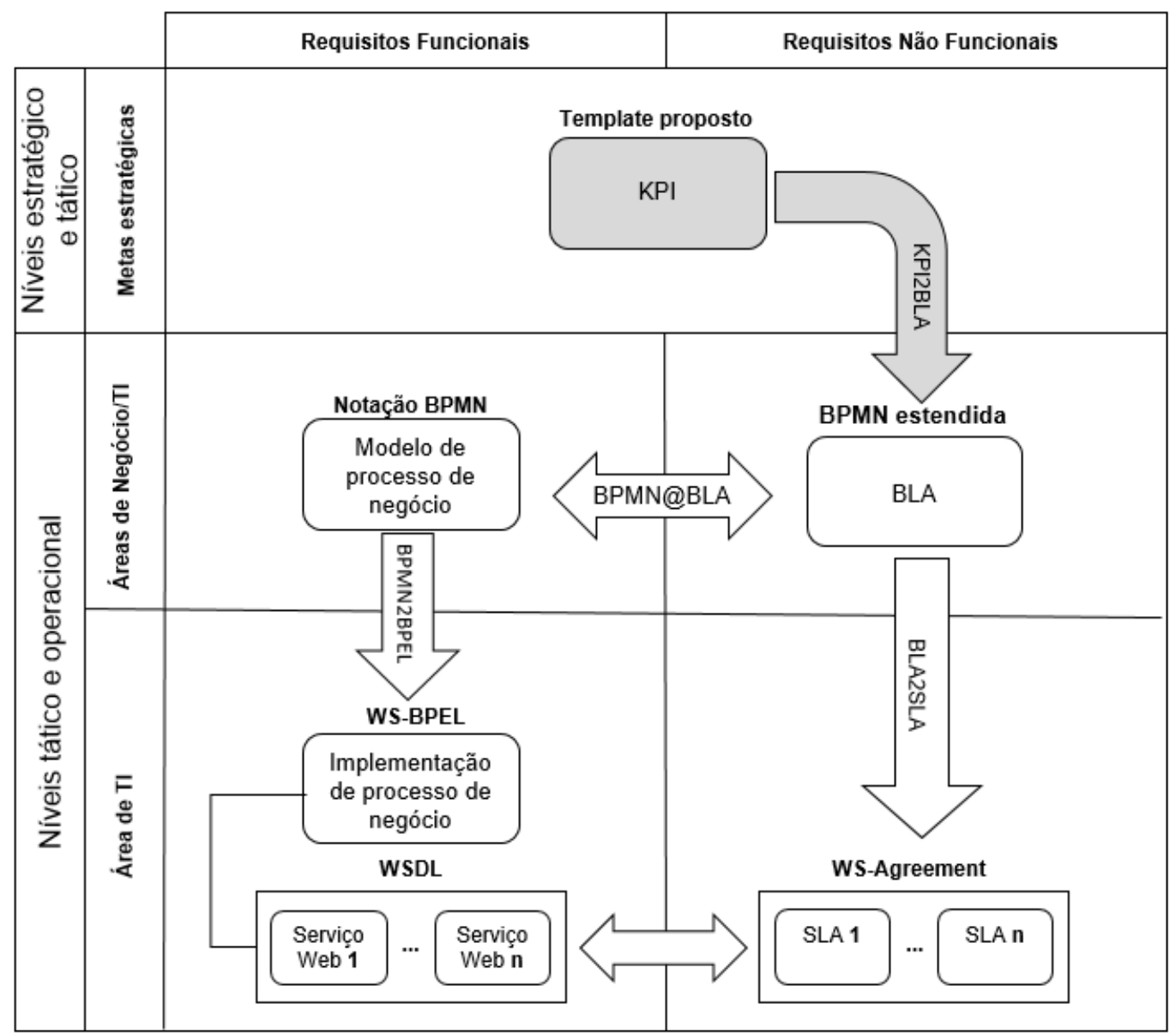

Fonte: Adson Rocha do Carmo, 2016

A modelagem do KPI relacionado ás metas estratégicas organizacionais podem ocorrer de duas formas: (i) o nível estratégico deve modelar o KPI usando a abordagem KPI2BLA; ou (ii) assumindo que os KPIs são criados usando outra estrutura, é necessário que essa estrutura apresente as características necessárias para interagir corretamente com a abordagem KPI2BLA.

Para apoiar a abordagem que está sendo proposta, foi desenvolvido um protótipo de ferramenta que apoia - de forma semiautomatizada - tanto a definição dos KPIs relacionados às metas estratégicas organizacionais na abordagem KPI2BLA (ou o mapeamento dos KPIs das metas estratégicas organizacionais definidas em outra estrutura para a estrutura proposta) quanto a extração de informações relevantes do KPI e seu mapeamento para os BLAs que devem ser criados. Para isso, o apoio semiautomatizado deve ser dividido em etapas. 
Caso os KPIs relacionados as metas estratégicas organizacionais não tenham sido definidos na estrutura da abordagem KPI2BLA, primeiramente, é necessário identificar as métricas usadas para apresentar os valores via KPI. A partir da identificação dessas métricas, é necessário que os "atributos" que compõem tais métricas sejam relacionados a estrutura proposta. Essa etapa deve ser realizada com o apoio de um especialista, que deve usar o apoio computacional para fazer a ligação entre dois esquemas diferentes de dados (por exemplo, por meio do relacionamento entre atributos de ambos os esquemas), mas que devem possuir conteúdo equivalente. É considerado sempre que a organização optou por usar a estrutura aqui proposta.

KPIs relacionados às metas estratégicas organizacionais criados em outra estrutura não deverão ser considerados por esta abordagem proposta, pelo fato de extrapolar o escopo deste trabalho de mestrado.

\subsection{Modelo para elaboração de KPIs relacionados às metas es- tratégicas organizacionais}

Na seção 2.1.1, é ilustrado o metamodelo de KPI, porém esses metamodelos isoladamente não contemplam os detalhes necessários para suprir as necessidades deste trabalho de mestrado. Por isso, um novo metamodelo foi criado reunindo os elementos e relacionamentos que podem vir a agregar a este estudo.

Com intuito de auxiliar na obtenção das informações dos KPIs relacionados ás metas estratégicas organizacionais expressadas em indicadores do tipo KPI sejam extraídas, vai usar um metamodelo normalizado ilustrado na figura 23. Este metamodelo exibe as entidades e os relacionamentos entre eles. E, como resultado do relacionamento entre as entidades, gerar um template contendo informações necessárias para ajudar na criação de BLA. As principais entidades ilustrados no metamodelo são: "goal", "metric", "restriction" e "KPI".

A entidade intitulada de KPI é a mais importante deste metamodelo pois contém atributos que satisfazem a criação de um indicador para controlar e acompanhar a busca das metas estratégicas organizacionais. A partir da associação da entidade KPI as outras entidades contidas neste metamodelo deve ser possível criar um BLA. A entidade KPI pode ter apenas uma instância de "Goal", por outro lado, o "Goal" pode vir a ter uma ou muitas instâncias do elemento KPI. O KPI tem relacionamento com a entidade Period - que 
Figura 23 - Metamodelo proposto de indicadores chave de desempenho

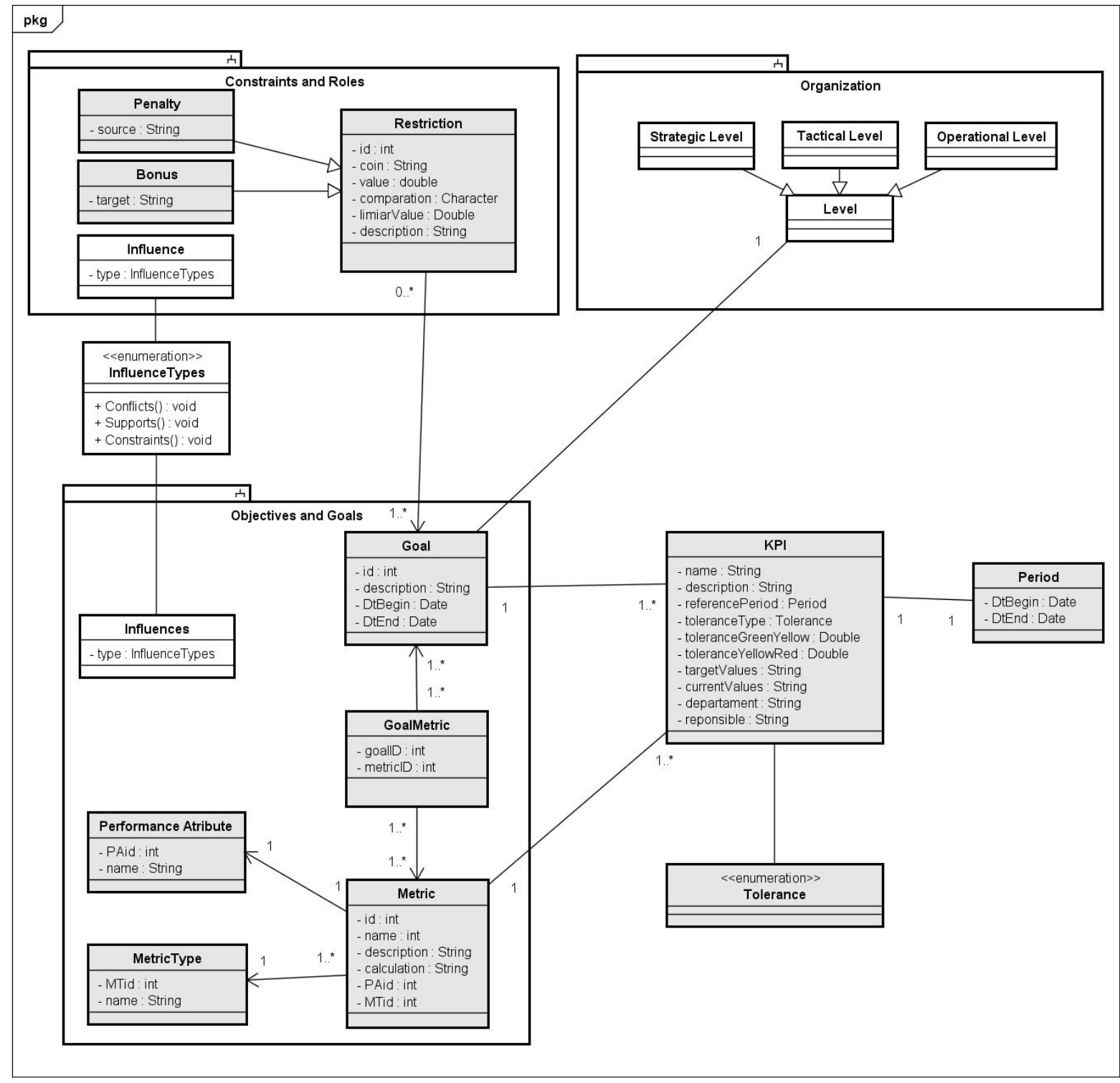

powered by Astah

Fonte: Adson Rocha do Carmo, 2016

representa início e fim da vigência do KPI, e a entidade "Tolerance" que são representados, por exemplo, por valores como: dia, mês, anos, percentual e hora.

No subconjunto "Objectives and Goals", as entidades "Goal" e "Metric" são ligados por uma entidade intermediária chamada "GoalMetric", que proporciona a seguinte relação: um "Goal" deve ter pelo menos uma instância e esta instância pode ter uma ou muitas instâncias da entidade "Metric".

Ainda no subconjunto "Objectives and Goals", é ilustrado a entidade "Metric Type" que representa o tipo da métrica que pode ser associada ao indicador. O "Metric 
Type" é representado pelas expressões $U p$, Equal e Down, que siginificam o simbolo >, = e < respectivamente. Um exemplo do uso de "Metric Type" é a necessidade de representar uma métrica que busca controlar o número de vendas maior que $60 \%$, então o "Metric Type" é o up.

Outra entidade é o "Performance Atribuite", que, da mesma forma como o "Metric Type", está associado ao "Metric" o "Perfformance Atribuite" também está associado ao "Metric". Esta entidade contém itens como availability, integrity, usability e efficiency, que visam definir qual o tipo de desempenho da métrica,

No subconjunto chamado "Constraints and Roles" são ilustrados os elementos "Restriction", "Role", "Constranct" e "Influence". As entidades "Restriction", "Role", "Constranct" expressam as regras e restrições que podem ser usados em um indicador de desempenho do tipo KPI. Essas regras e restrições geralmente representam o negócio da organização ou questões como política relacionada à organização ou regras governamentais. A entidade "Influence" está associada a uma área do tipo "enumeration", que representa as variáveis ("conflicts", "supports" e "constrainsts") que podem estar contidas no indicador, mas não é explorado por este trabalho, pois foge do escopo da proposta.

É importante frisar o subconjunto chamado "Organization" na figura 23, porque nele está contido os três níveis em que o "Goal" pode estar inserido - "Strategic", "Tactical" e "Operational". Apenas os elementos "Strategic" e "Tactical" são abordados neste trabalho de mestrado .

O metamodelo aqui proposto além de ter o objetivo de auxiliar na obtenção de informações de um KPI, ele também visa servir como base para criação de um template contendo as informações necessárias para criação de BLA.

\subsection{Mapeamento entre o metamodela abordagem KPI2BLA e o metamodelo BLA@BPMN}

Com o proposito de tornar claro a relação entre as entidades contempladas no metamodelo proposto neste trabalho de mestrado e o metamodelo de BLA proposto por Salles (2014), fez-se necessário ilustrar a relação entre eles. A figura 14 ilustra o metamodelo proposto por Salles (2014) que exibe as entidades que oferecem apoio à criação de BLA e seus atributos. Por outro lado, a figura 23 ilustra o metamodelo que busca representar as 
informações relevantes das metas estratégicas organizacionais e também devem permitir apoio a criação de BLAs em passos seguintes.

O metamodelo de KPI2BLA busca representar as informações relevantes dos KPIs das metas estratégicas organizacionais, que, por sua vez, deve servir para oferecer apoio na criação de BLAs no nível operacional (vide figura 22). Nesta seção, as entidades ilustradas nas figuras pela cor cinza são as propostas na abordagem KPI2BLA e as entidades na cor branca são as entidades propostas no metamodelo BLA@BPMN de (SALLES, 2014).

A entidade "Goal" do metamodelo BLA@BPMN pode ser relacionada com atributos de algumas das entidades do metamodelo da abordagem KPI2BLA, por exemplo, o atributo "Nome" do "KPI" está ligado diretamente ao atributo KPI do elemento "Goal" do metamodelo BLA@BPMN.

O atributo "Comparasion_operator" pode ser representado no metamodelo de KPI2BLA pelo atributo "Calculation" da entidade "Metric" (uma seta pontilhada é usada para identificar quando a relação não ocorre de forma direta mas sim por tratamento no atributo em questão para que ocorra a relação - "Calculation"), a depender do conteúdo do atributo "Calculation", que pode conter apenas sinais do tipo operador como $\leq, \geq$ ou $>$, ou conter uma fórmula contendo mais um operador e expressões (por exemplo: $\mathrm{x} \leq \mathrm{y}$ and y $>$ n). Caso o conteúdo do atributo "Calculation" seja uma fórmula que contenha mais de um sinal, será necessário gerar outras instâncias da entidade "Metric" do metamodelo BLA@BPMN para possibilitar a representação entre o metamodelo de KPI2BLA. Para exemplificar o caso de uma formula com mais de um operador, um indicador fictício que expressa os interesses da seguinte meta estratégica: melhorar a satisfação do cliente por meio de um atendimento mais rápido e com qualidade. Neste exemplo, temos a rapidez no atendimento e qualidade como itens para controlar via indicador, e o indicador usa a seguinte fórmula: Tempo Atendimento (TA) maior e igual a 15 minutos e Resposta na Avaliação de Satisfação do Cliente (RASC) menor e igual a 2, sendo a opção 1 a mais negativa e a 5 mais positiva (versão simplificada da formula: TA $\geq 15$ and $\mathrm{RASC} \leq 2$ ). Para resolver este caso, deve ser necessário gerar duas instâncias de BLA, uma para cada expressão da fórmula.

O atributo "Target_value" corresponde com o atributo "TargetValues" do metamodela abordagem KPI2BLA. O atributo "Unit" tem correspondência com o "ToleranceType". O último atributo "check_on_BLA_due_date" não apresenta uma correspondência no metamodelo da abordagem KPI2BLA. Os relacionamentos descritos neste parágrafo estão 
ilustrados na figura 24. Os atributos "id" contidos no metamodelo das entidades da abordagem KPI2BLA não fazem relação com os atributos do metamodelo BLA@BPMN, pois são de controle interno a este trabalho de mestrado.

Figura 24 - Relação entre as entidades da abordagem KPI2BLA e a entidade "Goal" do metamodelo BPMN

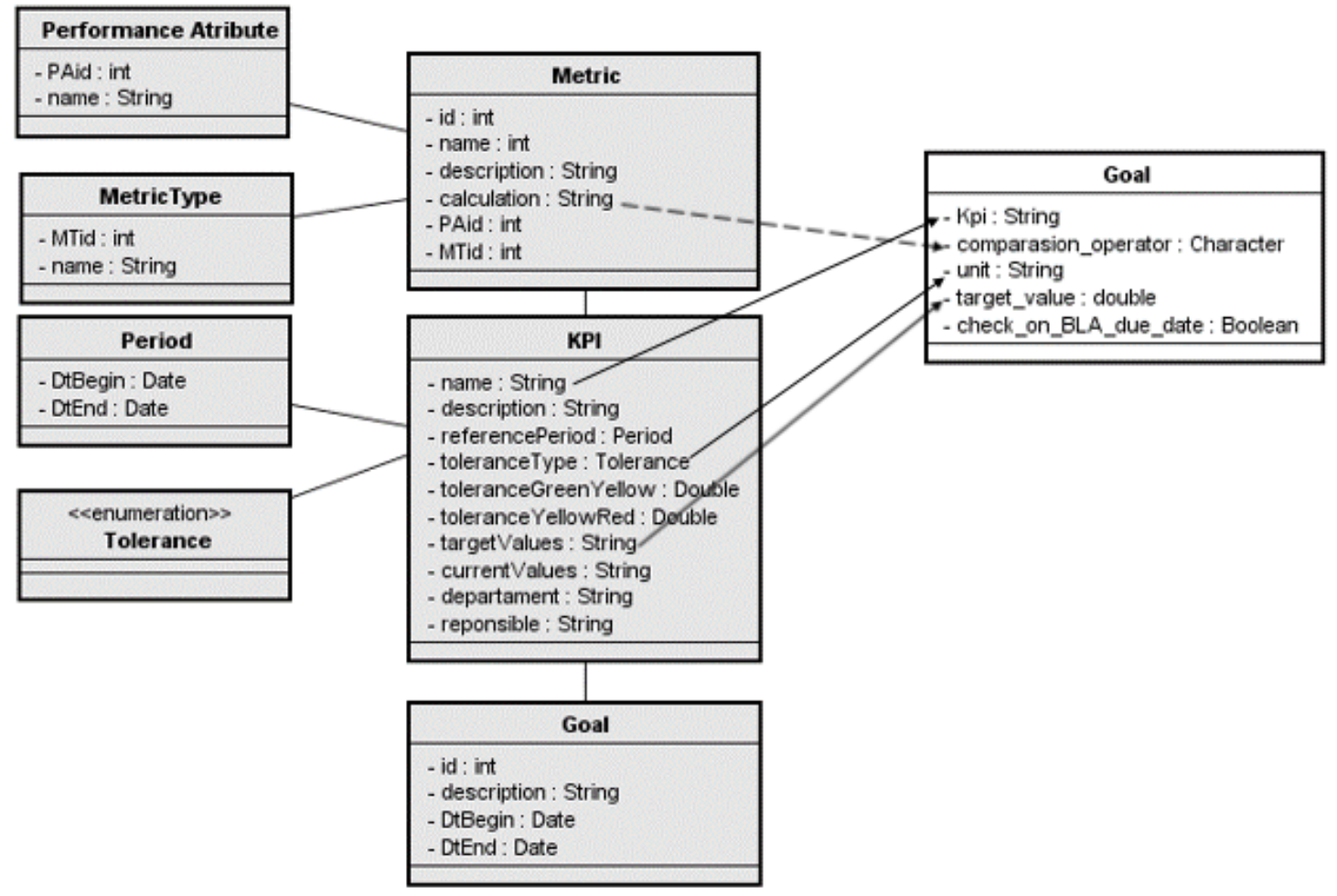

Fonte: Adson Rocha do Carmo, 2016

A respeito da entidade "Penalty" do metamodelo BLA@BPMN, a relação com o metamodela abordagem KPI2BLA é com a entidade "Penalty". A entidade "Reward" do metamodelo BLA@BPMN faz relação com a entidade "Bonus". Um detalhe destas entidades é o relacionamento de herança: as entidades "Penalty" e "Reward" herdam os atributos da entidade "Compensation"; as entidades "Penalty" e "Bonus" herdam os atributos da entidade "Restriction". Essas entidades citadas e suas relações entre os metamodelos são ilustradas na figura 25.

E por fim, a relação entre as entidades centrais dos dois metamodelos é visto na figura 26, que contém a entidade "BLA" do metamodelo BLA@BPMN e a entidade "KPI" do metamodelo de KPI2BLA. O atributo "name" do "BLA" tem o mesmo objetivo que o atributo "nome" do "KPI". Os atributos "star_date" e "due_date" são representados na entidade "KPI" pelo atributo "ReferencePeriod" e a seta usada para ligar as entidades é pontilhada pois significa que é necessário um tratamento para que ocorra a relação entre eles. 
Figura 25 - Relação entre as entidades do componente KPI2BLA e a entidade "Penalty", "Reward" e "Compensation" do metamodelo BLA@BPMN

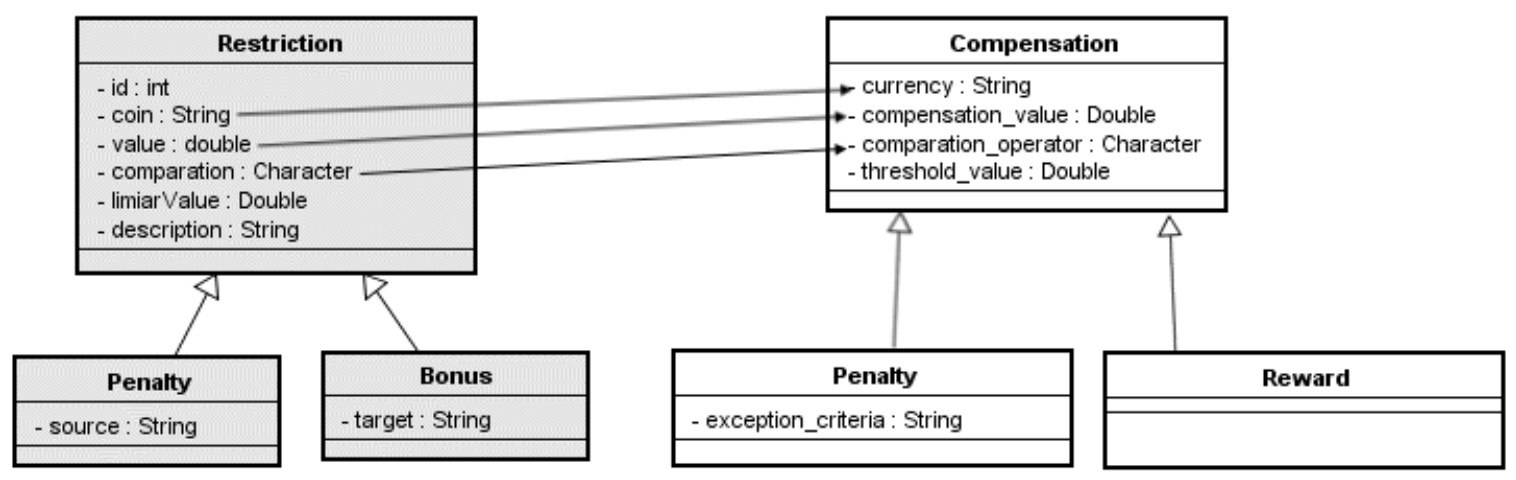

Fonte: Adson Rocha do Carmo, 2016

O atributo "corporative_context" tem sua relação com o atributo "Description" da entidade "KPI". O atributo "Customer_department" faz relação com o atributo "departament" da entidade "KPI". Os atributos "toleranceGreenYellow", "toleranceYellowRed" não têm relação com nenhum atributo ou entidade do metamodelo BLA@BPMN. Esses atributos mencionados têm o objetivo de exibir cores para determinado grupo de valores previamente definidos.

Figura 26 - Relação entre a entidade "BLA" e "KPI" do metamodelo BLA@BPMN com as entidades da abordagem KPI2BLA

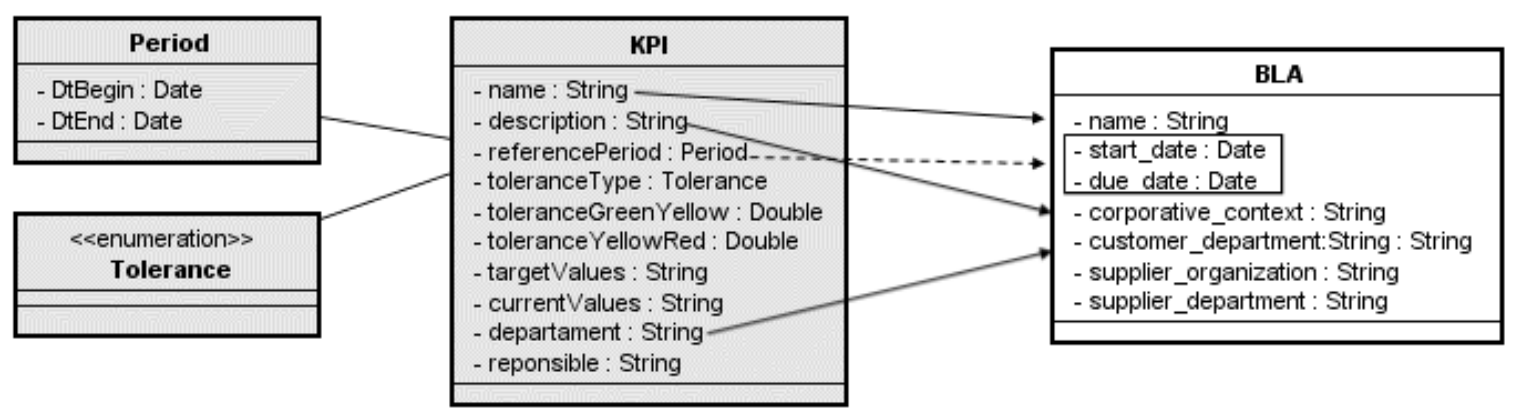

Fonte: Adson Rocha do Carmo, 2016

Em alguns casos, um KPI pode gerar mais de um BLA. Por outro lado, existem casos que um KPI gera apenas um BLA. Os motivos pelos quais um KPI pode gerar mais de um BLA são os seguintes: (i) pode haver casos em que existam mais de um atributo sendo tratado na métrica do KPI e, por consequência, faz-se necessário gerar mais de um BLA para representar os atributos do KPI; (ii) quando um dos atributos do KPI, por conta da sua característica, para ser representado em um BLA, é necessária mais de um BLA, de modo que, apenas um BLA não satisfaria o KPI devido a este atributo. Como exemplo ao primeiro caso citado, os atributos "ToleranceGreenYellow" e "ToleranceYellowRed" devem 
originar mais de um BLA, por apresentarem características (três variáveis - green, yellow e red) que não são comportadas em um único BLA; No que diz respeito ao segundo caso, um exemplo seria pelo atributo "Calculation" que, ao conter mais de um operador na expressão, provavelmente deve ser representado por mais de um BLA.

\subsection{Template derivado do componente KPI2BLA}

A criação do template, ilustrado na tabela 9, é o resultado do relacionamento entre as entidades que estão ilustradas no metamodelo da figura 23, do componente KPI2BLA do framework StrAli-BPM, e que contemplam a estrutura necessária para representação dos requisitos não funcionais extraído do KPI.

No atributo "Nome" deve ser informado o nome do indicador. No atributo "Descrição" deve conter o que motivou a criação do indicador. Os atributos "Data de início" e "Data de término" determinam o tempo de vigência do indicador. O atributo "Unidade de medida" deve conter a descrição da unidade usada no indicador.

"Tipo de tolerância" deve conter a informação para determinar a interpretação dos valores do KPI e também os valores exibidos nos atributos de "Tolerância", por exemplo: definir se os valores são do tipo dia, mês, ano, minuto, hora ou percentual. "Tolerância do verde para amarelo" e "Tolerância do amarelo para vermelho" são atributos responsáveis por expressar uma determinada faixa de valores que devem estar associadas às respectivas cores. "Valor desejado" é o atributo que contém o valor esperado pela organização como o ideal. Por outro lado, o "Valor atual" é o atributo que contém o valor atualmente obtido pela organização.

O atributo "Responsável" é para conter o nome da pessoa que analisa e se responsabiliza pelo indicador. "Departamento" é o atributo que contém o nome do departamento que solicitou o indicador. No atributo "Descrição da perspectiva" tem a finalidade de receber os motivos que levaram a criação do indicador. Sobre o atributo "Meta estratégica", ele é de multiplicidade de 1 para n, ou seja, podem ser expressadas várias metas, sendo que cada meta tem um "Nome", "Descrição", "Calculo", "Nome atributo de desempenho" e o "Tipo da métrica".

O indicador de desempenho também pode conter multas ou bonificações (como ilustrado pelos elementos "Penalty" e "Bonus" no metamodelo proposto na figura 23), por isso, o template contém atributos como: "Origem" ou "Algo" (depende da entidade), 
Tabela 9 - Template proposto para definição de KPI

\begin{tabular}{|c|c|c|}
\hline Atributo & Descrição & Qtde. \\
\hline Nome & Nome definido para o artefato & 1 \\
\hline Descrição & $\begin{array}{l}\text { O cenário que levou a exploração da necessidade } \\
\text { em questão }\end{array}$ & 1 \\
\hline Data de inicio & Data de início da verificação do indicador & 1 \\
\hline Data de termino & Data de termino da verificação do indicador & 1 \\
\hline Tipo de tolerância & $\begin{array}{l}\text { O tipo de tolerância indica como interpretar } \\
\text { o valor do KPI e de tolerância - Absoluto ou } \\
\text { Percentual, por exemplo }\end{array}$ & 1 \\
\hline $\begin{array}{l}\text { Tolerância do verde para } \\
\text { amarelo }\end{array}$ & $\begin{array}{l}\text { Faixa de valores que estão compreendidos entre } \\
\text { essas cores sinalizadas }\end{array}$ & $0 . .1$ \\
\hline $\begin{array}{l}\text { Tolerância do amarelo } \\
\text { para vermelho }\end{array}$ & $\begin{array}{l}\text { Faixa de valores que estão compreendidos entre } \\
\text { essas cores sinalizadas }\end{array}$ & $0 . .1$ \\
\hline Valor desejado & Valor estipulado à ser alcançado & 1 \\
\hline Valor atual & Valor obtido atualmente & 1 \\
\hline Responsável & $\begin{array}{l}\text { Nome do solicitante ou do responsável do indi- } \\
\text { cador }\end{array}$ & 1 \\
\hline Departamento & $\begin{array}{l}\text { Nome do departamento solicitante ou res- } \\
\text { ponsável }\end{array}$ & 1 \\
\hline Meta estratégica & $\begin{array}{l}\text { Detalhamento da meta (considerando o aspecto } \\
\text { a ser medido e monitorado) }\end{array}$ & 1 \\
\hline - Nome da métrica & Nome dado a métrica & 1 \\
\hline - Descrição da métrica & $\begin{array}{l}\text { Valor ou percentual que deve ser cumprido para } \\
\text { a meta estratégica em questão }\end{array}$ & 1 \\
\hline - Calculo da métrica & Formula ou calculo usado para obter a métrica & 1 \\
\hline $\begin{array}{l}\text { - Nome atributo de de- } \\
\text { sempenho }\end{array}$ & Nome dado ao atributo de desempenho adotado & 1 \\
\hline - Tipo da métrica & $\begin{array}{l}\text { Escolher se acima do destino é favorável, na } \\
\text { meta é favorável, abaixo da meta é favorável }\end{array}$ & 1 \\
\hline Penalidade & $\begin{array}{l}\text { Detalhamento do que se configura como Penali- } \\
\text { dade }\end{array}$ & $0 \ldots n$ \\
\hline - Origem & Fonte pagadora & 1 \\
\hline - Moeda & Qual a moeda praticada & 1 \\
\hline - Valor & Preço da "Penalidade" & 1 \\
\hline - Comparação & $\begin{array}{l}\text { Forma de verificação da aplicação da "Penali- } \\
\text { dade" }\end{array}$ & 1 \\
\hline - Valor limiar & Limite a ser considerado & 1 \\
\hline Bonificação & Detalhamento da forma de bonificação & $0 \ldots n$ \\
\hline - Alvo & Fonte pagadora & 1 \\
\hline - Moeda & Qual a moeda praticada & 1 \\
\hline - Valor & Preço da bônus & 1 \\
\hline - Comparação & $\begin{array}{l}\text { Forma de verificação da aplicação da "Boni- } \\
\text { ficação" }\end{array}$ & 1 \\
\hline - Valor limiar & Limite a ser considerado & 1 \\
\hline
\end{tabular}


"Moeda, Valor", "Comparação" e "Valor limiar", que servem para expressar tanto as regras de multa quanto de bonificação.

\subsection{Associação entre KPI e o BLA}

Nesta seção é apresentado o procedimento de extração das informações relevantes dos KPIs relacionados às metas estratégicas organizacionais para oferecer apoio à criação de BLAs. Para auxiliar este procedimento de associação, será usado o templete proposto.

O processo de associação entre KPI e o BLA envolve quatro perfis e tarefas associadas a cada perfil. Os perfis são os seguintes: analista estratégico, analista de negócio, analista de processos e implementador de processos.

A associação é feita seguindo os passos listados abaixo e ilustrados na figura 27:

1. o analista estratégico deve identificar de forma descritiva a meta estratégica para extrair as informações apontadas por este trabalho como um possível padrão de meta;

2. deve identificar as métricas da meta estratégica. Cada métrica deverá gerar um KPI, com intuito de preencher o template com essas informações;

3. caso a organização não use KPI, o analista de negócio deve modelar o KPI relacionado a métrica, que, por sua vez, deve estar relacionadas à meta estratégica organizacional usando o formato proposto; ou

4. caso o KPI já exista em outro formato, o analista de negócio deve remodelar o KPI existente para o formato proposto;

5. o analista de processos deve extrair as informações úteis do KPI; além disso ele também deve,

6. modelar BLA baseado em KPI para isso ele deve usar os atributos definidos no template, ilustrado na tabela 9 ;

7. o analista de negócio deve inserir informações extras caso seja necessário;

8. o analista de negócio deve validar o(s) BLA(s) criado(s) no modelo de processo de negócio;

9. caso seja necessário o analista de negócio pode inserir informações extra ao KPI;

10. por fim, o implementador de processos deve poder definir SLA com base em BLA. 
Mesmo com o tamplete criado para auxiliar na captura das informações, alguns dos seus campos não são obrigatórios. Nesse caso, fica a disponibilidade para o analista de negócio preencher essas informações apenas com o entendimento do negócio. Por exemplo: os atributos "Tolerância do verde para o amarelo" ou "Tolerância do amarelo para o vermelho" do template proposto podem ser preenchidos para aumentar o número de informações para auxílio na tomada de decisões.

Por outro lado, existem campos que são obrigatórios e podem não ser mapeados, sendo assim, é necessário a intervenção do analista de negócio. Por exemplo: o atributo "Tipo de métrica", do template proposto, caso não tenha a informação extraída da fonte de dados, neste caso, deverá ser feito a inclusão manual no campo "Tipo de métrica" pelo analista de negócio.

\subsection{Exemplo ilustrativo de uso da extensão proposta}

Nesta subseção está descrito um cenário real do mundo corporativo de uma empresa da área de saúde. Inicialmente, é detalhado o problema enfrentado pelas empresas de saúde pública e privada. Em seguida, a solução encontrada pelas mesmas e as ferramentas de apoio à solução. Ao final, é feito uma contextualização com o tema proposto neste trabalho e uma simulação usando a implementação do mesmo.

\subsubsection{Descrição do cenário usado no exemplo}

De acordo com Sérgio, o problema encontrado foi a elevação do custo devido o aumento na contratação de médicos. E a solução encontrada foi a criação de um programa de saúde interno para minimizar esse aumento na contratação de novos profissionais. $\mathrm{O}$ programa apresenta uma característica multiprofissional, só que, neste caso, quase todos os programas não tem a presença do médico. Este programa visa disponibilizar atendimentos de profissionais que não sejam da medicina em reuniões individuais ou em grupo. É um modelo intitulado de gestão de doenças, com foco nos problemas crônicos. A principal estratégia é oferecer ao paciente a noção de responsabilidade para que ele conscientize-se e saiba lidar com sua doença, e, como consequência, evitar uma internação. 


\subsubsection{Contextualização do problema}

Ne seção anterior, é exposto um dos problemas do sistema de saúde que foi discutido no debata da Faculdade Getúlio Vargas de Saúde (FGSaude) - o gasto com contratação excessiva de médicos para suprir uma grande demanda de pacientes com doenças crônicas não contagiosas.

Segundo Sérgio o objetivo estratégico da empresa, neste contexto, foi a melhoria da qualidade do atendimento dos pacientes com doenças crônicas não contagiosas, sendo a meta estratégica "a melhoria da qualidade do atendimento dos pacientes com doenças crônicas não transmissíveis em $40 \%$ no período de três anos". Então, a partir dessa meta, é possível extrair informações de nível estratégico organizacional para criação de um indicador com objetivo de controlar a meta estratégica referida.

Uma das formas de simular o controle da meta é por meio da criação do KPI "Atendimentos realizados por status" (os status podem ser: status (Participating, Engaged, Concluded)), seguindo a abordagem proposta, que tem o objetivo de controlar os atendimento dos pacientes por status, principalmente os pacientes com status parcipating, pois iniciaram o acompanhamento recentemente. Via o status é possível compreender a aderência dos pacientes ao programa, ilustrado na figura 3. Com o propósito de simular um KPI de acordo com a abordagem proposta, este KPI foi ajustado para que se adequasse à estrutura destinada a este trabalho.

\subsubsection{Exemplos dos artefatos elaborados seguindo a extensão pro- posta}

Em continuidade com o exemplo prático esta seção simula a aplicação da abordagem KPI2BLA, neste trabalho de mestrado, sobre o exemplo descrito na seção 5.5.

A aplicação da abordagem KPI2BLA é dividida como definido na seção 5.5: (i) o nível estratégico já modela o(s) KPI(s) das metas estratégicas organizacionais usando a estrutura proposta. (ii) após a modelagem do KPI das metas estratégicas organizacionais, via protótipo de ferramenta tecnológica, deve ser possível relacionar os atributos das métricas do KPI com os atributos definidos no template, ilustrado na tabela 9; (iii) validação das informações gerada pelo protótipo de ferramenta via criação de BLAs; 
Na sub seção 2.5 (StrAli-BPM), é exibido a figura 15 que ilustra a aplicação do artefato BLA à um processo BPMN. Este exemplo está relacionado com o KPI "Atendimentos realizados por status". Este KPI é usado para controlar a busca à meta estratégica organizacional que é "Melhorar em $40 \%$ a qualidade do atendimento dos pacientes com doenças crônicas não transmissíveis nos próximos três anos". E nesta seção, é por meio deste exemplo que é ilustrado a aplicação da abordagem proposta neste trabalho.

De antimão, é fundamental compreender a meta estratégica "Melhorar em $40 \%$ a qualidade do atendimento dos pacientes com doenças crônicas não transmissíveis nos próximos três anos" e os padrões encontrados nela, de acordo com a hipótese definida na seção 2.4. O primeiro padrão é o verbo "Melhorar" que representa um estado ao qual a organização deseja alcançar. O segundo padrão é a definição de valor à ser melhorado, neste caso é um percentual de $\mathbf{4 0 \%}$, ou seja, melhorar em $40 \%$ o atendimento. O terceiro e último é o prazo de três anos definido como período para melhorar em $40 \%$ o atendimento.

Este exemplo é conduzido usando o KPI "Atendimentos realizados por status" da empresa privada, porém com valores fictícios para manter a política de privacidade.

1. O KPI foi criado seguindo o modelo proposto por esta abordagem.

2. "Melhorar em 40\% a qualidade do atendimento dos pacientes com doenças crônicas não transmissíveis nos próximos três anos.", sendo o requisito não funcional a "qualidade de atendimento".

3. Formalização do KPI em template, visto na tabela 10.

4. O analista insere informações extras ao indicador, por exemplo: valor limiar ou critérios de exceção

5. Tratamentos em campos que o relacionamento ocorre de forma indireta.

6. Validação das informações geradas pelo protótipo de ferramenta via criação de esboço de BLAs.

Após o preenchimento do template proposto com as informações extraídas do KPI da meta estratégica organizacional, com auxilio do protótipo computacional que foi desenvolvido para auxiliar na avaliação da abordagem KPI2BLA, os devidos tratamentos para relacionar as informações vindas do KPI da meta estratégica organizacional ao template proposto devem ser aplicadas. Também faz-se necessário esboçar a criação de BLAs para constatar se as informações vindas dos passos anteriores realmente oferecem apoio ao processo de criação de BLAs. 
Tabela 10 - Exemplo ilustrativo do template proposto para o KPI da meta estratégica organizacional

\begin{tabular}{|c|c|}
\hline Atributo & Descrição \\
\hline Nome & $\begin{array}{l}\text { Consultas realizadas aos pacientes com status } \\
\text { "participating" }\end{array}$ \\
\hline Descrição & $\begin{array}{l}\text { Aumentar o percentual de consulta dos paci- } \\
\text { entes com status "participating" }\end{array}$ \\
\hline Data de inicio & $28 / 09 / 16$ \\
\hline Data de termino & $28 / 10 / 16$ \\
\hline Tipo de tolerância & Percentual \\
\hline Tolerância do verde para amarelo & $65 \%$ pacientes com 'status "participating" \\
\hline Tolerância do amarelo para vermelho & $50 \%$ pacientes com 'status "participating" \\
\hline Valor desejado & $80 \%$ participating \\
\hline Valor atual & $60 \%$ participating \\
\hline Responsável & Jorge Matheus \\
\hline Departamento & Diretoria hospitalar \\
\hline \multicolumn{2}{|l|}{ Meta estratégica } \\
\hline - Descrição & $\begin{array}{l}\text { Aumentar as consultas dos pacientes com sta- } \\
\text { tus "participating" }\end{array}$ \\
\hline - Nome da métrica & status \\
\hline - Descrição da métrica & $\begin{array}{l}\text { Aumentar em } 20 \% \text { as consultas dos pacientes } \\
\text { com status participating }\end{array}$ \\
\hline - Calculo da métrica & $\begin{array}{l}\text { TotalConsultasPacientesCronicosParticipating } \\
\text { / TotalConsultasPacientesCronicos }\end{array}$ \\
\hline - Nome atributo de desempenho & Effectiveness \\
\hline - Tipo da métrica & Acima da meta é favorável $(U p)$ \\
\hline \multicolumn{2}{|l|}{ Penalidade } \\
\hline - Descrição & $\begin{array}{l}\text { Departamento hospitalar deve penalizado } \\
\text { caso o alvo não seja alcançado }\end{array}$ \\
\hline - Origem & Diretoria hospitalar \\
\hline - Moeda & Real \\
\hline - Valor & $4.000,00$ \\
\hline - Comparação & $<$ \\
\hline - Valor limiar & $65 \%$ \\
\hline \multicolumn{2}{|l|}{ Bonificação } \\
\hline - Descrição & $\begin{array}{l}\text { Equipe multidisciplinar recebe bonificação } \\
\text { caso o alvo seja alcançado }\end{array}$ \\
\hline - Origem & Departamento multidisciplinar \\
\hline - Moeda & Real \\
\hline - Valor & $3.500,00$ \\
\hline - Comparação & $>$ \\
\hline - Valor limiar & $75 \%$ \\
\hline
\end{tabular}


Tabela 11 - Validação das informações retiradas do KPI da meta estratégica organizacional via o preenchimento do template de BLA

\begin{tabular}{ll}
\hline Atributo & Descrição \\
\hline Identificador & Atendimentos realizados \\
Data de inicio & $28 / 09 / 16$ \\
Data de término & $28 / 10 / 16$ \\
Contexto corporativo & Aumentar o percentual de consulta dos pacientes com status \\
& "participating" \\
Organização proprietária & Organização privada \\
Departamento proprietário & Departamento hospitalar \\
Organização fornecedora & Organização privada \\
Departamento fornecedor & Departamento clínico \\
Meta & \\
- KPI & Consultas realizadas aos pacientes com status "participatin" \\
- Operador de comparação & $>$ \\
- Valor alvo & $80 \%$ \\
- Unidade & Percentual \\
- Verificação no término do & Sim \\
BLA & \\
Multa & \\
- Moeda & Real \\
- Valor de compensação & $4.000,00$ \\
- Operador de comparação & $<$ \\
- Valor limiar & $65 \%$ \\
Bonificação & \\
- Moeda & Real \\
- Valor de compensação & $3.500,00$ \\
- Operador de comparação & $<$ \\
- Valor limiar & $75 \%$ \\
\hline
\end{tabular}

Fonte: Adson Rocha do Carmo, 2016

O mesmo processo de preenchimento das informações da tabela 10 pode ser feito via protótipo de ferramenta desenvolvido para auxiliar na avaliação desta abordagem. Na figura 28, é ilustrado a tela de criação do KPI. O primeiro passo deve ser escolher a meta que motiva a criação do BLA. Ao escolher a meta a lista de métricas é filtrada para exibir somente as que são relacionadas a meta selecionada. Em seguida deve ser selecionada uma das métricas disponíveis. Ao selecionar a métrica, é exibida uma visualização resumida da métrica (chamada na ferramente de Metric detail), com proposito de ajudar o usuário com os detalhes da métrica. Os detalhes da métrica exibida ao ser selecionada, são dispostos de uma forma a ajudar na leitura da métrica.

Na figura 29, as informações do KPI relacionadas a tipo de tolerância, valor alvo, valor atual e departamento, por exemplo, são ilustradas. 
Outro passo em que o protótipo de ferramenta auxilia na criação do KPI com recursos computacionais é no preenchimento das informações de bonificação e penalidade. Na parte inferior da tela de criação do KPI, a ferramenta exibe um resumo das informações do KPI relacionadas a bonificação e a penalização de acordo com o preenchimento do formulário. Este resumo, além da bonificação e da penalização, usa informações da métrica, criando uma expressão que envolve lógica e as informações preenchidas pelo usuário. A expressão exibida como resumo pode ser vista na figura 30 e são intituladas de "Bonus details e Penality details".

O penúltimo passo após o KPI ter sido criado, via protótipo, é a conversão das informações do KPI para BLA. Quando um KPI é criado no protótipo ele fica armazenado e a qualquer momento o usuário pode gerar um BLA a partir do KPI, para isso, basta clicar no KPI criado e o protótipo exibe o BLA e suas informações em campos abertos para edição, como ilustrado na figura 31. Isto é possível porquê um dos intuitos da abordagem é permitir autonomia ao usuário no momento da criação do BLA.

O último passo é, via protótipo, ilustrado na figura 32, gerar um XML do BLA criado. Este XML deverá ser passado para o nível operacional que deve tratar o BLA para criar os serviços que devem ajudar no cumprimento do acordo.

\subsection{Prototipação}

O ambiente de desenvolvimento de software usado será o Visual Studio (2013) com uso do C\# e o Asp.net como linguagem de programação, ambos da plataforma .Net Microsoft. Além desse ambiente descrito, será usado também um protótipo de ferramenta para auxiliar no mapeamento das informações do KPI. 
Figura 27 - Fluxo de passos para a extração de informações relevantes do KPI para KPI2BLA

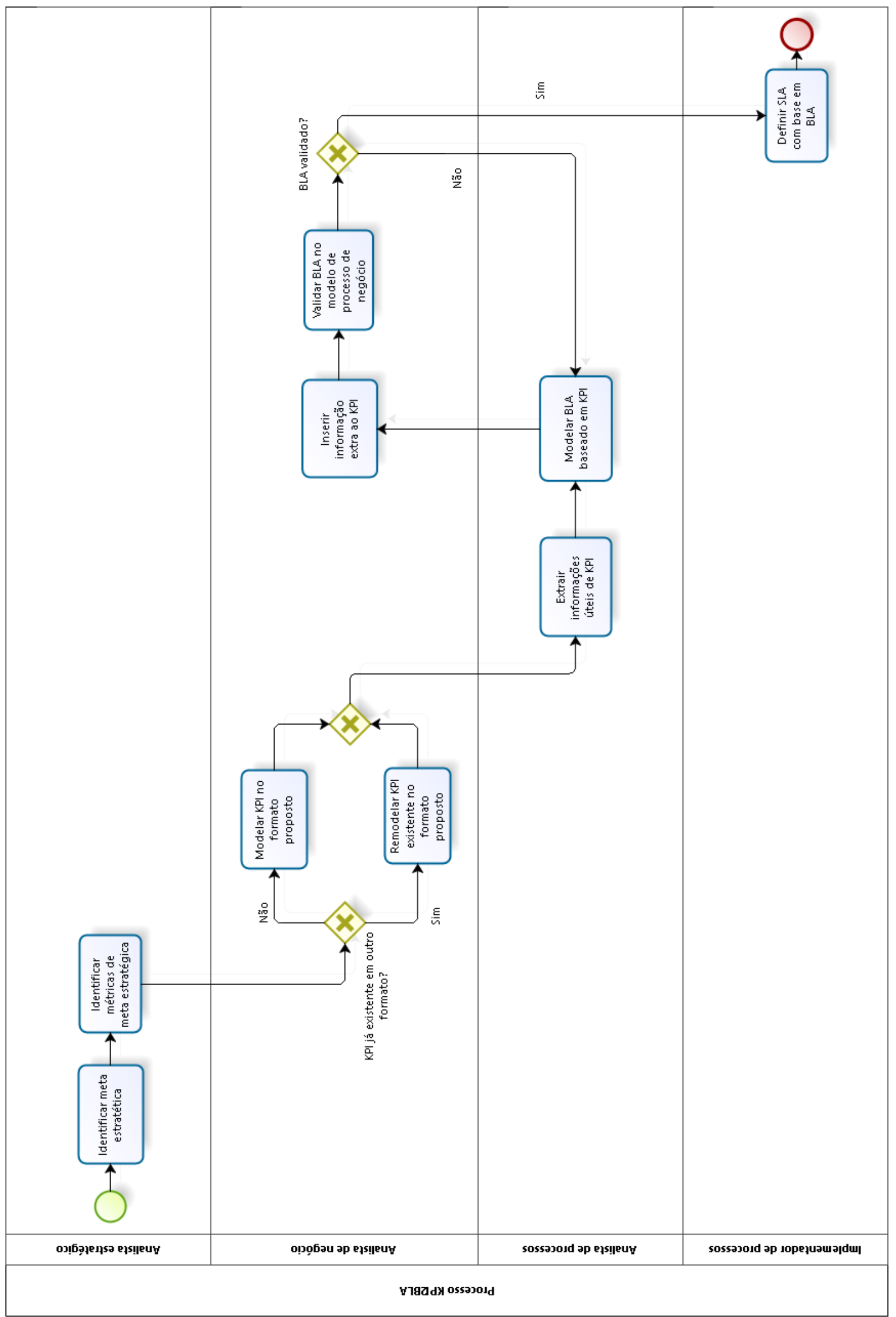

Fonte: Adson Rocha do Carmo, 2016 
Figura 28 - Tela de criação de KPI

Goal:

Melhorar em $40 \%$ a qualidade do atendimento dos pacientes com doenças crônicas não transmissíveis nos próxim -

Select metric:

Aumentar as consultas dos pacientes com staus participating

Metric details:

Aumentar em $20 \%$ as consultas dos pacientes com status participating Efficiency: Aumentar as consultas dos pacientes com staus participating =

(TotalConsultasPacientesCronicosParticipating / TotalConsultasPacientesCronicos) Up

General data

Name: *

Controle do percentual de consultas dos pacientes com status participating

Description: *

Consulta dos pacientes com doenças crônicas não transmissíveis e status participating

Dt Begin: *

$9 / 28 / 2016$

\section{Dt End:}

$10 / 28 / 2016$

Fonte: Adson Rocha do Carmo, 2016

Figura 29 - Tela de criação de KPI - detalhes tolerância e etc.

Tolerance Type: *

$\%$

Tolerance Yellow Red:

50

\section{Current Value:}

60

Responsible: *

Jorge Matheus
Tolerance Green Yellow:

65

Target Value: *

80

Departament: *

Diretoria hospitalar

Fonte: Adson Rocha do Carmo, 2016 
Figura 30 - Tela de criação de KPI - detalhes bonificação e penalidade Bonus

\section{Description: *}

Equipe multidisciplinar recebe bonificação caso o alvo s

\section{Coin: *}

reais

Comparation: *

'>

Penality

Description: *

Departamento hospitalar deve penalizado caso o alvo $r$

Coin: *

reais

Comparation: *

\section{Target: *}

Departamento multidisciplinar

Value: *

3500.00

Limiar Value: *

75

Source: *

Diretoria hospitalar

Value: *

4000.00

Limiar Value: *

65

\section{Bonus details:}

'if' Aumentar as consultas dos pacientes com staus participating (TotalConsultasPacientesCronicosParticipating /

TotalConsultasPacientesCronicos) $>80 \%$ ' then ' Departamento multidisciplinar ' must earn ' 3500.00 reais

\section{Penality details:}

'if' Aumentar as consultas dos pacientes com staus participating (TotalConsultasPacientesCronicosParticipating / TotalConsultasPacientesCronicos) $<80 \%$ ' then ' Diretoria hospitalar ' must pay ' 4000.00 reais

Fonte: Adson Rocha do Carmo, 2016 
Figura 31 - BLA baseado no KPI criado

\begin{tabular}{l} 
BLA content \\
General Information: \\
Name: \\
Melhorar em 40\% a qualidade do atendimento dos pacientes com doenças crônicas não \\
Start date: \\
2016-09-28T03:00:00 \\
Due date: \\
2016-10-28T02:00:00 \\
Corporative context: \\
Aumentar em 20\% as consultas dos pacientes com status participating \\
Customer organization: \\
Departamento multidisciplinar \\
Customer department: \\
Diretoria hospitalar \\
Supplier organization: \\
Diretoria hospitalar \\
\hline
\end{tabular}

Fonte: Adson Rocha do Carmo, 2016

Figura 32 - XML criado a partir do BLA

$<B L A><$ Name $>$ Melhorar em $40 \%$ a qualidade do atendimento dos pacientes com doenças crônicas não transmissíveis nos próximos três anos.</Name> <DtBegin>2016-09-28T03:00:00</DtBegin><DtEnd >2016-10-28T02:00:00</DtEnd > $<$ CorporativeContext $>$ Aumentar em $20 \%$ as consultas dos pacientes com status participating $<$ /CorporativeContext $><$ CustomerOrganization $>$ Departamento multidisciplinar $<$ /CustomerOrganization $><$ CustomerDepartment $>$ Diretoria hospitalar $<$ CustomerDepartment $><$ SupplierOrganization $>$ Diretoria hospitalar $<$ /SupplierOrganization $><$ SupplieDepartment $/><$ kpi $>$ Controle do percentual de consultas dos pacientes $</ \mathrm{kpi}>$ $<$ ComparisonOperator>TotalConsultasPacientesCronicosParticipating / TotalConsultasPacientesCronicos</ComparisonOperator $>$ $<$ TargetValue $>80</$ TargetValue $><$ Unit $>\%</$ Unit $><$ CheckOnBLADueDate $/>$ $<$ CurrencyPenalty $>$ reais $</$ CurrencyPenalty $>$ $<$ CompensationValuePenalty $>4000</$ CompensationValuePenalty $>$ $<$ ComparisonOperatorPenalty $>$ '\&lt:' $</$ ComparisonOperatorPenalty $>$ $<$ ThresholdValuePenalty $>65</$ ThresholdValuePenalty $>$ $<$ CurrencyBonus $>$ reais $</$ CurrencyBonus $>$ $<$ CompensationValueBonus $>3500</$ CompensationValueBonus $>$ $<$ ComparisonOperatorBonus >'\&gt,' $<$ /ComparisonOperatorBonus $>$ $<$ ThresholdValueBonus $>75</$ ThresholdValueBonus $><$ BLA $>$

Fonte: Adson Rocha do Carmo, 2016 


\section{Avaliação da abordagem}

Esta seção apresenta o procedimento realizado para avaliar a abordagem proposta neste trabalho de mestrado. Primeiramente, é apresentado o protocolo definido para conduzir a aplicação da avaliação desta abordagem. Na sequência, os resultados obtidos são apresentados e discutidos. A avaliação foi aplicada a uma turma da disciplina de Gestão Computacional em Processos de Negócio do programa de Pós-graduação em Sistemas de Informação da Escola de Artes, Ciência e Humanidades (EACH) da Universidade de São Paulo, Brasil. O principal objetivo foi verificar se a abordagem proposta contribui com a busca do alinhamento estratégico entre o negócio e a TI, via criação de BLA usando a protótipo de ferramenta criado para ajudar na avaliação, sob o ponto de vista dos alunos atuando como usuários da abordagem.

\subsection{Planejamento da avaliação da abordagem}

A avaliação foi aplicada apenas no ambiente acadêmico, pois uma aplicação da avaliação no ambiente industrial seria mais complexa devido às dificuldades organizacionais com respeito a acessar o ambiente organizacional e suas informações. Além disso, existe a questão da disponibilidade dos profissionais, que teriam que dedicar tempo para usar a abordagem e analisar os resultados. Não foi identificada nenhuma organização em a abordagem proposta pudesse ser avaliada, considerando tais restrições. Assim, considerouse que, para o escopo e objetivos de um trabalho de mestrado, uma avaliação com alunos que possuíssem embasamento teórico nos conceitos de gestão de processos de negócio já poderia ser considerado suficiente.

A avaliação da abordagem proposta aos participantes segue a abordagem GoalQuestion-Metric (GQM), considerando os seguintes aspectos, de forma mais específica(SOLINGEN et al., 2002):

- analisar o uso da abordagem KPI2BLA;

- com o propósito de verificar se a abordagem contribui para a definição de BLAs representando requisitos não funcionais em modelos de processo de negócio com base em KPIs; 
- com respeito a facilidade de uso, viabilidade e benefícios proporcionados pela abordagem proposta comparado a uma abordagem ad hoc;

- de acordo com o ponto de vista de especialistas de processos de negócio representados por alunos;

- no contexto de alinhamento estratégico entre o negócio e a TI com apoio de BPM.

Em relação aos aspectos avaliados, os seguintes entendimentos foram considerados tanto pelos avaliadores quanto pelos participantes da avaliação:

- facilidade: quando não existem dificuldades ou obstáculos para realização de uma tarefa;

- viabilidade: quando há condições para se realizar uma tarefa;

- benefício: quando há vantagens associadas à realização de uma tarefa]

Para atender os aspectos citados pela abordagem GQM, o Prof. Dr. Marcelo Fantinato, que ministra a disciplina Gestão Computacional em Processos de Negócio e é o orientador deste trabalho, ofereceu a possibilidade de conduzir essa avaliação com sua turma. Os seguintes passos foram executados para realizar a avaliação:

1. apresentou-se aos participantes o Framework StrAli-BPM original (SALLES, 2014), incluindo um exemplo de BLA especificado para um modelo BPMN; disponibilizou-se, ainda, para os participantes a dissertação que descreve o Framework StrAli-BPM original para eles usarem como referência em seus trabalhos de avaliação;

2. apresentou-se a lacuna existente no Framework StrAli-BPM original explorada neste trabalho, que é a dificuldade de saber quais informações devem ser usadas como base para a definição de BLAs;

3. apresentou-se a proposição de que KPIs, representando metas estratégicas organizacionais, poderiam ser usados como uma fonte adequada para a definição de BLAs, contribuindo para tratar a limitação existente; apresentou-se, então, o objetivo geral da abordagem KPI2BLA;

4. apresentou-se um exemplo de KPI, na forma textual; para isso, usou-se o exemplo de um KPI que foi usado na definição do BLA apresentado inicialmente aos participantes, de acordo com o item (1);

5. apresentou-se um cenário em que todos os participantes deveriam usar para realizar a avaliação da abordagem, incluindo um novo KPI, representado de forma textual, 
e um novo modelo de processo de negócio para o qual um BLA deveria ser criado, com base no KPI disponibilizado;

6. apresentou-se aos participantes que, a seus critérios, dividissem-se em duplas e, na sequência, as duplas formadas foram divididas, via sorteio, em dois grupos, identificados aqui como grupo "KPI2BLA" e grupo "ad hoc";

7. apresentou-se que as duplas do grupo "ad hoc" realizassem a criação do BLA, com base no KPI apresentado de forma textual, da forma como julgarem mais apropriado, sem usar qualquer ferramenta ou técnica sistemática que eventualmente pudessem encontrar para apoiar seu trabalho;

8. as duplas do grupo "ad hoc" foram então liberadas para sair da sala de aula, a fim de não terem conhecimentos detalhados de como o grupo "KPI2BLA" deveria realizar seus trabalhos, para diminuir a possibilidade de viés;

9. solicitou-se que as duplas do grupo "KPI2BLA" realizassem a criação do BLA, com base na abordagem KPI2BLA, também com base no KPI apresentado inicialmente de forma textual; para isso, apresentou-se mais detalhes da abordagem KPI2BLA, incluindo o metamodelo definido para KPI, o template criado para KPI, e o protótipo de ferramenta desenvolvido a ser usado como apoio. Para isso, realizou-se uma apresentação geral do protótipo de ferramenta;

10. para ambos os grupos, solicitou-se que realizassem seus trabalhos e entregassem um relatório dos mesmos em sete dias;

11. após a realização do trabalho, solicitou-se a todas as duplas que respondessem um questionário relacionado às tarefas realizadas, a ser retonado em cinco dias;

12. para compartilhamento de informação e melhoria no aprendizado, ao final, apresentouse também ao grupo "ad hoc" a abordagem KPI2BLA usada pelo outro grupo;

13. como última tarefa da avaliação, realizou-se a análise das informações extraídas das respostas dos questionários.

Em relação ao questionário de avaliação, inicialmente, houve uma série de perguntas para identificar o perfil dos participantes na avaliação, por meio de questões objetivas em que, dependendo do caso, os participantes poderiam escolher mais do que uma escolha e até mesmo apresentando opções adicionais. Na sequência, houve um conjunto de perguntas para identificar a opinião dos participantes sobre os três aspectos avaliados, ou seja: facilidade de aplicação, viabilidade e benefícios potenciais da aplicação. Para isso, foram usadas 
perguntas objetivas, considerando a escala Likert, ou seja, com cinco alternativas definidas entre 1 e 5 , em que o valor 1 representa as opiniões mais negativas, e, em contrapartida, o valor 5 da escala representa as opiniões mais positivas. Foi também incluída uma questão aberta para que os participantes informassem qualquer tipo de aspecto qualitativo da avaliação realizada.

Com o propósito de alcançar maior assertividade na leitura das informações extraídas dos questionários respondidos pelos participantes, uma pergunta adicional foi incluída ao final do questionário. Conhecida como "pergunta de controle", ela tem o objetivo de verificar a coerência nas respostas (ROUX; THÖNI, 2015); neste caso, as respostas dos participantes. O uso desta técnica ocorre, no questionário, com uma pergunta relacionada a se o participante "recomendaria a alguém a abordagem (usada por ele na avaliação) para modelar BLAs com base em KPIs", incluindo tanto a abordagem KPI2BLA quanto a abordagem ad hoc. Caso um participante tenha apresentado opinião positiva em relação a facilidade de aplicação, viabilidade e benefícios potenciais da abordagem usada (KPI2BLA or ad hoc, mas indicado que não a recomendaria para uso, isso indica uma potencial incoerência nas respostas do participante. O mesmo poderia ocorrer com o caso contrários, opiniões negativas sobre a abordagem usada, associada a uma possível recomendação da mesma. Em ambos os casos, o mais apropriado seria eliminar as respostas de tal participante.

Ameaças de interferência na análise dos resultados dos questionários foram identificadas e, como forma de combatê-las, foi solicitado que, para cada uma das duplas, cada participante deveria responder seu próprio questionário, para representar suas opiniões individuais. Além disso, para os casos em que apenas um dos participantes da dupla realmente realizou o trabalho, então foi solicitado que o outro participante não respondesse o questionário, sem qualquer prejuízo na avaliação da atividade para fins de nota da disciplina.

Para auxiliar no alcance dos aspectos propostos pela abordagem GQM, foram usados os seguintes artefatos na execução da avaliação da abordagem:

1. um cenário ilustrativo composto de uma meta estratégica organizacional e de sua representação como KPI;

2. um modelo BPMN contendo a representação gráfica de um requisito não funcional por meio de BLA; 
3. um questionário dividido em três partes principais: uma para identificar a formação e a experiência dos participantes, de forma geral; uma para identificar o conhecimento prévio dos participantes, em relação aos conceitos abordados neste trabalho; e outra para identificar a opinião dos participantes em relação ao trabalho realizado, usando a abordagem KPI2BLA ou a abordagem ad hoc.

As seguintes proposições foram consideradas para essa avaliação:

1. Sobre facilidade de aplicação:

- Proposição nula (h0): a abordagem KPI2BLA não é menos ou igualmente fácil de aplicar do que a abordagem ad hoc.

- Proposição alternativa (h1): a abordagem KPI2BLA é mais fácil de aplicar do que a abordagem ad hoc.

2. Sobre viabilidade:

- Proposição nula (h0): a abordagem KPI2BLA é menos ou igualmente viável para aplicar do que a abordagem ad hoc.

- Proposição alternativa (h1): a abordagem KPI2BLA é mais viável para aplicar do que a abordagem ad hoc.

3. Sobre benefícios potenciais da aplicação:

- Proposição nula (h0): a abordagem KPI2BLA possui menos ou iguais benefícios potenciais de aplicação do que a abordagem ad hoc.

- Proposição alternativa (h1): a abordagem KPI2BLA possui mais benefícios potenciais de aplicação do que a abordagem ad hoc.

A seguinte variável independente foi considerada: a abordagem usada pelos participantes - KPI2BLA ou ad hoc.

As variáveis dependentes são as seguintes:

1. facilidade de uso;

2. viabilidade;

3. benefícios potenciais.

Após a execução das tarefas previstas com os participantes, os dados obtidos foram analisados - levando em consideração quatro aspectos de validade - interna, externa, construção e conclusão; conforme apresentadas a seguir: 
- Validade interna: prover tratamento similar para todos os participantes da avaliação, evitando assim inesperadas reações para tratamentos diferentes; prover treinamento para os participantes minimizarem ao máximo uma suposta dificuldade em contribuir com a avaliação por falta de conhecimento; auxiliar que a meta estratégica organizacional e o KPI sejam compreendidos pelos participantes, objetivando evitar erros de interpretação;

- Validade externa: selecionar participantes do programa de graduação e pósgraduação;

- Validade de construção: não revelar as proposições aos participantes para que não ocorra indução na execução das tarefas; relevar aos participantes que a abordagem KPI2BLA foi proposto recentemente e que está em fase de teste; revelar aos participantes que a avaliação aplicada tem o objetivo de auxiliar na avaliação da abordagem KPI2BLA; revelar aos participantes que o questionário tem o objetivo de compreender o nível de conhecimento de cada um; e, por fim,

- Validade de conclusão: aplicação de analise qualitativa e quantitativa para avaliar se há diferenças significativas entre os vários grupos.

\subsection{Resultados da avaliação da abordagem}

O processo de avaliação da abordagem foi realizado em duas partes. A primeira consistiu em uma análise qualitativa dos resultados da tarefa de criação do BLA pelos participantes (tando via KPI2BLA quando de forma ad hoc). A segunda consistiu em fazer uma análise quantitativa das respostas dos questionários entregues pelos participantes.

\subsubsection{Resultados qualitativos da criação do BLA}

A análise foi realizada baseada no BLA criado, no relatório elaborado pelos participantes, nas dúvidas levantadas pelos participantes enviadas durante o processo de criação.

São apresentadas a seguinte, uma descrição dos resultados obtidos pelos participantes em termos dos BLAs criados, para ambos os grupos.

- Para os grupos que seguiram a abordagem ad hoc: 
- Onze participantes receberam a tarefa de criar o BLA de forma ad hoc (cinco duplas e um participante individual).

- Algumas dificuldades foram identificadas no processo de criação do BLA por alguns alunos, incluindo: pouco conhecimento com os principais conceitos usados na abordagem (BPMN, KPI, por exemplo), o que resultou em má interpretação da tarefa e má compreensão dos atributos do BLA. Mesmo assim, esses alunos conseguiram alcançar o objetivo final do trabalho. A partir dessas informações, é possível concluir que o processo de criação de BLA feito por indivíduos com pouco conhecimento dos conceitos envolvidos neste contexto e de forma ad hoc teve uma pequena interferência na qualidade do BLA criado. O que está sendo considerado aqui como falta de qualidade é a criação de BLA contendo algumas informações incoerentes com os respectivos tipos de atributos encontrados no KPI.

- Duas duplas não conseguiram criar o BLA corretamente e receberam notas abaixo de sete: uma não preencheu as informações de bonificação e penalidade alegando falta de informação; a outra não compreendeu o objetivo da tarefa e criou o BLA fora da estrutura proposta. As outras três duplas e o participante individual conseguiram concluir a tarefa com uma qualidade aceitável para a avaliação.

- Por outro lado, outros alunos apresentaram menor desenvoltura na execução da tarefa. Prova disso foram os BLAs criados com maior qualidade. Esse resultado contrariou o fato deles terem maior conhecimento nos conceitos usados e experiência profissional. Esses alunos apresentaram um aparente descaso no desenvolvimento da tarefa. Em alguns casos aplicaram minimamente a solução, sem atender alguns dos critérios de nota informados anteriormente. Em outros casos alegaram falta de informação na descrição da tarefa, no entanto, não questionaram e nem usaram a criatividade para auxiliar na aplicação da solução. Um dos caso, o principal objetivo não foi alcançado, ou seja, o BLA não foi criado no formado solicitado.

- A respeito da pergunta de controle, nenhum alunos apresentou incoerência as respostas. Principalmente entre as perguntas quatro ("Quão benéfico você acha que seja modelar BLAs com base em KPIs seguindo a abordagem usada por 
você?") e cinco ("Você recomendaria a alguém a abordagem usada por você para modelar BLAs com base em KPIs?") da parte quatro do questionário.

- KPI2BLA:

- Dezesseis participantes receberam a tarefa de criar o BLA usando o KPI2BLA (cinco duplas e dois trios).

- Em contraste com os resultados obtidos no processo de criação de BLA de forma ad hoc, os alunos que usaram o KPI2BLA conseguiram notas acima da média. A hipótese é a de que provavelmente o uso da abordagem KPI2BLA daria apoio à correta criação do BLA, mas ainda não é possível confirmar esta hipótese sem a análise das respostas dos questionários que podem confirmá-la ou negá-la, a depender do nível de conhecimento dos participantes.

- Todos os alunos apresentaram regularidade no processo de criação e demonstraram bom entendimento da tarefa, prova disso foi o cumprimento da tarefa com sucesso e sem grandes dificuldades. Pode-se concluir que, no mínimo, independente da questão do conhecimento prévio sobre os conceitos usados na abordagem, a abordagem KPI2BLA auxilia na criação de um BLA correto.

- Houveram dificuldades no entendimento de alguns atributos do template proposta pela abordagem KPI2BLA, por exemplo: tipo de tolerância e limiar (bonificação e penalização).

- A respeito da pergunta de controle, nenhum alunos apresentou incoerência as respostas. Principalmente entre as perguntas quatro ("Quão benéfico você acha que seja modelar BLAs com base em KPIs seguindo a abordagem usada por você?") e cinco ("Você recomendaria a alguém a abordagem usada por você para modelar BLAs com base em KPIs?") da parte quatro do questionário.

\subsubsection{Resultados quantitativos das respostas do questionário}

Um questionário foi criado, vide apêndice B, com o objetivo de coletar informações, essas informações foram divididas em quatro partes: a primeira parte trata de informações gerais sobre o desenvolvimento do trabalho; a segunda parte trata da identificação da formação e da experiência dos participantes; a terceira parte trata da identificação dos 
conhecimentos prévios necessários para a realização do trabalho; a quarta parte trata sobre a avaliação da abordagem usada pelos participantes para a realização do trabalho.

A respeito da primeira parte, que trata sobre o desenvolvimento do trabalho (criação do BLA), foi constatado que a avaliação foi submetida a vinte e sete participantes, porém apenas vinte e quatro responderam o questionário, o que indica que três participantes de fato não participaram da realização do trabalho. Desses vinte e quatro participantes que responderam o questionário, dez usaram a abordagem ad hoc e os outros catorze participantes usaram a abordagem KPI2BLA, como descrito na tabela 12.

Tabela 12 - Número de participantes e respostas ao questionário

\begin{tabular}{ccc}
\hline & Total participantes & Total questionário respondido \\
\hline$a d h o c$ & 11 & 10 \\
KPI2BLA & 16 & 14 \\
\hline Total & 27 & 24 \\
\hline \multicolumn{2}{c}{ Fonte: Adson Rocha do Carmo, 2016 }
\end{tabular}

A segunda parte, que trata da identificação da formação e experiência dos participantes, foi dividida em cinco perguntas.

Sobre a primeira pergunta ("Possui experiência profissional?"): dos dez participantes que usaram a abordagem ad hoc e responderam o questionário, 90\% tem experiência profissional, 10\% tem experiência como estagiário. Dos catorze participantes que usaram a abordagem KPI2BLA e responderam o questionário, 78\% tem experiência profissional e $22 \%$ tem experiências como estagiário. Essas informações podem ser consultadas na tabela 13. De forma mais específica, a tabela 14 descreve o número de participantes para cada faixa de experiência em anos (agrupados em três anos). É possível identificar que, dos participantes que usaram a abordagem KPI2BLA, a maioria tem experiência maior que seis anos. Por outro lado, os participantes que usaram a abordagem ad hoc apresentaram menor período de experiência. Isso pode ter gerado um desequilibro na avaliação, pelo fato de ter participantes mais experientes usado a abordagem KPI2BLA e não um equilíbrio entre os participantes experientes e as abordagens.

Tabela 13 - Experiência como profissional ou estagiário

\begin{tabular}{ccc}
\hline Abordagem & Emprego & Estágio \\
\hline ad hoc & $90 \%$ & $10 \%$ \\
KPI2BLA & $79 \%$ & $21 \%$ \\
\hline
\end{tabular}

Fonte: Adson Rocha do Carmo, 2016 
Tabela 14 - Experiência dos participantes por faixa três em três anos

\begin{tabular}{lcc}
\hline Faixa de experiência (anos) & $\boldsymbol{a d}$ hoc & KPI2BLA \\
\hline$<3$ & 2 & 2 \\
3 à 6 & 4 & 2 \\
6 à 9 & 1 & 2 \\
$>9$ & 3 & 8 \\
\hline
\end{tabular}

Fonte: Adson Rocha do Carmo, 2016

A segunda pergunta "Se possui experiência profissional, em que função", buscou identificar as área de experiência dos participantes caso tivessem. Como alguns participantes relataram ter experiência em mais de uma área, os valores apresentados na tabela 15 consideram os números de participantes e as áreas de experiência profissional relatadas por eles, sendo que alguns participantes podem estar sendo contados mais do que uma vez. Entre os participantes que usaram a abordagem KPI2BLA, as áreas que mais prevaleceram foram a de engenharia de software e similares e analista de TI e similares. Pode-se extrair uma possível relação entre ter mais tempo de experiência e a Analista de TI e similares, pois são áreas que tendem mais para gestão e geralmente é preciso mais tempo de experiência e, por consequência disso, mais contato com questões relacionadas às metas estratégicas organizacionais e os requisitos não funcionais relacionados. Em contrapartida, outra possível relação pode existir entre os participantes com menor experiência, que usaram a abordagem ad hoc, os quais atuam mais como Engenheiro de software e similares, que são áreas que tendem a exercerem atividades mais operacionais, ou seja, mais longe das metas estratégicas organizacionais.

Tabela 15 - Áreas de experiência dos participantes

\begin{tabular}{lccc}
\hline Área & ad hoc & KPI2BLA & Total \\
\hline Engenheiro de software e similares & 3 & 5 & 8 \\
Analista de TI e similares & 6 & 4 & 10 \\
Professor & 3 & 1 & 4 \\
Outro & 2 & 3 & 5 \\
\hline
\end{tabular}

Fonte: Adson Rocha do Carmo, 2016

A terceira pergunta, "Qual seu nível de escolaridade?", ilustrado na tabela 16, ajudou a classificar os participantes por nível de escolaridade: graduandos e pós-graduandos. A maioria dos participantes submetidos à avaliação tem nível de escolaridade de pósgraduando, tanto para os que usaram a abordagem KPI2BLA quanto para os que usaram a abordagem ad hoc. 
Tabela 16 - Nível de escolaridade

\begin{tabular}{lcc}
\hline Abordagem & Graduando & Pós-graduando \\
\hline ad hoc & $20 \%$ & $80 \%$ \\
KPI2BLA & $21 \%$ & $79 \%$ \\
\hline
\end{tabular}

Fonte: Adson Rocha do Carmo, 2016

A quarta pergunta foi aplicada somente para os participantes da graduação, "Qual seu semestre no curso? e Quais dessas disciplinas já cursou?" Os alunos de graduação que responderam as perguntas estão entre o sexto e oitavo semestre e a maioria já cursou todas, senão quase todas as disciplinas listadas no questionário, que são disciplinas mais relacionadas ao tema deste projeto, a saber:

- Introdução à administração para computação.

- Prática e gestão de projetos.

- Economia para computação.

- Empreendedorismo em informática.

- Contabilidade para computação.

A quinta e última pergunta desta parte do questionário foi aplicada somente aos alunos de pós-graduação, com intuito de identificar qual foi o curso de graduação de cada um deles. De acordo com a tabela 17, dos participantes que usaram a abordagem ad hoc, $40 \%$ tem graduação em sistemas de informação, seguido por ciência da Ccomputação e engenharia na área da computação. Já entre os participantes que usaram a abordagem KPI2BLA, 36\% tem graduação em tecnologia na área de computação, seguido por ciência da computação com $21 \%$.

Tabela 17 - Área de graduação dos alunos da Pós-graduação

\begin{tabular}{lcc}
\hline & ad hoc & KPI2BLA \\
\hline Sistemas de informação & $40 \%$ & $14 \%$ \\
Ciência da computação & $10 \%$ & $21 \%$ \\
Tecnologia na área de computação & $10 \%$ & $36 \%$ \\
Engenharia de software & $10 \%$ & $0 \%$ \\
Outros & $10 \%$ & $7 \%$ \\
\hline
\end{tabular}

Fonte: Adson Rocha do Carmo, 2016

A terceira parte, intitulada "Identificação de Conhecimento Prévio", foi dividida em seis perguntas. O objetivo era compreender qual o nível de conhecimento dos participantes que foram submetidos ao trabalho de avaliação da abordagem. 
A primeira pergunta "Conceitue sua experiência prévia (ou seja, antes da realização deste trabalho) em relação a processos de negócio e gestão de processos de negócio (BPM) em geral" tem seus resultados apresentado na tabela 18. Dos participantes que usaram o ad hoc, um total de $90 \%$ alegou ter "nenhuma", "pouca" ou "média" experiência (30\% para cada uma das opções). Os participante que usaram o KPI2BLA tiveram grande concentração de respostas entre "nenhuma" (36\%), "pouca" (21\%) e "média" (29\%) de experiência. Destaca-se que, para o grupo ad hoc, apenas 10\% dos participantes alegaram ter "bastante" conhecimento no máximo. Destaca-se, para o grupo KPI2BLA, que 14\% dos participantes informaram ter "bastante" ou "muita" experiência prévia em BPM.

Tabela 18 - Experiência prévia em BPM

\begin{tabular}{lcc}
\hline & ad hoc & KPI2BLA \\
\hline Nenhuma & $30 \%$ & $36 \%$ \\
Pouca & $30 \%$ & $21 \%$ \\
Média & $30 \%$ & $29 \%$ \\
Bastante & $10 \%$ & $7 \%$ \\
Muita & $0 \%$ & $7 \%$ \\
\hline
\end{tabular}

Fonte: Adson Rocha do Carmo, 2016

A segunda pergunta "Conceitue sua experiência prévia (ou seja, antes da realização deste trabalho) em relação à notação BPMN:" tem seus resultados apresentado na tabela 19. Para esse caso, identificou-se um cenário parecido à questão anterior. Dos participantes que usaram o ad hoc, 30\% informou "nenhuma", $40 \%$ "pouca"e apenas $20 \%$ informou "média" experiência em relação a seu nível de conhecimento em BPMN. Dos participantes que usaram o KPI2BLA 50\% informou ter "pouca" experiência. Destaca-se que apenas dois participantes informaram que tinham "bastante" experiência com BPMN: um usou a abordagem ad hoc (representa 10\%) o outro a abordagem KPI2BLA (representa 7\%).

Tabela 19 - Experiência prévia em BPMN

\begin{tabular}{lcc}
\hline & ad hoc & KPI2BLA \\
\hline Nenhuma & $30 \%$ & $21 \%$ \\
Pouca & $40 \%$ & $50 \%$ \\
Média & $20 \%$ & $21 \%$ \\
Bastante & $0 \%$ & $0 \%$ \\
Muita & $10 \%$ & $7 \%$ \\
\hline
\end{tabular}

Fonte: Adson Rocha do Carmo, 2016

A terceira questão "Conceitue sua experiência prévia em relação a requisitos não funcionais" tem seus resultados apresentado na tabela 20. Neste quesito, ambos 
os grupos mostraram um pouco mais de experiência quando comparado aos dois itens anteriores. Porém, os participantes que usaram a abordagem ad hoc $60 \%$ indicaram ter conhecimento "médio". Já os participantes que usaram a abordagem KPI2BLA 50\% alegaram ter "pouco" conhecimento. Destaca-se que, dos alunos dos dois grupos, $0 \%$ alegou ter "nenhuma" experiência com requisitos não funcionais. Destaca-se, também, que dentre os grupos apenas 14\% do grupo KPI2BLA declarou ter "muita" experiência.

Tabela 20 - Experiência prévia em requisitos não funcionais

\begin{tabular}{lcc}
\hline & ad hoc & KPI2BLA \\
\hline Nenhuma & $0 \%$ & $0 \%$ \\
Pouca & $20 \%$ & $50 \%$ \\
Média & $60 \%$ & $21 \%$ \\
Bastante & $20 \%$ & $14 \%$ \\
Muita & $0 \%$ & $14 \%$ \\
\hline
\end{tabular}

Fonte: Adson Rocha do Carmo, 2016

A quarta pergunta "Conceitue sua experiência prévia em relação a SLA (Service Level Agreement) e QoS (Quality of Service)" tem seus resultados apresentado na tabela 21. Os participantes que usaram a abordagem ad hoc, 70\% alegaram ter conhecimento "médio" ou "pouco" conhecimento (40\% e 30\% respectivamente). Para os participantes que usaram a abordagem KPI2BLA, $43 \%$ alegaram ter "médio" conhecimento e 29\% "nenhum" conhecimento. Destaca-se que nenhum dos participantes, de ambos os grupos, alegaram ter "muita" experiência prévia em SLA e QoS.

Tabela 21 - Experiência prévia em SLA (Service Level Agreement) e QoS (Quality of Service)'

\begin{tabular}{lcc}
\hline & ad hoc & KPI2BLA \\
\hline Nenhuma & $10 \%$ & $29 \%$ \\
Pouca & $30 \%$ & $7 \%$ \\
Média & $40 \%$ & $43 \%$ \\
Bastante & $20 \%$ & $21 \%$ \\
Muita & $0 \%$ & $0 \%$ \\
\hline
\end{tabular}

Fonte: Adson Rocha do Carmo, 2016

A quinta questão "Conceitue sua experiência prévia (ou seja, antes da realização deste trabalho) em relação a planejamento/plano estratégico e metas estratégicas organizacionais" tem seus resultados apresentado na tabela 22. Os resultados mostram que 40\% dos participantes que usaram a abordagem ad hoc informaram "média" experiência, enquanto que entre os participantes que usaram a abordagem KPI2BLA, 29\% (a maioria) 
informaram ter "muita" experiência. Destaca-se que entre as opções os participantes do grupo KPI2BLA alegaram ter mais experiência.

Tabela 22 - Experiência prévia em planejamento/plano estratégico e metas estratégicas organizacionais

\begin{tabular}{lcc}
\hline & ad hoc & KPI2BLA \\
\hline Nenhuma & $10 \%$ & $14 \%$ \\
Pouca & $30 \%$ & $29 \%$ \\
Média & $40 \%$ & $14 \%$ \\
Bastante & $10 \%$ & $14 \%$ \\
Muita & $10 \%$ & $29 \%$ \\
\hline \multicolumn{2}{c}{ Fonte: Adson Rocha do Carmo, 2016 }
\end{tabular}

Fonte: Adson Rocha do Carmo, 2016

A sexta questão "Conceitue sua experiência prévia (ou seja, antes da realização deste trabalho) em relação a KPI (Key Performance Indicator)" tem seus resultados apresentado na tabela 23. Os participantes que usaram a abordagem ad hoc apresentaram $40 \%$ de conhecimento médio sobre KPI, seguido por 30\% com pouca experiência. No caso dos participantes que usaram a abordagem KPI2BLA, o nível de conhecimento foi menor comparado com os que usaram a abordagem ad hoc: $29 \%$ informaram ter "nenhum" ou "pouco" conhecimento em KPI. Destaca-se que apenas 7\% dos alunos do grupo KPI2BLA informaram ter "muita" experiência prévia em KPI. Por outro lado, nenhum participante informou ter "muita" experiência prévia em KPI.

Tabela 23 - Experiência prévia em KPI

\begin{tabular}{lcc}
\hline & ad hoc & KPI2BLA \\
\hline Nenhuma & $10 \%$ & $29 \%$ \\
Pouca & $30 \%$ & $29 \%$ \\
Média & $40 \%$ & $21 \%$ \\
Bastante & $20 \%$ & $7 \%$ \\
Muita & $0 \%$ & $7 \%$ \\
\hline
\end{tabular}

Fonte: Adson Rocha do Carmo, 2016

A quarta parte do questionário e também a última teve o objetivo de coletar informações sobre a avaliação da abordagem usada para realização do trabalho. Essa parte foi divida em seis perguntas (cinco objetivas e uma dissertativa). A primeira pergunta foi usada apenas para recuperar qual das abordagens havia sido seguida pelo participante.

Na segunda pergunta "Quão fácil você achou modelar o BLA com base no KPI informado seguindo a abordagem usada por você?", os participantes foram levados a responder sobre a facilidade em usar a abordagem. De acordo com a tabela $24,70 \%$ dos 
participantes do grupo ad hoc informaram ter sido pelo menos "nem fácil, nem difícil" realizar o trabalho com sua abordagem, enquanto que $83 \%$ dos participantes do grupo KPI2BLA informaram ter sido pelo menos "nem fácil, nem difícil" realizar o trabalho com sua abordagem. Destaca-se que nenhum participante, de nenhum dos grupos, identificou como "muito fácil". Destaca-se também que $10 \%$ do grupo ad hoc informou ter sido "muito difícil" enquanto nenhum participante do grupo KPI2BLA informou esse nível de dificuldade. Destaca-se, também, que nenhum dos alunos alegaram ser "muito fácil" modelar BLA usando uma das abordagem.

Tabela 24 - Facilidade em modelar BLA usando as abordagens

\begin{tabular}{lcc}
\hline & ad hoc & KPI2BLA \\
\hline Muito difícil & $10 \%$ & $0 \%$ \\
Difícil & $20 \%$ & $7 \%$ \\
Nem fácil, nem difícil & $40 \%$ & $43 \%$ \\
Fácil & $30 \%$ & $50 \%$ \\
Muito fácil & $0 \%$ & $0 \%$ \\
\hline
\end{tabular}

Fonte: Adson Rocha do Carmo, 2016

Na terceira pergunta "Quão viável você acha que seja modelar BLAs com base em KPIs seguindo a abordagem usada por você?", os participantes foram levados a responder sobre a viabilidade para usar a abordagem. De acordo com a tabela 25, 80\% dos participantes do grupo ad hoc informaram ser pelo menos "nem viável, nem inviável" ou "viável" aplicar sua abordagem (20\% e 60\% respectivamente), enquanto que $100 \%$ dos participantes do grupo KPI2BLA informaram ser pelo menos "nem viável, nem inviável" ou "viável" aplicar sua abordagem (14\% e $86 \%$ respectivamente). Destaca-se que nenhum participante, de nenhum dos grupos, identificou como "muito viável". Destaca-se também que $10 \%$ do grupo ad hoc informou ser "muito inviável" enquanto nenhum participante do grupo KPI2BLA informou esse nível de inviabilidade.

Tabela 25 - Viabilidade em modelar BLA usando as abordagens

\begin{tabular}{lcc}
\hline & ad hoc & KPI2BLA \\
\hline Muito inviável & $10 \%$ & $0 \%$ \\
Inviável & $10 \%$ & $0 \%$ \\
Nem viável, nem inviável & $20 \%$ & $14 \%$ \\
Viável & $60 \%$ & $86 \%$ \\
Muito viável & $0 \%$ & $0 \%$ \\
\hline
\end{tabular}

Fonte: Adson Rocha do Carmo, 2016 
Na quarta pergunta "Quão benéfico você acha que seja modelar BLAs com base em KPIs, seguindo a abordagem usada por você?", os participantes foram levados a responder sobre os benefícios potenciais de uso da abordagem. De acordo com a tabela 26, 90\% dos participantes do grupo ad hoc informaram ser pelo menos "nem maléfico, nem benéfico" à benéfico aplicar sua abordagem, enquanto que 100\% dos participantes do grupo KPI2BLA informaram ser pelo menos "benéfico" à "muito benéfico" aplicar sua abordagem. Destaca-se que nenhum participante do grupo ad hoc identificou como "muito benéfico", mas que $21 \%$ dos participantes do grupo ad hoc identificaram como "muito benéfico". Destaca-se também que $10 \%$ do grupo ad hoc informou ser "maléfico" seu uso enquanto nenhum participante do grupo KPI2BLA informou esse nível de não benefício.

Tabela 26 - Benefícios em modelar BLA usando as abordagens

\begin{tabular}{lcc}
\hline & ad hoc & KPI2BLA \\
\hline Muito maléfico & $0 \%$ & $0 \%$ \\
Maléfico & $10 \%$ & $0 \%$ \\
Nem maléfico, nem benéfico & $30 \%$ & $0 \%$ \\
Benéfico & $60 \%$ & $79 \%$ \\
Muito benéfico & $0 \%$ & $21 \%$ \\
\hline
\end{tabular}

Fonte: Adson Rocha do Carmo, 2016

Na quinta pergunta "Você recomendaria a alguém a abordagem usada por você para modelar BLAs com base em KPIs?", os participantes foram levados a confirmar as respostas apresentadas nas três perguntas anteriores. De acordo com a tabela 27, $30 \%$ dos participantes do grupo ad hoc informaram que pelo menos "poderiam tanto recomendar quanto não recomendar" a aplicação de sua abordagem, enquanto que 100\% dos participantes do grupo KPI2BLA informaram que pelo menos "poderiam tanto recomendar quanto não recomendar" a aplicação de sua abordagem. Destaca-se que, para o grupo ad hoc, nenhum participante informou que "certamente recomendaria" e que $10 \%$ dos participantes informaram que "certamente não recomendaria", o que está de acordo com os resultados das três questões anteriores. Para o grupo KPI2BLA, destaca-se que, nenhum participante informou que "certamente não recomendaria" ou "não recomendaria" e que $14 \%$ dos participantes informaram que "certamente recomendaria", o que também está de acordo com os resultados das três questões anteriores. Assim, verifica-se que a pergunta de controle indicou existir coerência entre as respostas apresentadas pelos participantes de ambos os grupos. 
Tabela 27 - Recomendação da abordagem

\begin{tabular}{lcc}
\hline & ad $\boldsymbol{h o c}$ & KPI2BLA \\
\hline Certamente não recomendaria & $10 \%$ & $0 \%$ \\
Provavelmente não recomendaria & $20 \%$ & $0 \%$ \\
Poderia tanto recomendar quanto não recomendar & $20 \%$ & $36 \%$ \\
Provavelmente recomendaria & $50 \%$ & $50 \%$ \\
Certamente recomendaria & $0 \%$ & $14 \%$ \\
\hline
\end{tabular}

Fonte: Adson Rocha do Carmo, 2016

Na sexta pergunta da quarta parte do questionário, os participantes expressaram por meio de comentários sua experiência com a abordagem usada no processo de criação do BLA. A seguir, são apresentadas as três respostas mais relevantes relacionadas a cada abordagem.

Sobre a abordagem ad hoc foi comentado que:

- "O benefício de criar um BLA partindo de um KPI é que partindo do seu processo você garante o cumprimento de determinada tarefa/meta de forma realista e aderente a seu processo. Obtendo assim uma maior taxa de acerto/sucesso. Sobre a abordagem, é necessário criar uma forma padronizada para elaboração do BLA, para que não haja erros de perspectiva, completude e exatidão na criação dos benefícios e penalidades."

- "Acredito que haja benefícios desde que a pessoa que está modelando já possua alguma experiência prática na área ou conheça bem as metas."

- "Usar a metodologia ad hoc é muito difícil na determinação do BLA pois acaba sendo um processo muito subjetivo, sem embasamento em teorias e técnicas que poderiam levar à um resultado mais eficiente e correto."

Pode-se concluir, a respeito dos comentários dos participantes sobre a experiência de modelar BLA usando a abordagem ad hoc, que: partir de KPIs auxilia no cumprimento da meta estratégica organizacional, porém a falta de uma técnica que defina os passos para correta extração das informações desses KPIs dificulta a criação do BLA. Também a falta de experiência dificulta bastante na modelagem do BLA sem uma técnica ou teoria para direcionar a criação do BLA. Pode-se observar que mesmo com o cumprimento da tarefa os participantes alegaram dificuldades, outro indicador que comprova isso (além do que foi comentado pelo participante) é o ilustrado na tabela 24 , que apresenta $30 \%$ de participantes informando que é difícil modelar usando a abordagem ad hoc. Não somente a informação extraída da tabela 24, mas também a informação extraída da tabela 25, 
com $20 \%$ de participantes afirmando que a abordagem ad hoc é muito inviável ou inviável. Contudo, os respectivos valores extraídos das mesmas tabelas citadas apontam o contrário quando se trata do uso da abordagem KPI2BLA. Pois apenas 7\% dos participantes (tabela 24) informaram que a abordagem é muito difícil ou difícil de usar. E na tabela 25, nenhum participante informou que a abordagem é muito inviável ou inviável.

Sobre a abordagem KPI2BLA foi comentado que:

- "O interessante sobre a abordagem é que ela poderia evitar falhas na modelagem, porém acredito que poderiam ser feitas otimizações como um KPI singularmente poder servir para penalizar ou bonificar departamentos ou pessoas diferentes sem ter a necessidade de replicar o mesmo KPI."

- "Usamos a abordagem KPI2BLA. No primeiro momento que usei a ferramenta, encontrei alguns problemas na mesma, sendo estes relatados e corrigidos. Após isso, consegui gerar os BLAs sem dificuldades. Sugeri algumas melhorias no relatório entregue, que podem ser pertinentes."

- "Achei a abordagem interessante para o público de analistas de TI, pois simplifica o plano estratégico através do foco em metas (KPIs). Porém acredito que essa simplificação deve ter limitações, especialmente considerando uma modelagem mais completa considerando todos os requisitos não funcionais pertinentes a uma determinada ação estratégica. A ferramenta poderia ser melhorada no sentido de orientar melhor o preenchimento dos campos (com dicas, exemplos, unidades). O exemplo de KPI no template fornecido nos slides deixou dúvidas em relação a como preencher o valor limiar."

Pode-se concluir, a respeito dos comentários dos participantes sobre a experiência de modelar BLA usando a abordagem KPI2BLA, que: há uma certa dificuldade em usar a ferramenta por conta de duvidas quanto ao entendimento de alguns campos dos formulários. No entanto, essa dificuldade se justifica pela falta de experiência de alguns participantes ou não terem consultado corretamente o material disponibilizado. Outro ponto citado como negativo foi alguns bugs apresentados pela ferramenta, mas que foram resolvidos e o mesmo participante que informou o problema alegou que não teve dificuldade em criar o BLA. Foi citado que a ferramenta talvez não atendesse cenários mais complexos, porém, certamente que como um protótipo a ferramenta não atenderia todos os cenários. Inclusive esse mesmo argumento, do fato da ferramenta ser somente um protótipo, se 
aplica a alguns bugs encontrados e funcionalidades limitadas. De fato, foram apontados pontos negativos, por outro lado, os pontos positivos foram mais relevantes como por exemplo as relações feitas com experiências no ambiente profissional sobre a necessidade de modelar as metas estratégicas organizacionais e como a abordagem auxilia neste aspecto. Outro ponto positivo foi a simplificação proporcionada pela abordagem devido ao foco nas metas via KPIs. Por fim, a tabela 27 ilustra o quão positivo a abordagem foi para os participantes por apresentar $64 \%$ dos participantes informando que provavelmente recomendaria e certamente recomendaria (50\% e 14\%), ao contrário dos participantes que usaram a abordagem ad hoc, que $50 \%$ informaram que provavelmente recomendaria e nenhum informou que certamente recomendaria.

\subsubsection{Análise dos resultados da avaliação}

Nesta seção são apresentadas as conclusões a respeito da análise dos resultados desta avaliação. E para isto, as análises estão separadas em dois grupos: Aspectos sobre riscos da validade da abordagem e experiência prévia dos alunos e a análise feita sobre as respostas das perguntas da quarta parte do questionário.

6.2.3.1 Aspectos sobre riscos da validade da abordagem e experiência prévia dos alunos

Um dos aspectos que favoreceram na validade desta avaliação foi o fato de $79 \%$ dos alunos do grupo KPI2BLA terem experiência como profissional, e os alunos do grupo ad hoc $90 \%$. Desta forma, a abordagem KPI2BLA ganha mais credibilidade pois mesmo tendo menos alunos com experiência profissional, ainda assim, os resultados obtidos com a abordagem foram mais positivos. Provando que a abordagem contribui no processo da modelagem do BLA, mesmo os alunos não tendo tanta experiência.

Porém, mesmo o grupo KPI2BLA tendo menor numero de alunos com experiência profissional, os que tem experiência profissional apresentaram maior tempo de experiência com relação aos alunos do ad hoc. Por exemplo, oito dos alunos, do grupo KPI2BLA, tem mais de nove anos de experiência. Contudo, o fato de ter mais tempo de experiência não determina que o aluno vai ter mais facilidade no processo de criação do BLA. 
Um fator trouxe equilíbrio no aspecto da vulnerabilidade da avaliação pelo fato da maioria dos alunos terem experiência nas área de engenharia de software e similares e analise de TI e similares. Pois se houvesse um desequilíbrio entre os alunos que usaram o KPI2BLA com mais experiências nas áreas citadas e os alunos que usaram o ad hoc tivessem pouca experiência nessas áreas, poderia colar em risco a viabilidade da avaliação.

Outro fator que trouxe equilíbrio a validade da avaliação foi pelo fato de ter uma divisão proporcional entre os alunos de graduação e pós-graduação entre as abordagens. Porque se houvesse um desequilíbrio (mais alunos de pós-graduação no grupo KPI2BLA do que no $a d h o c$ ) poderia gerar um descredito na avaliação do KPI2BLA, pela simples conclusão que normalmente um aluno de pós-graduação poderia ter mais conhecimento ou tempo de experiência que um de graduação. E para constatar este fato, relação entre nível escolar e experiência, as tabelas 18 à 23 ilustram os valores relacionados ao assunto.

A conclusão que pode-se chegar a partir da análise das tabelas, 18 à 23, é que existe um equilíbrio entre a experiência dos alunos, a abordagem usada e os principais conceitos apresentados pelo questionário - BPM, BPMN, requisito não funcional, SLA e QoS, metas estratégicas e KPI. Então, mais uma vez, um fator que traz credibilidade a avaliação desta abordagem.

\subsubsection{A análise feita sobre as respostas das perguntas da quarta parte do questionário}

Na tabela 14, pode-se observar que os alunos que usaram a abordagem KPI2BLA alegaram ter sido fácil modelar um BLA. Diferentemente dos alunos que usaram o ad hoc que, mesmo com 30\% deles alegando achar fácil seu uso, 30\% alegou ser "muito difícil" ou "difícil" usá-lo. E somente 7\% dos alunos que usaram KPI2BLA achou "difícil" usá-lo para modelar BLA. Conclui-se que neste aspecto, facilidade em modelar BLA, o KPI2BLA se mostrou superior ao ad-hoc.

Na tabela 25, que trata sobre a viabilidade da abordagem em modelar BLA, o KPI2BLA demostrou - de acordo com as respostas dos alunos - superioridade por apresentar 86\% contra $60 \%$ na opção "viável". Ou seja, o KPI2BLA é a opção mais viável para modelar BLA em comparação com o ad hoc.

A tabela 26 auxilia a concluir que no quesito "benefícios", novamente, o KPI2BLA demonstra superioridade por apresentar 100\% entre "benéficio" e "muito benéfico". Ou 
seja, os alunos do grupo KPI2BLA se sentiram beneficiados com o uso da abordagem no processo de modelagem do BLA. Em contrapartida, 60\% dos alunos do grupo ad hoc alegaram "benéfico" seu uso. Ainda pior, 10\% dos alunos do grupo ad hoc alegaram ter sido atrapalhados ("maléfico") no processo de modelagem do BLA pela abordagem.

Quando se tratou de recomendação da abordagem, ambas as abordagem tiveram valores próximos, mas com uma leve vantagem do KPI2BLA sobre o ad hoc (64\% e 50\%), sendo que somente no grupo KPI2BLA ouve alegação de que "certamente recomendaria" e não apresentou nenhuma alegação desfavorável. Diferentemente do ad hoc, que os alunos alegaram de forma negativa que 10\% "certamente não recomendaria" e $20 \%$ "provavelmente não recomendaria". Conclui-se que além do ad hoc não ser mais recomendado entre os alunos ele também foi relatado como "não recomendável" para modelagem de BLA.

A respostas das perguntas abertas do questionário, leva a conclusão que a abordagem KPI2BLA realmente é ajuda no processo da modelagem do KPI. Pois todas as respostas dos alunos, do grupo KPI2BLA, falam dos benefícios da abordagem como ela auxilia no processo da modelagem do BLA. Mesmo a abordagem apresentando algumas limitações, por conta do escopo definido e o fato do prototipo de ferramenta computacional usado para ajudar na avaliação ter limitações - até porque é um protótipo - os alunos concluíram que a abordagem é positiva. A respeito do ad hoc, os comentários foram bem diferentes. Nenhum ponto positivo foi abordado pelos alunos que a usaram, somente dificuldades no processo de criação do BLA.

\section{Sobre facilidade de aplicação:}

- A proposição nula (h0) pode ser descartada devido aos valores observados na tabela 24, que demonstram que $30 \%$ dos alunos do grupo acharam o ad hoc "Muito difícil" ou "Difícil". Mas nos alunos do grupo KPI2BLA, somente 7\% alegam ter achado "Difícil".

- A proposição alternativa (h1) pode ser aceita, por considerar os mesmos dados da tabela 24, que ilustra as respostas dos alunos do grupo KPI2BLA e apontam que 50\% informam que o uso da abordagem é fácil, $43 \%$ alegam "Nem fácil, nem difícil". Dentre os alunos do grupo ad hoc apenas 30\% informaram ser "Fácil". Ou seja, o uso do KPI2BLA traz mais facilidades do que o ad hoc.

\section{Sobre viabilidade:}


- A proposição nula (h0) pode ser descarta pois de acordo com a tabela 25, nenhum dos alunos do grupo KPI2BLA alegou que a abordagem é ou "Muito inviável" ou "Inviável". Porém entre os alunos do grupo ad hoc, 10\% alegaram que abordagem é "Muito inviável" e 10\% "Inviável".

- A proposição alternativa (h1) pode ser aceita, porque de acordo com a tabela 25 o KPI2BLA é mais viável do que o ad hoc, pois $86 \%$ dos alunos do grupo KPI2BLA informaram que a abordagem é "Viável" e 60\% dos alunos do grupo ad hoc informaram que a abordagem é "Viável".

\section{Sobre benefícios potenciais da aplicação:}

- A proposição nula (h0) pode ser descartada, pois de acordo com a tabela 26 nenhum dos alunos do grupo KPI2BLA alegaram que a abordagem pode ser "Muito maléfica" ou "Maléfica", já os alunos do grupo ad hoc 10\% alegaram que a abordagem é "Maléfica".

- A proposição alternativa (h1) pode ser aceita, pois de acordo com a tabela 26 o KPI2BLA traz mais benefícios potenciais em comparação com ad hoc. Isto porque $79 \%$ dos alunos do grupo KPI2BLA afirma como "Benéfico' e $21 \%$ como "Muito benéfico" o uso da abordagem. Por outro lado, 60\% dos alunos do grupo ad hoc informaram o uso da abordagem como "Benéfico" e nenhum informou como "Muito benéfico". Então de acordo com os alunos que a usaram o KPI2BLA, 100\% deles afirmaram que seu uso traz benefícios contra $60 \%$ dos alunos que usaram ad hoc e que afirmaram que o uso da abordagem traz benefícios.

Por fim, após uma visão geral dos três pilares usados nesta avaliação (experiência prévia, experiência com a abordagem via perguntas fechadas e pergunta aberta) é possível compreender que, de acordo com os resultados das tabelas 24, 25, 26 e 27 a abordagem KPI2BLA, de fato, auxilia no processo de criação do BLA por apresentar valores maiores nos itens de favorecimento (benéfico, recomendável, viável e fácil). 
6.2.3.3 Análise entre o perfil, experiência dos participantes do questionário e as respostas das perguntas da quarta parte do questionário

É possível observar que 90\% dos alunos com experiência profissional se encontram dentre os alunos que usaram o Ad hoc como abordagem, como visto na tabela 13. Porém, mesmo a maioria dos alunos tendo experiência profissional ao invés de experiência com estágio, a maioria deles tem pouco tempo de experiência profissional, como pode ser visto na tabela 14 (Na tabela 14,60\% dos alunos tem tempo pouco de experiência, de 1 à 6 anos). Ao contrário dos alunos que usaram o KPI2BLA, que $71 \%$ deles tem tempo de experiência profissional maior que seis anos.

Fazendo correlação com as tabelas 15 à 17, os alunos que usaram o Ad hoc, 6 tem experiência como Analista de TI e similares (áreas mais próximas dos assuntos usados neste trabalho), $80 \%$ são pós graduando, e dos pós graduando $40 \%$ cursam Sistemas de Informação. Entende-se que esses alunos podem estar aptos para tarefas aplicadas na avaliação desta abordagem. Diferentemente dos alunos que usaram o KPI2BLA, pois 5 deles (maioria) informaram ter experiência com Engenharia de Software e similares. Áreas não tão próximas ao assunto aqui abordado. Contudo, 79\% desses alunos com experiência em engenharia de software são pós graduando e 36\% estudam assuntos na área da Tecnologia da Informação, que neste caso, os alunos estão mais propensos ao contato com os assuntos aqui abordados.

Para as experiências prévias, ilustradas entre as tabelas 18 à 23, os alunos, em termos gerais, informaram terem poucas experiências em: BPM, BPMN, Requisitos não funcionais, Planejamento/Plano estratégico e metas estratégicas organizacionais e KPI. Exceto a respeito de Planejamento/Plano estratégico e metas estratégicas organizacionais entre os alunos que usaram o KPI2BLA, que $43 \%$ informaram ter experiência prévia. O fato de existir pouca experiência nesses assuntos, significa que as experiências profissionais e/ou tempo de experiência foram determinantes na execução das tarefas, pois pode testar das abordagem se para este nível de usuário a abordagem auxiliaria. Outro fato é que os alunos informarem que a abordagem KPI2BLA é fácil, benéfica e viável (50\%, 79\% e 86\%) mesmo com pouca e/ou média experiência, isto é um indicio de que a abordagem auxilia na modelarem. E também aumenta a credibilidade da avaliação por tratar de alunos que tem pouco conhecimento nos assuntos e ainda assim foi possível executar as tarefas, principalmente os que usaram o KPI2BLA. 


\section{Conclusão}

BPM tornou-se essencial às organizações na busca de vantagem competitiva por meio da melhoria de seus processos de negócio. BPM pode favorecer o alinhamento estratégico entre áreas de negócio e TI, sendo a TI um dos responsáveis finais pelo alcance de metas estratégicas organizacionais (GALAS; PONTE, 2006). Dentro desse contexto, requisitos não funcionais precisam ser tratados corretamente para facilitar a obtenção tanto de alinhamento estratégico quanto de vantagem competitiva (PRESSMAN; MAXIM, 2014).

Este trabalho de mestrado busca propor uma abordagem que possa auxiliar neste contexto, por meio da extensão do framework StrAli-BPM. A extensão aqui proposta visa apresentar mecanismos para que os KPIs relevantes possam ser usados para o levantamento de requisitos não funcionais a comporem os modelos de processo de negócio, na forma de BLAs. O KPI e suas propriedades foram exploradas na abordagem visando auxilar na coleta dos requisitos não funcionais das metas estratégicas organizacionais. De pose das informações extraídas do KPI e a correta criação dos BLAs, esses BLAs poderão ser mapeados para SLAs ligados à implementação do processo de forma a auxiliar no alinhamento estratégico completo dentro dos diferentes níveis organizacionais: estratégico, tático e operacional.

Para preencher esta lacuna, fez-se necessário definir um metamodelo que exibe entidades, e os relacionamentos entre elas (no contexto das metas estratégicas organizacionais e KPIs). E, como resultado do relacionamento entre as entidades, é gerado um template (chamado de KPI2BLA) que contempla a estrutura necessária para representação dos requisitos não funcionais extraídos do KPI e contendo informações necessárias para a criação de BLA. Alguns tratamentos para auxiliar o relacionamento entre o template KPI2BLA e o BLA@BPM foram necessários, porém a maioria dos relacionamentos ocorreram de forma direta.

Buscando avaliar a abordagem, um protótipo de ferramenta computacional foi desenvolvido para auxiliar nesta tarefa. O protótipo auxilia desde a criação das metas estratégicas organizacionais, das métricas, do KPI e, por fim, a criação do BLA. Em continuidade ao processo de avaliação, uma turma da Universidade de São Paulo da disciplina de Gestão Computacional em Processos de Negócio foi submetida a tarefa de criação de BLA, ou via ad hoc ou KPI2BLA. 
Como resultado da avaliação da abordagem, foi possível concluir que o KPI2BLA contribui no processo de modelagem de BLA. No entanto, algumas limitações foram identificadas e são apresentadas na seção de trabalhos futuros.

Por fim, uma consequência resultante deste trabalho é o auxilio à comunicação mais eficiente e mais assertiva entre o negócio e a TI, no contexto de alto nível da organização, aonde as metas estratégicas organizacionais são definidas. Devido este auxílio na comunicação entre o negócio e a TI, a TI deverá estar alinhada às metas organizacionais, assim, poderá dar mais apoio aos objetivos organizacionais possibilitando alcançá-los oferecendo um diferencial em relação ao mercado e um posicionamento estratégico mais rápido. Outro ponto em que este trabalho contribui é no auxílio a tomada de decisão organizacional, pelo fato de prover meios para controlar às metas estratégicas organizacionais e contextualizar com a gestão de processo de negócio.

\subsection{Trabalhos futuros}

O escopo deste trabalho de mestrado ficou limitado à criação do conteúdo de BLAs com base nas informações extraídas de KPIs. Assim, não fez parte desse escopo a definição de quais subprocessos do modelo em BPMN teria BLAs associados. O esperado para essa abordagem de forma completa é que: (i) baseado em um conjunto de KPIs, seja possível identificar quais desses KPIs são valiosos para um determinado modelo de processo de negócio para o qual requisitos não funcionais na forma de BLA devem ser especificados; (ii) a partir do conjunto de KPIs selecionados, o esperado é que um especialista consiga, com o apoio da abordagem KPI2BLA identificar quais BLAs devem ser criados para tal modelo de processo de negócio, incluindo a seleção dos respectivos subprocessos que estarão associados a cada um dos BLAs sendo definidos; (iii) por fim, o conteúdo dos KPIs usados como entrada deveria poder ser usado para definir o conteúdo dos BLAs definidos e associados a subprocessos de negócio. Atualmente, apenas o item (iii) está sendo coberto, de forma que os dois primeiros itens se configuram como lacunas da abordagem a serem ainda tratadas.

A solução do item (ii), por exemplo, pode ocorrer de duas formas: top down - em que a partir dos KPIs sejam criados/definidos BLAs (associados a subprocessos de negócio existentes no modelo BPMN) que sejam identificados como necessário, ou seja, a existência de KPIs deveria ditar a necessidade de determinados BLAs para um 
modelo de processo de negócio; ou button up - em que a criação de BLAs seria realizada considerando exclusivamente o modelo BPMN apresentado, e, após a criação dos BLAs, os KPIs apropriados seriam buscados para serem usados na definição do conteúdo apropriado para tais BLAs.

Além disso, verifica-se também a oportunidade de usar o Business Activity Monitoring (BAM) em função de suas propriedades de mapeamento de metas estratégicas organizacionais, principalmente por usar KPI como fonte para seu monitoramento e documentos com informações sobre os requisitos não funcionais relacionados às metas estratégicas organizacionais. Apesar de ter como principal objetivo o monitoramento de métricas de negócio, de forma a emitir alertas em tempo de execução, o BAM pode também ser útil como auxílio à definição de BLAs com base em KPIs.

Outra opção para trabalhos futuros é a aplicação da abordagem em um ambiente organizacional com intuito de avaliar a abordagem com variáveis reais e com profissionais experientes. Profissionais que convivam com situações relacionadas às metas estratégicas organizacionais como analistas de negócio ou algum outro relacionado à área de negócio. A partir desta avaliação no ambiente organizacional, a abordagem poderá obter maior credibilidade com relação a sua contribuição e também reduzir a vulnerabilidade. Após a aplicação da abordagem em um ambiente organizacional, efetuar testes de hipótese para reduzir a margem de erro nas conclusões do trabalho.

Outra lacuna deixada pelo trabalho é o fato do protótipo não permitir que um KPI posa gerar vários BLAs. Hoje o protótipo permite apenas que um KPI gere um BLA, no entanto, na definição da abordagem e o modelo criado isso é possível. Outra situação que o protótipo não permite é a partir de vários KPIs gerar um BLA. Resumindo, são duas situações: de um KPI gerar vários BLAs e de vários KPIs gerar um BLA.

É apresentado alguns requisitos não funcionais neste trabalho, que são usados por (FERnÁndeZ; PEnZEnstadleR, 2015) em seu trabalho. Porém, é necessário formalizar melhor quais requisitos não funcionais, além dos abordados no trabalho, e como tratá-los. Por exemplo: requisitos não funcional relacionado a segurança, desempenho e etc.

Em pesquisas posteriores ao final deste trabalho, percebeu-se que o uso da técnica SMART pode ser de valia na busca do tratamento das metas estratégicas organizacionais, se elas são ou não viáveis à organização. O SMART é um acrônimo da língua inglesa que apresenta as seguintes perguntas: S - Specific, o que exatamente é desejado?; M Measurable, é um valor que pode ser medido?; A - Attainable, s meta pode ser alcançável?; R 
- Realistic, faz sentido em uma perspectiva empresarial?; T - Timely, pode ser completado em um período de tempo aceitável? (LAWLOR, 2012). 


\section{Referências $^{1}$}

AALST, W. M. van der. Business process management: A comprehensive survey. ISRN Software Engineering, Hindawi Publishing Corporation, v. 2013, 2013. Citado 3 vezes nas páginas 18, 30 e 31.

ABETI, L.; CIANCARINI, P.; MORETTI, R. Wiki-based requirements management for business process reengineering. In: IEEE. 2009 ICSE Workshop on Wikis for Software Engineering. [S.1.], 2009. p. 14-24. Citado 5 vezes nas páginas 60, 65, 66, 67 e 68.

AGHDASI, M.; MALIHI, S. Rule based business process optimization. In: IEEE. IEEE International Conference on Industrial Engineering and Engineering Management (IEEM). [S.l.], 2010. p. 305-309. Citado 5 vezes nas páginas 17, 33, 60, 65 e 66.

ALAN, R. H. von et al. Design science in information systems research. MIS quarterly, Springer, v. 28, n. 1, p. 75-105, 2004. Citado 2 vezes nas páginas 51 e 52.

ANDRIEUX, A. et al. Web services agreement specification (ws-agreement). In: Open Grid Forum. [S.l.: s.n.], 2007. v. 128, p. 216. Citado na página 42.

ATKINSON, B. et al. Web services security (ws-security). Specification, Microsoft Corporation, 2002. Citado na página 41.

BALDAM, R. et al. Bpm, gerenciamento de processos de negócios. São Paulo: Editora Érica, 2007. Citado 4 vezes nas páginas 28, 31, 32 e 36.

BEHNAM, S. A.; AMYOT, D.; MUSSBACHER, G. Towards a pattern-based framework for goal-driven business process modeling. In: IEEE. Software Engineering Research, Management and Applications (SERA), 2010 Eighth ACIS International Conference on. [S.l.], 2010. p. 137-145. Citado 5 vezes nas páginas 60, 64, 65, 66 e 67.

BIOLCHINI, J. et al. Systematic review in software engineering. Systematic review in software engineering COPPE/UFRJ, Technical Report ES, v. 679, n. 05, p. 45, 2005. Citado 2 vezes nas páginas 53 e 67.

BISOGNO, S. et al. Combining modelling and simulation approaches: How to measure performance of business processes. Business Process Management Journal, v. 22, n. 1, p. 56-74, 2016. Citado 3 vezes nas páginas 62, 65 e 66.

BLOOMFIELD, B. P. et al. Information Technology and Organizations: Strategies, Networks, and Integration: Strategies, Networks, and Integration. [S.l.]: OUP Oxford, 1997. Citado na página 22.

BOCCIARELLI, P.; D'AMBROGIO, A. A BPMN extension for modeling non functional properties of business processes. In: SOCIETY FOR COMPUTER SIMULATION INTERNATIONAL. Proceedings of the 2011 Symposium on Theory of Modeling 8 Simulation: DEVS Integrative MES Symposium. [S.1.], 2011. p. 160-168. Citado na página 66.

BOCCIARELLI, P.; D'AMBROGIO, A. A model-driven method for enacting the design-time QoS analysis of business processes. Software and Systems Modeling, v. 13, n. 2, p. 573-598, 2014. Citado 5 vezes nas páginas 36, 61, 64, 65 e 66.

1 De acordo com a Associação Brasileira de Normas Técnicas. NBR 6023. 
BRATANIS, K.; DRANIDIS, D.; SIMONS, A. J. Towards run-time monitoring of business-level agreements for web services. In: Proceedings Of the 5th Annual South East European Doctoral Student Conference. [S.1.: s.n.], 2010. p. 370-379. Citado 3 vezes nas páginas 18, 42 e 43.

BRODBECK, Â. F.; HOPPEN, N. Alinhamento estratégico entre os planos de negócio e de tecnologia de informação: um modelo operacional para implementação. Revista de Administração Contemporânea, SciELO Brasil, v. 7, n. 3, p. 9-33, 2003. Citado 2 vezes nas páginas 23 e 24.

CABEZA, L. F. et al. Key performance indicators in thermal energy storage: Survey and assessment. Renewable Energy, Elsevier, v. 83, p. 820-827, 2015. Citado na página 26.

CORTES-CORNAX, M. et al. Intentional fragments: Bridging the gap between organizational and intentional levels in business processes. In: On the Move to Meaningful Internet Systems: OTM 2012. [S.l.]: Springer, 2012. p. 110-127. Citado 3 vezes nas páginas 62,65 e 66.

DER, W. M. V. Business process management demystified: A tutorial on models, systems and standards for workflow management. In: Lectures on concurrency and Petri nets. [S.l.]: Springer, 2004. p. 1-65. Citado na página 30.

DUMAS, M. et al. Fundamentals of business process management. [S.l.]: Springer, 2013. Citado 3 vezes nas páginas 16, 30 e 34 .

FAWAZ, W. et al. Service level agreement and provisioning in optical networks. Communications Magazine, IEEE, IEEE, v. 42, n. 1, p. 36-43, 2004. Citado na página 40.

FERNÁNDEZ, D. M.; PENZENSTADLER, B. Artefact-based requirements engineering: the amdire approach. Requirements Engineering, Springer, v. 20, n. 4, p. 405-434, 2015. Citado 4 vezes nas páginas 27, 29, 38 e 115.

FLORIO, L.; SALLES, G. B.; FANTINATO, M. Apoiando alinhamento estratégico em organizações usando contratos eletrônicos estendidos com BLA. In: SOCIEDADE BRASILEIRA DE COMPUTAçãO. VIII Simp. Bras. de Sist. de Inf. - Trilhas Técnicas. [S.l.], 2012. p. 348-359. Citado 3 vezes nas páginas 16, 17 e 18.

GALAS, E. S.; PONTE, V. M. R. O balanced scorecard e o alinhamento estratégico da tecnologia da informação: Um estudo de casos múltiplos. Revista Contabilidade $\mathscr{G}$ Finanças, v. 17, n. 40, p. 37-51, 2006. Citado 2 vezes nas páginas 23 e 113.

HENDERSON, J. C.; VENKATRAMAN, H. Strategic alignment: Leveraging information technology for transforming organizations. IBM systems journal, International Business Machines Corporation, v. 38, n. 2/3, p. 472, 1999. Citado 3 vezes nas páginas 22, 23 e 24.

JESTON, J.; NELIS, J. Business process management. [S.l.]: Routledge, 2014. Citado na página 30.

KARAGIANNIS, D.; RONAGHI, F.; FILL, H.-G. Business-oriented it management: developing e-business applications with e-bpms. In: ACM. Proceedings of the ninth international conference on Electronic commerce. [S.l.], 2007. p. 97-100. Citado 2 vezes nas páginas 27 e 28. 
KEELE, S. Guidelines for performing systematic literature reviews in software engineering. In: CITESEER. Technical report, Ver. 2.3 EBSE Technical Report. EBSE. [S.1.], 2007. Citado 3 vezes nas páginas 53, 54 e 57.

KOLÁR, J. Business activity monitoring. Unpublished Master Thesis. Masaryk University, 2009. Citado na página 26.

KOTONYA, G.; SOMMERVILLE, I. Requirements engineering with viewpoints. Software Engineering Journal, IET, v. 11, n. 1, p. 5-18, 1996. Citado 2 vezes nas páginas 38 e 44.

LAPADULA, A.; PUGLIESE, R.; TIEZZI, F. Using formal methods to develop ws-bpel applications. Science of Computer Programming, Elsevier, v. 77, n. 3, p. 189-213, 2012. Citado na página 37.

LAWLOR, K. B. Smart goals: How the application of smart goals can contribute to achievement of student learning outcomes. Developments in Business Simulation and Experiential Learning, v. 39, 2012. Citado na página 116.

LETSHOLO, K.; CHIOASCA, E.-V.; ZHAO, L. An integration framework for multi-perspective business process modeling. 2012. 33-40 p. Citado 3 vezes nas páginas 62, 65 e 66.

LEVIN, R. The importance of key performance indicators. Jornal of the American Dental Assocociation, 2012. Citado na página 16.

LEVIN, R. P. The importance of key performance indicators. Journal of the American Dental Association (1939), v. 143, n. 11, p. 1248, 2012. Citado na página 26.

LUFTMAN, J.; PAPP, R.; BRIER, T. Enablers and inhibitors of business-it alignment. Communications of the AIS, Association for Information Systems, v. 1, n. 3es, p. 1, 1999. Citado na página 23.

MARKOVIC, I.; KARRENBROCK, M. Semantic web service discovery for business process models. p. 272-283, 2007. Citado 4 vezes nas páginas 59, 65, 66 e 68.

MELO, C. et al. Towards an Organizational Strategic Alignment Driven by Business Level Agreements. 2014. 98-109 p. Citado na página 42.

MOORSEL, A. V. Metrics for the internet age: Quality of experience and quality of business. In: CITESEER. Fifth International Workshop on Performability Modeling of Computer and Communication Systems, Arbeitsberichte des Instituts für Informatik, Universität Erlangen-Nürnberg, Germany. [S.l.], 2001. v. 34, n. 13, p. 26-31. Citado 2 vezes nas páginas 40 e 41.

OUYANG, C. et al. Formal semantics and analysis of control flow in ws-bpel. Science of Computer Programming, Elsevier, v. 67, n. 2, p. 162-198, 2007. Citado na página 37.

PAPAZOGLOU, M. P. Service-oriented computing: Concepts, characteristics and directions. In: IEEE. Proceedings of the Fourth International Conference on Web Information Systems Engineering. [S.1.], 2003. p. 3-12. Citado na página 36.

PARMENTER, D. Key performance indicators: developing, implementing, and using winning KPIs. [S.1.]: John Wiley \& Sons, 2015. Citado 2 vezes nas páginas 25 e 26. 
PIERANTONIO, A. et al. Metamodeling architectures for business processess in organizations. Projects Showcase@ STAF'15, p. 27, 2015. Citado 2 vezes nas páginas 28 e 29.

POURSHAHID, A. et al. Business process management with the user requirements notation. Electronic Commerce Research, v. 9, n. 4, p. 269-316, 2009. Citado 5 vezes nas páginas 33, 59, 64, 65 e 66.

POURSHAHID, A. et al. A systematic review and assessment of aspect-oriented methods applied to business process adaptation. Journal of Software, v. 7, n. 8, p. 1816-1826, 2012. Citado 5 vezes nas páginas 61, 64, 65, 66 e 67.

PRESSMAN, R. S.; MAXIM, B. Engenharia de software: A Practitioner's Approach. [S.l.]: AMGH Editora, 2014. Citado 2 vezes nas páginas 17 e 113.

ROUX, C.; THÖNI, C. Do control questions influence behavior in experiments? Experimental Economics, Springer, v. 18, n. 2, p. 185-194, 2015. Citado na página 93.

RUOKONEN, A.; PAJUNEN, L.; SYSTÄ, T. Scenario-Driven approach for business process modeling. In: IEEE. Web Services, 2009. ICWS 2009. IEEE International Conference on. [S.l.], 2009. p. 123-130. Citado 6 vezes nas páginas 33, 63, 65, 66, 67 e 68.

SALLES, G. et al. A contribution to organizational and operational strategic alignment: Incorporating business level agreements into business process modeling. In: IEEE. 2013 IEEE International Conference on Services Computing (SCC). [S.1.], 2013. p. 17-24. Citado 3 vezes nas páginas 34, 39 e 43.

SAlLES, G. B. M. Tratamento de Acordos em Processos de Negócio: Em Busca de Alinhamento Estratégico. Dissertação (Mestrado) - Univ. de São Paulo, SP - Brasil, 2014. Citado 14 vezes nas páginas 16, 18, 32, 37, 38, 43, 44, 46, 47, 49, 50, 73, 74 e 91.

SCHEER, A.-W.; SCHNEIDER, K. Aris - architecture of integrated information systems. In: Handbook on architectures of information systems. [S.l.]: Springer, 1998. p. 605-623. Citado na página 28.

SKENE, J.; LAMANNA, D. D.; EMMERICH, W. Precise service level agreements. In: IEEE COMPUTER SOCIETY. Proceedings of the 26th International Conference on Software Engineering. [S.1.], 2004. p. 179-188. Citado na página 40.

SOLINGEN, R. V. et al. Goal question metric (gqm) approach. Encyclopedia of software engineering, Wiley Online Library, 2002. Citado na página 90.

SOMMERVILLE, I.; KOTONYA, G. Requirements engineering: processes and techniques. [S.l.]: John Wiley \& Sons, Inc., 1998. Citado na página 38.

SOUSA, H. P.; LEITE, J. C. S. do P. Modeling organizational alignment. In: SPRINGER. Conceptual Modeling. [S.l.], 2014. p. 407-414. Citado 2 vezes nas páginas 16 e 36.

SPITZER, D. R. Transforming performance measurement: Rethinking the way we measure and drive organizational success. [S.l.]: AMACOM Div American Mgmt Assn, 2007. Citado na página 25.

VEDAMUTHU, A. S.; HONDO, M.; YALÇINALP, Ü. Web services policy 1.5-framework 2. Citeseer, 2007. Citado na página 41. 
WESKE, M. Business process management architectures. Business Process Management: Concepts, Languages, Architectures, Springer, p. 305-343, 2007. Citado na página 17.

WHITE, S. A. Introduction to bpmn. IBM Cooperation, v. 2, n. 0, p. 0, 2004 . Citado na página 33.

XAVIER ALENCAR, C. P. Integração de requisitos não funcionais a processos de negócios: Integrando BPMN e NFR. In: 13th Workshop em Engenharia de Requisitos (WER 2010). [S.l.: s.n.], 2010. p. 29-40. Citado 2 vezes nas páginas 16 e 38. 
Apêndices 
Apêndice A

Artigo submetido ao 


\title{
An Analysis of Strategic Goals and Non-Functional Requirements in Business Process Management
}

\author{
Author $\mathrm{A}^{1}$, Author $\mathrm{B}^{2}$, Author $\mathrm{C}^{3}$ \\ ${ }^{1}$ Affiliation $A$ \\ ${ }^{2}$ Affiliation $B$ \\ ${ }^{3}$ Affiliation $C$ \\ email A, email B, email C
}

Keywords: Strategic Alignment, Strategic Goals, Business Processes, Non-Functional Requirements, Systematic Review.

Abstract: Organizations increasingly rely on Information Technology (IT) to achieve their strategic goals. As a consequence, business processes implemented by IT should be aligned with the organizational strategic goals. Business processes' Non-Functional Requirements (NFR) can be used to foster such a strategic alignment. Our goal was to evaluate to what extent there are approaches that seek to support the modeling of business processes' NFR based on strategic goal-related information and the features of the found approaches. To achieve this goal, we conducted a literature study based on systematic review concepts. As a result, we identified 19 works addressing strategic goals and business processes with NFRs. The most commonly used techniques are: $i^{*}$ and Key Performance Indicators (KPI) for modeling strategic goals and Business Process Model and Notation (BPMN) for modeling business processes. According to our analysis, no approach fully addresses business processes' NFR based on strategic goals which was our primary question in conducting this study.

\section{INTRODUCTION}

Organizations need the support of Information Technology (IT) to quickly evolve their business processes and gain competitive edge (Lee et al., 2011). However, the strategic alignment between business and IT is required to achieve this dynamism (Tallon, 2008).Strategic alignment enables efficient communication among the strategic, tactical and operational levels of an organization (Sousa and Leite, 2014).

Business Process Management (BPM) can support strategic alignment. However, only addressing both functional requirements and Non-Functional Requirements (NFR) throughout the BPM lifecycle, a complete strategic alignment between business and IT can be achieved. Nevertheless, while functional requirements have been well explored BPM, NFRs have been neglected (Salles et al., 2013).

A good practice is to use strategic goals to identify business processes' NFRs since strategic goals represent the major organizational interests, which in turn need to be mapped to business processes. Strategic goals are fundamental to strategic alignment since they are the basis for organizing and planning activities at the tactical and operational levels.

This paper presents the results of a literature study conducted to identify and evaluate approaches that propose using strategic goals as support for modeling business processes' NFRs. Although we could find some published literature studies exploring strategic goals and business processes, none of them was particularly concerned with business processes' NFRs.

This study is characterized as an empirical and qualitative research with some quantitative aspects. As an empirical study, we focused on the search for relevant and convenient data reported through scientific papers that represent prior experiences of other researchers. Our goal was to reach new conclusions in this research subject from the experimental maturity of the works which could be found and evaluated. The selected works were evaluated in a predominantly qualitative way, based on the main information presented in each one. From the quantitative outlook, we do not produce strong statistical evidence since the number of selected works represents a small sample to allow in-depth quantitative analyzes. Some results could be measured in numbers and then classified and analyzed through basic descriptive statistics.

As main results, we identified 19 works addressing strategic goals, business processes and NFRs. The most commonly used techniques are: $i^{*}$ and Key Perfomance Indicators (KPI), for modeling strate- 
gic goals; and Business Process Model and Notation (BPMN), for modeling business processes. According to our analysis, although partial solutions have been found, no approach fully addresses business processes' NFR based on strategic goals which was our primary research question in conducting this study.

The remainder of this paper contains: Section 2 with the necessary background and rationale to this study; Section 3 with a summary of related work; Section 4 with the description of the applied research method; Section 5 with an analysis of the selected works; Section 6 with a discussion of the obtained results; and, finally, Section 7 with the conclusion.

\section{STUDY BACKGROUND}

We present here the main concepts related to this study, i.e., strategic goals, BPM and NFRs.

\subsection{Strategic Alignment and Goals}

Strategic alignment between business and IT refers to the synchronization between these two organization's sides to ensure that the services provided by IT are adherent to the strategic needs of the business areas (Henderson and Venkatraman, 1993). Business areas are those that represent the functions of an organization, such as: finance, human resources, manufacturing, marketing, logistics, accounting etc. Strategic alignment represents the dynamic adequacy of the IT structure and tasks so that it is always in tune with the organization's business areas, which represent the IT's customers (Henderson and Venkatraman, 1993).

Strategic goals are used to foster strategic alignment. Strategic goals are qualitative or quantitative values to be achieved at a predetermined future time. They represent business or organizational requirements (Janes and Faganel, 2013). Examples of strategic goals are: "increasing customer satisfaction to $99 \%$ by 2020 " and "reducing project execution time by $25 \%$ over the next two years". Once modeled, strategic goals are used as the basis for setting expectations and aligning communication among different organization areas, including the business areas and IT. Each business area can model specific subgoals, which rely on IT services to be met.

IT solutions applied in line with strategic goals lead to business success (De Bruin and Rosemann, 2006). By focusing on the processes and projects that most add value to the business, IT is seen as an asset (i.e., a revenue generator) and not as a liability (i.e., an expense source). A strategic goal consists of: description, expected benefits, ways to achieve it, and ways to measure its achievement (Plösch et al., 2011). Most organizations represent strategic goals via KPI, which support the systematic definition and measurement of strategic goals. KPIs can model quantitative indicators, which are measurable and useful for monitoring the progress and success of strategic goals (Parmenter, 2015). Good KPIs follow the SMART logic, which is an acronym for: Specific (i.e., target a specific area for improvement), Measurable (i.e., quantify or at least suggest an indicator of progress), Assignable (i.e., specify who will do it), Realistic (i.e., state what results can realistically be achieved, given available resources) and Time-related (i.e., specify when the results can be achieved) (Doran, 1981).

Organizations can manage their business goals via KPIs (Parmenter, 2015). Business analysts interpret the combination of KPIs and their target values as goals (e.g., "order approval time up to three days") (Wetzstein et al., 2009). Metrics varying during process execution can influence KPIs, and IT services can influence these metrics (e.g., "processing time", "results accuracy", "services availability" etc.). Thus, KPIs are specified based on business goals matched with expected values, which are transformed into targets, including delimitations of deviations below and above the expected value (Friedenstab et al., 2012).

The $i^{*}$ framework presents important characteristics for this context. The $\mathrm{i}^{*}$ framework is a goalbased technique, used to model organizational contexts based on dependencies among actors (Yu et al., 1996). The $i *$ framework uses: actor, role, dependency, goal, softgoal, resource and task. It aims to model the involved actors (whose behavior is abstractly characterized by roles) and the dependencies among them, so that their goals are reached, resources are provided, tasks are performed and softgoals are minimally fulfilled (Yu et al., 1996). This technique is driven by a set of organizational goals to be achieved. A goal represents a condition or state that stakeholders want to achieve. Goals (also called rigid goals or concrete goals) are complemented by softgoals, which represent conditions or a state that the stakeholders wish to achieve, but without a clear definition of the expected values. Softgoals in $i^{*}$ share some concepts and aims with strategic goals in KPIs.

Other techniques to model strategic goals are: Tropos, Security i* (Si*), Balanced Scorecard (BSC), Keep All Objectives Satisfied (KAOS), User Requirements Notation (URN) / Goal-oriented Requirements (GRL), Unified Modeling Language (UML) diagrams, Business Activity Monitoring (BAM), among others. Although all these techniques are applicable to strategic goal modeling, they can target different purposes and work in different degrees of abstraction. 


\subsection{Business Process Management}

BPM is an interdisciplinary area that involves aspects of business administration and information systems to manage business processes supported by automated systems. A business process consists of tasks performed by an organization, in a specific sequence, to achieve a specific goal (Weske, 2012). Examples of business processes are: "granting real estate credit by a financial organization" and "enrollment of new students by an educational organization".

BPM aims to organize work to ensure consistent results and take advantage of opportunities for improvement (Dumas et al., 2013). BPM includes concepts, techniques and tools to support technical and managerial aspects of business processes (van der Aalst et al., 2003). The BPM lifecycle includes the following phases: (i) process modeling; (ii) process implementation; (iii) process execution and administration; ( $i v)$ process monitoring and auditing; and ( $v$ ) process evaluation and improvement (Weske, 2012).

BPM contributes to achieve the strategic alignment between business and IT via management and improvement of technological solutions related to organizational value-added business processes (Fantinato et al., 2010). BPM enables one to transform the dialog between business and IT in an interactive and iterative approach. BPM combines top-down strategic vision with bottom-up continuous improvement.

Modeling business process means represent generically all actions and decisions that can be performed during process execution, considering that different actions can be performed for specific cases. The main notation currently used by organizations for this goal is BPMN (Kocbek et al., 2015). BPMN allows to model business processes assuming their execution through the integration of services offered by various information systems. Before the emergence of BPMN, many organizations adapted the UML activity diagrams for this goal (Mili et al., 2010), which are focused on software internal processes.

Other techniques to model business processes are: Event-driven Process Chains (EPC), Role Activity Diagrams (RAD), User Requirements Notation (URN) / Use Case Maps (UCM), Integrated DEFinition's Process Description Capture (IDEF3), Yet Another Workflow Language (YAWL), Petri nets, Finite State Machines (FSM), among others.

\subsection{Non-Functional Requirements}

NFRs are used primarily in software engineering, although this concept is adaptable to other types of products (or services) (Pressman, 2009; Sommerville,
2010). A requirement is a condition, property or capability that a product must meet. A functional requirement defines a behavior - including inputs and outputs - that a product must perform. NFRs define constraints on how a function can or should be used, associated with minimum levels of quality.

NFRs typically relate to performance, usability, availability, security, technologies that should be used, and constraints on the development process (Pressman, 2009). NFRs should consider customer needs. Failure to meet certain NFRs may render the entire product ineffective (Sommerville, 2010).

The concept of requirements, both functional and non-functional, can be mapped from software engineering to BPM by considering business processes as the product being developed (Charfi and Zhi, 2015). In BPM, functional requirements represent what the business process must perform while NFRs represent quality constraints which need to be met during the process execution. Typical examples of NFRs of software engineering may also be used in BPM such as those related to performance and usability. For example, "a sequence of activities in a business process must run within a maximum of 24 hours".

NFRs are commonly declared late and informally during product development, making it difficult their enforcement (Pressman, 2009; Sommerville, 2010). This weakness is evident in BPM by BPMN not supporting NFRs (Bocciarelli and D'Ambrogio, 2014). Moreover, some techniques that have been proposed to represent business processes' NFRs have not fully addressed the problem. Such techniques usually address only how to represent NFRs without addressing the source of information needed to model them (Salles and Fantinato, 2012).

Considering the need for strategic alignment, a business process should be implemented and executed in line with the strategic goals linked to the scope that encompasses this process. This alignment could be supported by NFRs specified in the business process model, which is used to guide the process implementation. Thus, a strategic goal would be represented in a process model via NFRs, which would in turn be used to support the process implementation.

\section{RELATED STUDIES}

This section presents an analysis of works related to our study, i.e., other reviews - systematic or not - with a purpose similar to ours. We identified six BPM-related reviews that address some aspect of strategic goals. None of the identified reviews fully meets the purpose of our literature study 
that is "identifying and assessing approaches that use strategic goals as support for modeling business processes' NFRs". In addition, several of the identified reviews have been driven to specific contexts such as aspect-orientation (Pourshahid et al., 2012) and service choreography (Leite et al., 2013) while our study is intended to be context free.

Evidence that these previously published reviews have purposes other than our literature study is the low overlap of selected papers among them. One of the related reviews evaluated 19 papers, of which four are also the target of our study, which represents about only $20 \%$ of overlap. However, this existing review presents a broader purpose - "investigating goaloriented requirements engineering for business processes" (Poels et al., 2013) in a generic way rather than focused on NFRs. The only other existing overlap refers to a single work also evaluated in another review whose main purpose is to evaluate "compliance measurement based on goals and indicators" (Shamsaei et al., 2011). Its authors do not specifically address the representation of business processes' NFRs; instead, they are concerned with a following step, i.e., measuring how much business processes comply to strategic goals. We do not identified any other overlap of our study with some other identified review.

Two additional related reviews were found, but also without addressing the same target of our study, and only tangentiating it. The first one presents a very wide proposal, which is "business process modeling challenges and solutions" (Alotaibi, 2014). Like other existing reviews, this one is not concerned with the representation of business processes' NFRs. Finally, the latest identified review is concerned with "business process modeling quality" (de Oca et al., 2015), assuming that the quality of process modeling is key to achieving strategic goals. Its authors are focused on identifying approaches that analyze whether process models have quality and whether such quality influences strategic alignment.

\section{RESEARCH METHOD}

This literature study was based on systematic review concepts. A systematic review refers to the identification, evolution and interpretation of all available relevant research papers that address the issues defined in a research protocol (Kitchenham and Charters, 2007). Individual studies evaluated in a review are called primary studies, and a systematic review is a secondary study. A systematic review differs from traditional reviews and surveys because it is a transparent, scientific and replicable approach used to avoid bias (Biolchini et al., 2005). To conduct this literature study, the guidelines proposed by Kitchenham and Chartes were used (Kitchenham and Charters, 2007). The following subsections present the study planning and conduction.

\subsection{Need for Literature Study}

No previous literature study has been conducted with the specific goal presented here (cf. Section 3), with which our research group is interested. In addition, given the importance of research relating strategic goals, strategic alignment and BPM, this literature study may be of interest and utility to other researchers and the industry. We have empirically identified that strategic goals can be an important source of information for modeling business processes' NFRs. We intend to work along this train of thought, and hence decided to carry out this study. The main goal was to investigate possible previous approaches in this context to be used as the basis by us and other researchers interested in such subject.

\subsection{Research Questions}

The main research question guiding this study is: "Are there approaches proposed to modeling business processes' NFRs based on strategic goals?"

In addition, in order to better characterize the found approaches, two subquestions were defined:

- What strategic goal modeling techniques are used in the found approaches? Per the rationale presented in Section 2, our empirically raised hypothesis was that KPIs should be the technique most often used to model strategic goals in BPM. Nevertheless, we also expected to find other techniques, including, for example, $\mathrm{i}^{*}$.

- What business process modeling techniques are used in the found approaches? Per the rationale presented in Section 2, our empirically raised hypothesis was that BPMN should be the technique most often used to model business processes in strategic goal-driven BPM. Nevertheless, we also expected to find other techniques, including, for example, UML activity diagrams.

\subsection{Data Sources and Search Strategy}

The selected data sources are Scopus (www.scopus. com) and Web of Science (pcs.webofknowledge. com). Both databases together provide access to papers published and indexed by leading international publishers in the area of interest, including IEEE, ACM, Springer, among several others. 
As for the search strategy, we created a search string that expresses the goals of this literature study and should filter papers that could answer our research questions. The following basic search string was created, without the syntax influences of each data source's search engine: ("business process model" OR BPMN OR "activity diagram" OR "use case maps" OR UCM OR "event-driven process chain" OR EPC OR "integrated definition" OR "process description capture" OR IDEF3 OR "role activity diagram" OR RAD OR "yet another workflow language" OR YAWL OR "petri nets" OR "state machine" OR statecharts) AND ("strategic goal" OR "business goal" OR "business requirement" OR "organizational requirement" OR "key performance indicator" OR KPI OR $i *$ OR Si* OR "balanced scorecard" OR BSC OR "keep all objectives satisfied" OR KAOS OR "user requirements notation" OR URN OR "goal-oriented requirements" OR GRL OR "business activity monitoring" OR BAM).

Overall, we searched for papers addressing concepts related to both "business process modeling" and "strategic goals". To increase the chance of finding all related papers, we also used different expressions identified as synonyms or related to business process modeling and to strategic goals, which are resulting of an exploratory study of the area. For "business process modeling", we also used the names and acronyms for the most important process modeling notations and languages as introduced in Section 2.2. Moreover, for "strategic goals", we used similar or related expressions as presented in Section 2.1 and 2.3.

\subsection{Selection Strategy}

We specified Inclusion Criteria (IC) and Exclusion Criteria (EC) aiming to ensure that only papers actually related to the investigated context were selected as primary studies for this literature study. Each result returned by the search engines, in order to be selected for this literature study, should satisfy both inclusion criteria and not be eliminated by any of the exclusion criteria. The defined criteria are presented below.

\section{Inclusion criteria:}

- IC-1: the paper addresses strategic goals.

- IC-2: the paper addresses process modeling.

- IC-3: the paper addresses NFRs at some level.

\section{Exclusion criteria:}

- EC-1: the paper is not available on the web.

- EC-2: the publication is not a peer-reviewed scientific paper such as: technical reports, books, book chapters, proceedings preface, journal editorials, master's dissertations, doctoral theses.

- EC-3: the paper is not written in English.

- EC-4: the paper is not primarily related to information systems or business administration.

- EC-5: business processes are addressed in the scope of software engineering instead of BPM.

\subsection{Paper Selection}

Paper selection was performed in three steps (cf. Figure 1) described as follows (Kitchenham and Charters, 2007). Table 1 presents the list of the works selected as primary studies for this literature study.

Figure 1: Identification and selection of primary studies

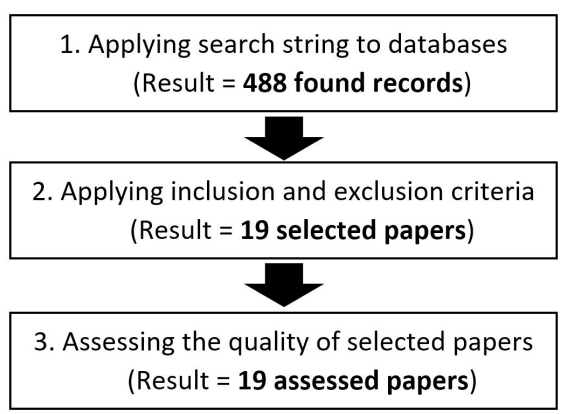

Step 1. Applying search string to databases: the search string was submitted to the chosen data sources. As a result, 465 records were obtained in Scopus and 215 in Web of Science. Disregarding those repeated, 488 initial records were obtained.

Step 2. Applying inclusion and exclusion criteria: each record resulting from the search described in the previous step was subjected to the inclusion and exclusion criteria. For this, we analyzed the following parts of each paper: title, abstract and keywords. For some cases, a more thorough reading of the content of the paper was required. Based on this analysis, papers that did not meet the criteria were removed. When two similar papers of the same authors were found, only the most up-to-date and complete one was chosen. As a result, 19 primary studies were selected.

Step 3. Assessing the quality of selected papers: the exclusion criteria EC-1, EC-2 and EC-3 were used as quality criteria. For the first case (EC-1), we assumed that the unavailability of a paper on the web is an indication of lack of quality of the publication vehicle, considering the current web readiness. For the second case (EC-2), we considered that papers peerreviewed have a higher quality assurance than those papers that have not undergone this type of review process before publication such as invited book chapters. Finally, for the third case (EC-3), we assumed 
Table 1: Final list of the 19 works selected as primary studies

\begin{tabular}{|c|c|c|c|}
\hline Id & Paper title & Paper reference & $\mathbf{P T}^{a}$ \\
\hline P01 & A Framework for Integrating Business Processes and Business Requirements & (Kazhamiakin et al., 2004) & $\mathrm{C}$ \\
\hline $\mathrm{P} 02$ & $\begin{array}{l}\text { B-SCP: A requirements analysis framework for validating strategic alignment of } \\
\text { organizational IT based on strategy, context, and process }\end{array}$ & (Bleistein et al., 2006) & $\mathrm{J}$ \\
\hline P03 & A combined approach for supporting the business process model lifecycle & (Koliadis et al., 2006) & $\mathrm{C}$ \\
\hline $\mathrm{P} 04$ & $\begin{array}{l}\text { Requirements-driven design and configuration management of business pro- } \\
\text { cesses }\end{array}$ & (Lapouchnian et al., 2007) & $\mathrm{C}$ \\
\hline P05 & Business process management with the user requirements notation & (Pourshahid et al., 2009) & $\mathrm{J}$ \\
\hline P06 & Scenario-driven approach for business process modeling & (Ruokonen et al., 2009) & $\mathrm{C}$ \\
\hline P07 & Wiki-based requirements management for business process reengineering & (Abeti et al., 2009) & $\mathrm{C}$ \\
\hline P08 & Rule based business process optimization & (Aghdasi and Malihi, 2010) & $\mathrm{C}$ \\
\hline P09 & Towards a pattern-based framework for goal-drive & (Behnam et al., 2010) & $\mathrm{C}$ \\
\hline P10 & Synthesizing enterprise strategic model and business processes in active-i* & (Xu et al., 2010) & $\mathrm{C}$ \\
\hline P11 & $\begin{array}{l}\text { A method for eliciting goals for business process models based on non- } \\
\text { functional requirements catalogues }\end{array}$ & (Cardoso et al., 2011) & $\mathrm{J}$ \\
\hline $\mathrm{P} 12$ & Extending BPMN for business activity monitoring & (Friedenstab et al., 2011) & $\mathrm{C}$ \\
\hline P13 & An integration framework for multi-perspective business process modeling & (Letsholo et al., 2012) & $\mathrm{C}$ \\
\hline P1 & Event-driven manuf: & h and Álvaro, 2012) & $\mathrm{J}$ \\
\hline P15 & $\begin{array}{l}\text { A bi-directional mapping between } \mathrm{i} \text { and BPMN models in the context of business } \\
\text { process management }\end{array}$ & (Alves et al., 2013) & $\mathrm{C}$ \\
\hline P16 & $\begin{array}{l}\text { Making a link between strategy and process model collections: A multi-layered } \\
\text { approach }\end{array}$ & (Dallilo et al., 2014) & $\mathrm{C}$ \\
\hline P17 & Modeling organizational alignment & and Leite, 2014) & $\mathrm{C}$ \\
\hline P18 & $\begin{array}{l}\text { Combining modelling and simulation approaches: How to measure performance } \\
\text { of business processes }\end{array}$ & (Bisogno et al., 2016) & $\mathrm{J}$ \\
\hline P19 & $\begin{array}{l}\text { A framework for systematic analysis and modeling of trustworthiness require- } \\
\text { ments using } i^{*} \text { and BPMN }\end{array}$ & $\begin{array}{l}\text { (Mohammadi and Heisel, } \\
\text { 2016) }\end{array}$ & $\mathrm{C}$ \\
\hline
\end{tabular}

that papers not published in English also present an indication of lack of quality considering the use of English as a universal language. No extra paper was removed since no new criterion was used for this step.

\section{ANALYSIS OF THE SELECTED WORKS}

We present here a discussion of the selected works, per Table 1, following their publication order. We focused on highlighting how the approaches deal with modeling of strategic goals and their mapping to business processes' NFRs. All acronyms and initialisms used in this section are defined in Section 2, except for those not yet presented in the text.

[P01] "A Framework for Integrating Business Processes and Business Requirements" (Kazhamiakin et al., 2004): this paper proposes a framework for representing strategic goals using Tropos and implementing related processes through web services orchestrated by Web Services Business Process Execution Language (WS-BPEL). This framework does not provide an intermediate step of process modeling prior to its implementation in WS-BPEL. Formal annotations are used at all levels to model constraints to business requirements and to processes. Tropos' softgoals are used to describe NFRs at the business requirements level, but no clear direction of how map them to the web services orchestrations is presented.

[P02] "B-SCP: A requirements analysis framework for validating strategic alignment of organizational IT based on strategy, context, and process" (Bleistein et al., 2006): this paper proposes cross-referencing processes with organizational goal models and context diagrams. Tasks, goals and softgoals are modeled in $\mathrm{i}^{*}$ models, which are integrated with context diagrams, and in turn are integrated with RADs to model the processes. In the end, activities and state descriptions in RADs are cross-referenced with $i^{*}$, i.e., processes in RADs are linked to goals in $i^{*}$. Softgoals representing NFRs in $i^{*}$ are mapped to $\mathrm{RAD}$ in terms of specific types of actions, i.e., they are addressed as functional elements.

[P03] "A combined approach for supporting the business process model lifecycle" (Koliadis et al., 2006): this approach addresses the management of process change throughout the BPM lifecycle supported by combined notations. $i^{*}$ models are used for the organizational context, representing strategic goals, and BPMN for the operational context, representing the process model. The authors' intent is to provide a way of expressing changes, which arise 
in one model, effectively in the other model. With this purpose, they present constrained development methodologies capable of guiding an analyst when reflecting changes from an $i^{*}$ model to a BPMN model and vice-versa. As BPMN does not support the modeling of NFRs, the softgoals specified using $i *$ for the organizational context cannot be mapped to the process model. No clear direction is presented on the treatment of NFRs through this approach.

[P04] "Requirements-driven design and configuration management of business processes" (Lapouchnian et al., 2007): this paper proposes an approach that uses goal models to address process configurations to tailor deployed process aiming to meet non-functional requirements, which represent business priorities or customer preferences. No specific technique is used to model strategic goals, although the used technique is like $i^{*}$. NFRs are hence modeled as softgoals in the goal models. Processes are implemented through WS-BPEL and they are configured considering the goal models, including their softgoals. Like paper [P01], this approach does not provide for an intermediate step of process modeling prior to its implementation in WS-BPEL. The emphasis of this approach is on goal-driven process variability. NFRs are not directly addressed at the process level; instead, processes' functional requirements are configured (i.e., chosen) based on the goal models' NFRs represented as softgoals.

[P05] "Business process management with the user requirements notation" (Pourshahid et al., 2009): this approach is based on URN extended with KPI, including GRL for modeling goals and UCM for modeling processes. A URN-based framework provides process monitoring and performance management capabilities integrated across the BPM lifecycle. KPIs are used to model NFRs linked to processes models since they are not supported by UCM. In summary, GRL supports goals and softgoals, which are used for the functional modeling of processes, and in turn must be tied to KPIs representing its NFRs.

[P06] "Scenario-driven approach for business process modeling" (Ruokonen et al., 2009): this approach is formed by four steps: first, the essential business requirements, representing strategic goals, are modeled as scenarios using UML sequence diagrams; then, the modeled scenarios are synthesized by a UML state machine, which represents the process model; next, the process model is translated into a process skeleton using a UML activity diagram; and, finally, the process skeleton is implemented in WSBPEL. Although NFRs is a concern which can be addressed by this approach, no clear direction is presented on their treatment through the approach steps.
NFRs can be modeled as exception behavior in scenarios but cannot be directly mapped to process models and hence need to be recovered and addressed only during translation to process skeletons.

[P07] "Wiki-based requirements management for business process reengineering" (Abeti et al., 2009): this paper presents an approach to managing both organizational and system requirements for process reengineering. The proposed method uses requirements acquired by a semantic wiki to partially automate the translation from business requirements description to processes and system artifacts. The semantic wiki is built by means of $\mathrm{Si}^{*}$ concepts which include the modeling of NFRs as softgoals. Processes are specified in terms of UML use case diagram (for the static aspects) and BPMN (for the dynamic interactions). In both UML use case diagram and BPMN, it is not possible to model the NFRs. Therefore, the $\mathrm{Si}^{*}$ softgoals should be mapped to functional requirements at the process level.

[P08] "Rule based business process optimization" (Aghdasi and Malihi, 2010): these authors propose process optimization through changing process model with respect to business goals. KPI-based business rules represent strategic goals, which are mapped to rule-based processes. The authors are concerned with achieving and maintaining strategic alignment by a changing control. It breaks down business goals into subgoals so that the desired performance measures specified in KPIs are met in business rules. NFRs are inherently addressed by the approach since it is proposed as a single framework in which all the concepts involved are systematized in a metamodel.

[P09] "Towards a pattern-based framework for goal-driven business process modeling" (Behnam et al., 2010): related to paper [P05], this paper proposes a goal-driven, pattern-based framework to build processes from organization goals while maintaining traceability between them. Patterns are made up of goal templates and process templates as well as their relationships. As notations, URN/GRL and URN/UCM are respectively used for modeling goals and processes. Unlike paper [P05], KPIs are not used here to model NFRs tied to processes models since they are not supported by UCM. Thus, NFRs are explicitly addressed only as softgoals in GRL and not explicitly addressed at the process level.

[P10] "Synthesizing enterprise strategic model and business processes in active-i*" (Xu et al., 2010): this paper proposes to combine goals and process modeling through $\mathrm{i}^{*}$ models and UML activity diagrams. Potential synergy points between the $i^{*}$ framework and UML activity diagrams are found by matching and mapping the major concepts of their 
metamodels. This approach aims at: identifying processes out of business objectives, extracting business goals through process abstraction, and identifying mismatches between business goals and processes. A combined metamodel is proposed in which both goals elements (including softgoals) and process elements are addressed together. This metamodel is presented at a higher level of abstraction without presenting a clear mapping between softgoals and processes.

[P11] "A method for eliciting goals for business process models based on non-functional requirements catalogues" (Cardoso et al., 2011): these authors propose a systematic way of identifying organizational goals for "as-is" process models. They propose using NFR catalogs, defined by other authors, to tackle the difficulty in identifying business goals and softgoals to be later used in process modeling. The approach is based on $i^{*}$ and Tropos. No specific notation is used to model processes. Per these authors, their approach allows modeling processes aligned with the business goals identified with the support of the mentioned catalogs.

[P12] "Extending BPMN for business activity monitoring" (Friedenstab et al., 2011): this paper proposes a BPMN extension that incorporates BAM concepts which aims to represent KPIs' real-time scores for process activities. A metamodel was built to systematically describe the aspects of the extension as well as the symbols added to BPMN to represent KPIs. The authors recommend that KPIs should be identified during the modeling phase in parallel with the functional requirements elicitation.

[P13] "An integration framework for multiperspective business process modeling" (Letsholo et al., 2012): a multi-perspective integration framework for process modeling is proposed to better align organizational goals and processes. The proposed framework is guided by the six models, proposed by other authors, which covers the following concerns: "what", "how", "where", "who", "when" and "why"). The authors suggest the following techniques for process modeling: (i) goal-oriented $-\mathrm{i}^{*}$, KAOS and Tropos; (ii) data-oriented - entity-relationship model, data flow diagrams and UML class diagram; and (iii) process-oriented - BPMN, IDEF3, UML activity diagrams, RAD and EPC. Each suggested technique can be appropriate at different levels for each concern presented. By this approach, NFRs are inherently addressed when combining the techniques useful for that although this is not explicitly addressed.

[P14] "Event-driven manufacturing process management approach" (Estruch and Álvaro, 2012): an approach is proposed to manage process through an event-driven architecture based on BAM concepts. The proposed approach is based on concepts such as BAM, KPI and CEP. The notation used to model processes is BPMN, which is extended to express logic for both: processing complex events and evaluating related KPIs. NFRs are addressed through CEP and KPIs which are embedded in BPMN representing both strategic goals and processes' NFRs.

[P15] "A bi-directional mapping between $\mathbf{i}$ and BPMN models in the context of business process management" (Alves et al., 2013): this paper extends the paper [P03] by refining the proposed heuristics to obtain $\mathrm{i}^{*}$ models from BPMN models beyond BPMN from $i^{*}$. Similar to the paper [P03], the mapping from BPMN to i* also addresses NFRs only indirectly. As NFRs are not modeled in BPMN, they should be inferred by searching quality attributes related to the activities performed by the participants.

[P16] "Making a link between strategy and process model collections: A multi-layered approach" (Dallilo et al., 2014): this paper proposes a multilevel approach, including a multi-layered metamodel, which extends BPMN and links strategic goals with an organization's collection processes, based on the Business Motivation Model (BMM) and BPMN. KPIs link the BMM and BPMN levels. While BPM represents the strategic goals, BPMN represents the process modeled to address such goals. KPIs systematically models the indicators responsible for assessing if the process execution is meeting the strategic goals.

[P17] "Modeling organizational alignment" (Sousa and Leite, 2014): this paper proposes a conceptual model that merges $i^{*}$, BPMN and KPI. The $i^{*}$ models are used to interconnect the other two. KPIs are linked only to the goals (including the softgoals that represent NFRs), detailing them by expressing what is necessary to satisfy them. Accordingly, NFRs are not directly addressed at the process level through BPMN. KPIs only insert an implicit link of traceability that helps identify crucial elements in the process.

[P18] "Combining modelling and simulation approaches: How to measure performance of business processes" (Bisogno et al., 2016): a method is proposed to analyze and improve operational performance of processes. The proposed method employs BPMN and Business Processes Simulation (BPSim) to measure KPIs. Like paper [P09], this work uses an inverse approach comparing to other approaches, i.e., strategic goals (specified as KPIs) are obtained from process models (modeled in BPMN) rather than the other way around. Based on process models, operational performance can then be measured using BPSim. The method allows testing of process designs and quantified measurement of variations in operational performance through four pre- 
defined KPIs. The only mapping between NFR and BPMN is through the four KPIs which should be modeled based on the process model evaluation.

[P19] "A framework for systematic analysis and modeling of trustworthiness requirements using $i^{*}$ and BPMN" (Mohammadi and Heisel, 2016): this paper proposes a framework for analyzing and modeling user-centered trustworthiness requirements. These authors use goal models to capture users' trust strategic goals, which should motivate design decisions with respect to trustworthiness. These authors use $\mathrm{i}$ * for goal modeling and BPMN for process modeling. The framework supports the refinement of softgoals right up to the elicitation of corresponding trustworthiness requirements. Trustworthinessrelated NFRs are firstly specified as softgoals in $i^{*}$ and mapped to BPMN, which has been extended to allow annotations capable of representing such NFRs.

\section{DISCUSSION OF THE RESULTS}

This section presents a discussion of our study's overall outcomes. First, Figure 2 shows the distribution of the 19 selected papers in relation to the publication year. One can see a low number of found papers, but steadily since 2009 . Considering the importance of strategic alignment for organizations as well as the importance of the support provided by BPM in this context, one could expect a larger number of works related to this research topic. This low number is probably reflex of the negligence commonly associated to NFRs in this and similar contexts.

Figure 2: Distribution of papers by publication year

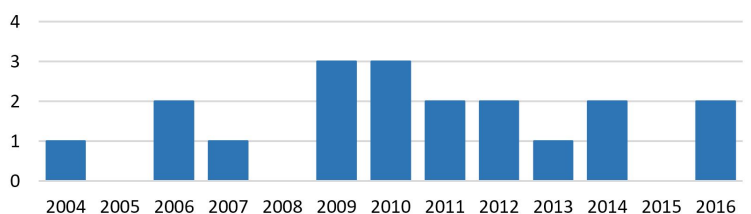

Our main result is the absence of approaches that fully meet the research problem that motivated this literature review. Our primary goal was to find research papers proposing some approach to model business processes' NFR based on organizational strategic goals. Per our analysis, no approach has been proposed specifically for this purpose. Aiming to support our findings, Table 2 presents the main characteristics of the works found and analyzed in Section 5.

As for "strategic goal modeling", we found eight techniques used for this purpose in the 19 evaluated papers. Figure 3 summarizes the techniques used to model strategic goals. Two techniques stand out: $i^{*}$ and KPI, respectively present in $47 \%$ and $37 \%$ of the papers. Tropos and URN/GRL (the third and forth most used technique) as well as $\mathrm{Si}^{*}$ are associated with the $i^{*}$ framework, which highlights the importance of $i^{*}$ for this context. All three other techniques are used in no more than one paper each. Per Table 2, one can verify that, for most of the approaches found, NFRs are modeled at the goal level through the softgoal concept (cf. column "NFRs at goal level"). Softgoals are used in 13 papers (of the total of 19 papers), for which goal modeling is always performed with $i^{*}$ or some $i^{*}$-related technique. We were expecting to find KPI as the most used technique instead of $i^{*}$, since KPI is highly known and used in both industry and academia. Either way, both technique are widely used and well distributed in time terms for the period considered. On the other hand, BSC did not occur in any of the 19 papers found, although it is also widely used in industry and in scientific research.

Figure 3: Techniques used to model strategic goals

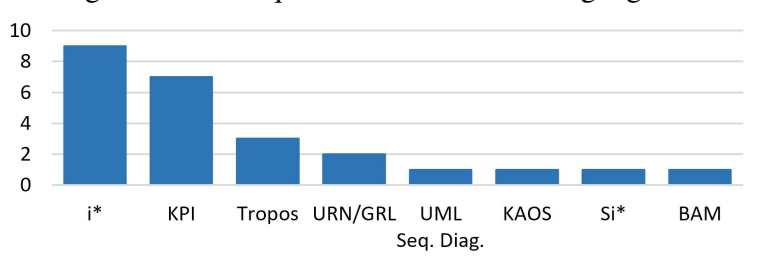

As for "business process modeling", we found nine techniques used for this purpose in the 19 evaluated papers. Figure 4 summarizes the techniques used to model business processes. Corroborating to our initial expectation, BPMN is notably the most widely used technique used to model business processes in this context, present in $53 \%$ of the papers. The second most widely used technique is UML Activity Diagrams, present in $16 \%$ of the papers. BPMN is the most popular notation used to model business processes while UML Activity Diagrams is the most popular technique used to model internal software processes. All seven other techniques are used in no more than two papers each. There are also three papers that do not mention any particular modeling technique. Per Table 2, NFRs are not modeled at the process level for most of works (cf. column "NFRs at process level"). In five works, KPI are used to model NFRs at both goal and process levels. In fact, KPIs are used to model NFRs in an integrated way for both perspectives. Therefore, there is no direct way of modeling business processes' NFRs even for these works.

Figure 5 presents a cross-analysis between goal modeling techniques and process modeling techniques as a result of overlapping Figures 3 and 4. We 
Table 2: Summary of the main characteristics of the 19 selected works

\begin{tabular}{|c|c|c|c|c|}
\hline Id & Strategic goal modeling & Business process modeling & Goals' NFRs & Processes' NFRs \\
\hline P01 & Tropos & [None] & Softgoals & [None] \\
\hline $\mathrm{P} 02$ & $i^{*}$ & RAD & Softgoals & [None] \\
\hline P03 & $i^{*}$ & BPMN & Softgoals & [None] \\
\hline P04 & $i^{*}$ & [None] & Softgoals & [None] \\
\hline P05 & KPI, URN/GRL & URN/UCM & Softgoals + KPI & [None] \\
\hline P06 & Sequence diagram & Activity diagram, FSM & Exception behavior & [None] \\
\hline P07 & $\mathrm{Si}^{*}$ & BPMN, Use cases diagram & Softgoals & [None] \\
\hline P08 & KPI & Rule-based & KPI & KPI \\
\hline P09 & URN/GRL & URN/UCM & Softgoals & [None] \\
\hline P10 & $i^{*}$ & Activity diagram & Softgoals & [None] \\
\hline P11 & $i^{*}$, Tropos & [None] & Softgoals & [None] \\
\hline P12 & KPI & BPMN & KPI & KPI \\
\hline P13 & i*, Tropos, KAOS & BPMN, Activity diag., RAD, EPC, IDEEF3 & [Several] & [Several] \\
\hline P14 & KPI, BAM & BPMN & KPI & KPI \\
\hline P15 & $i^{*}$ & BPMN & Softgoals & [None] \\
\hline P16 & KPI & BPMN & KPI & KPI \\
\hline P17 & $i^{*}$, KPI & BPMN & Softgoals + KPI & [None] \\
\hline P18 & KPI & BPMN & KPI & KPI \\
\hline P19 & $i^{*}$ & BPMN & Softgoals & Annotation \\
\hline
\end{tabular}

Figure 4: Techniques used to model business processes

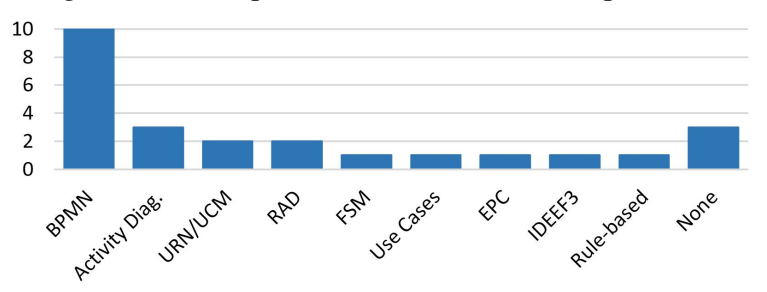

though we did not identify any approach that completely addresses the modeling of business processes' NFR based on strategic goals, one can infer that the way to reach this end, as indicated in the literature, would be to define an approach based on $i^{*}$ or KPI for goal modeling and BPMN for process modeling.

\section{CONCLUSION}

This paper presented the results of a literature study conducted to identify and evaluate approaches that propose the use of strategic goals as support for modeling business processes' NFRs. To the best of our knowledge, no previous study has been carried out with this specific goal as presented here.

We identified 19 works addressing strategic goals, business processes, and NFRs at some level. The most commonly used techniques are: $\mathrm{i}^{*}$ and KPI for goal modeling and BPMN for process modeling. Although we found partial solutions, no approach fully addresses business processes' NFR based on strategic goals which was our primary research question. Nevertheless, considering the evolution of the techniques found, we concluded that the indicated way to reach this end is by defining an approach based on $i^{*}$ or KPI for goal modeling and BPMN for process modeling.

Our conclusions were obtained from the experimental maturity of the 19 evaluated works. The evaluation was primarily qualitative, based on the main information presented in each paper. In quantitative terms, we did not produce any strong statistical evidence considering the small sample of found works which could not allow in-depth quantitative analyses. 
Figure 5: Cross-analysis between techniques to model strategic goals and techniques to model business processes

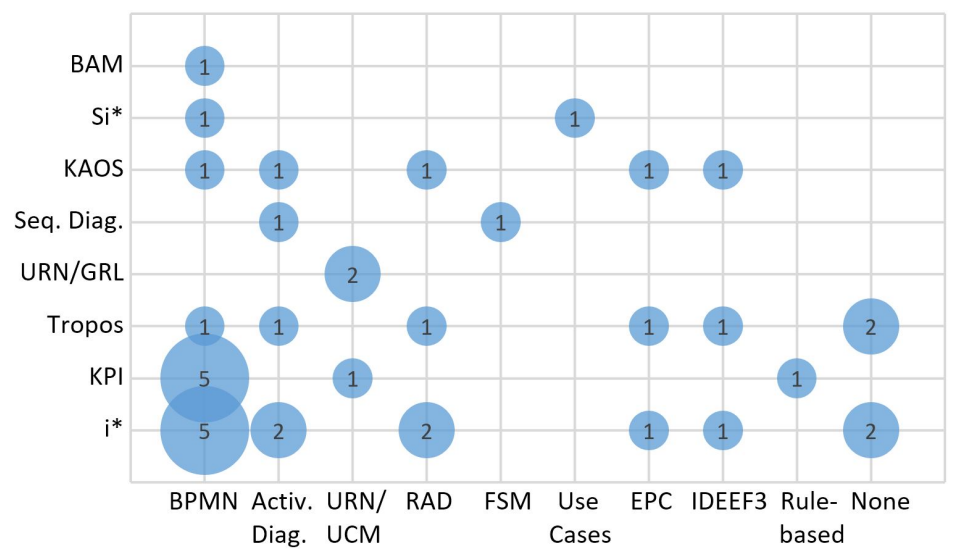

\section{ACKNOWLEDGEMENTS}

[to be included in case of paper acceptance.]

\section{REFERENCES}

Abeti, L., Ciancarini, P., and Moretti, R. (2009). Wikibased requirements management for business process reengineering. In ICSE Works. on Wikis for Soft. Engin., pages 14-24. IEEE.

Aghdasi, M. and Malihi, S. (2010). Rule based business process optimization. In IEEE Int. Conf. on Indust. Engin. and Engin. Manag., pages 305-309. IEEE.

Alotaibi, Y. (2014). Business process modelling challenges and solutions: A literature review. J. of Intel. Manufac., 27(4):1-23.

Alves, R., Silva, C., and Castro, J. (2013). A bi-directional mapping between $\mathrm{i}$ and BPMN models in the context of business process management. In Requir. Engin.@Brazil,pages 27.1-27.6. CEUR.

Behnam, S. A., Amyot, D., and Mussbacher, G. (2010). Towards a pattern-based framework for goal-driven business process modeling. In 8th ACIS Int. Conf. on Soft. Engin. Res., Manag. and Applic., pages 137-145. IEEE.

Biolchini, J., Mian, P. G., Natali, A. C. C., and Travassos, G. H. (2005). Systematic review in software engineering. Technical Report RT-ES 679/05, PESC - COPPE, UFRJ, Brazil.

Bisogno, S., Calabrese, A., Gastaldi, M., and Levialdi Ghiron, N. (2016). Combining modelling and simulation approaches: How to measure performance of business processes. Bus. Proc. Manag. J., 22(1):56-74.

Bleistein, S., Cox, K., Verner, J., and Phalp, K. (2006). BSCP: A requirements analysis framework for validating strategic alignment of organizational IT based on strategy, context, and process. Inform. and Soft. Tech., 48(9):846-868.

Bocciarelli, P. and D'Ambrogio, A. (2014). A model-driven method for enacting the design-time QoS analysis of business processes. Soft. and Syst. Model., 13(2):573598.

Cardoso, E. C. S., Almeida, J. P. A., Guizzardi, R. S. S., and Guizzardi, G. (2011). A method for eliciting goals for business process models based on non-functional requirements catalogues. Int. J. of Inform. Syst. Model. and Design, 2(2):1-18.

Charfi, A. and Zhi, H. (2015). Aspect-based realization of non-functional concerns in business processes. In $3 \mathrm{rd}$ Int. Conf. on Netw. Syst., pages 140-154. Springer.

Dallilo, F., De Albuquerque, J., and Fantinato, M. (2014). Making a link between strategy and process model collections: A multi-layered approach. In Int. Conf. on Soft. Engin. and Knowl. Engin., pages 387-392.

De Bruin, T. and Rosemann, M. (2006). Towards understanding strategic alignment of business process management. In 17th Austral. Conf. on Inf. Syst., pages 6-8. AAIS.

de Oca, I. M.-M., Snoeck, M., Reijers, H. A., and Rodríguez-Morffi, A. (2015). A systematic literature review of studies on business process modeling quality. Inform. and Soft. Tech., 58:187-205.

Doran, G. T. (1981). There's a S.M.A.R.T. way to write management's goals and objectives. Manag. Review, 70(11):35-36.

Dumas, M., La Rosa, M., Mendling, J., and Reijers, H. A. (2013). Fundamentals of business process management. Springer.

Estruch, A. and Álvaro, J. A. H. (2012). Event-driven manufacturing process management approach. In 10th Int. Conf. on Bus. Proc. Manag., pages 120-133. Springer.

Fantinato, M., de Souza, I. M. G., and Toledo, M. B. F. (2010). Product line in the business process management domain. In Kang, K. C., Sugumaran, V., and Park, S., editors, Applied Software Product Line Engineering, chapter 20, pages 497-530. Auerbach Public.

Friedenstab, J.-P., Janiesch, C., Matzner, M., and Mller, O. (2011). Extending bpmn for business activity monitoring. In Annual Hawaii Int. Conf. on Syst. Sci., pages 4158-4167. IEEE.

Friedenstab, J.-P., Janiesch, C., Matzner, M., and Müller, O. (2012). Extending BPMN for business activity moni- 
toring. In 45th Hawaii Int. Conf. on Syst. Sci., pages 4158-4167. IEEE.

Henderson, J. C. and Venkatraman, N. (1993). Strategic alignment: Leveraging information technology for transforming organizations. IBM Syst. J., 32(1):4-16.

Janes, A. and Faganel, A. (2013). Instruments and methods for the integration of company's strategic goals and key performance indicators. Kybernetes, 42(6):928942.

Kazhamiakin, R., Pistore, M., and Roveri, M. (2004). A framework for integrating business processes and business requirements. In Int. Enterp. Dist. Object Comp. Works., pages 9-20. IEEE.

Kitchenham, B. and Charters, S. (2007). Guidelines for performing systematic literature reviews in software engineering. Technical Report EBSE 2007-001, Keele University and University of Durham, UK.

Kocbek, M., Jost, G., Hericko, M., and Polancic, G. (2015). Business process model and notation: The current state of affairs. Comp. Sci. and Inform. Syst., 12(2):509-539.

Koliadis, G., Vranesevic, A., Bhuiyan, M., Krishna, A., and Ghose, A. (2006). A combined approach for supporting the business process model lifecycle. In 10th Pacific Asia Conf. on Inform. Syst., page 76. AIS.

Lapouchnian, A., Yu, Y., and Mylopoulos, J. (2007). Requirements-driven design and configuration management of business processes. In 5th Int. Conf. on Bus. Proc. Manag., pages 246-261. Springer.

Lee, Y.-C., Chu, P.-Y., and Tseng, H.-L. (2011). Corporate performance of ICT-enabled business process re-engineering. Indust. Manag. \& Data Syst., 111(5):735-754.

Leite, L. A., Oliva, G. A., Nogueira, G. M., Gerosa, M. A., Kon, F., and Milojicic, D. S. (2013). A systematic literature review of service choreography adaptation. Serv. Orient. Comp. and Applic., 7(3):199-216.

Letsholo, K., Chioasca, E.-V., and Zhao, L. (2012). An integration framework for multi-perspective business process modeling. In 9th Int. Conf. on Serv. Comp., pages 33-40. IEEE.

Mili, H., Tremblay, G., Jaoude, G. B., Lefebvre, É., Elabed, L., and Boussaidi, G. E. (2010). Business process modeling languages: Sorting through the alphabet soup. ACM Comp. Surv., 43(1):4.

Mohammadi, N. G. and Heisel, M. (2016). A framework for systematic analysis and modeling of trustworthiness requirements using $\mathrm{i}^{*}$ and BPMN. In 13th Int. Conf. on Trust, Priv. and Sec. in Dig. Bus., pages 318. Springer.

Parmenter, D. (2015). Key performance indicators: Developing, implementing, and using winning KPIs. John Wiley \& Sons.

Plösch, R., Pomberger, G., and Stallinger, F. (2011). Software engineering strategies: Aligning software process improvement with strategic goals. In 11th Int. Conf. on Soft. Proc. Improv. and Capab. Determ., pages 221-226. Springer.

Poels, G., Decreus, K., Roelens, B., and Snoeck, M. (2013). Investigating goal-oriented requirements engineering for business processes. J. of Datab. Manag., 24(2):3571.

Pourshahid, A., Amyot, D., Peyton, L., Ghanavati, S., Chen, P., Weiss, M., and Forster, A. J. (2009). Business process management with the user requirements notation. Elec. Comm. Research, 9(4):269-316.

Pourshahid, A., Amyot, D., Shamsaei, A., Mussbacher, G., and Weiss, M. (2012). A systematic review and assessment of aspect-oriented methods applied to business process adaptation. J. of Soft., 7(8):1816-1826.

Pressman, R. S. (2009). Software engineering: a practitioner's approach.

Ruokonen, A., Pajunen, L., and Systä, T. (2009). Scenariodriven approach for business process modeling. In IEEE Int. Conf. on Web Serv., pages 123-130. IEEE.

Salles, G. B. and Fantinato, M. (2012). Análise da incorporação de requisitos não funcionais na modelagem de processos de negócio. In VIII Simp. Bras. de Sist. de Inf., pages 79-90.

Salles, G. B. M., Fantinato, M., Nishijima, M., and Albuquerque, J. P. (2013). A contribution to organizational and operational strategic alignment: Incorporating business level agreements into business process modeling. In 10th Int. Conf. on Serv. Comp., pages 17-24. IEEE.

Shamsaei, A., Amyot, D., and Pourshahid, A. (2011). A systematic review of compliance measurement based on goals and indicators. In 4th Int. Works. on Govern. Risk and Compl.: Applic. in Inform. Syst., pages 228237. Springer.

Sommerville, I. (2010). Software Engineering. AddisonWesley, 9th edition.

Sousa, H. and Leite, J. (2014). Modeling organizational alignment. In 33rd Int. Conf. on Concep. Model. pages 407-414. Springer.

Tallon, P. P. (2008). Inside the adaptive enterprise: An information technology capabilities perspective on business process agility. Inform. Tech. and Manag., 9(1):21-36

van der Aalst, W. M. P., Hofstede, A. T., and Weske, M. (2003). Business process management: A survey. pages 1-12. Springer.

Weske, M. (2012). Business Process Management. Springer-Verlag Berlin Heidelberg, 2 edition.

Wetzstein, B., Leitner, P., Rosenberg, F., Brandic, I., Dustdar, S., and Leymann, F. (2009). Monitoring and analyzing influential factors of business process performance. In IEEE Int. Enterp. Dist. Object Comp. Conf., pages 141-150. IEEE.

Xu, T., Ma, W., Liu, L., and Karagiannis, D. (2010). Synthesizing enterprise strategic model and business processes in active-i*. In IEEE Int. Enterp. Dist. Object Comp. Works., pages 345-354. IEEE.

Yu, E. S. K., Mylopoulos, J., and Lespérance, Y. (1996). AI models for business process reengineering. IEEE Expert, 11(4):16-23. 
Apêndice B 
Questionário para levantamento de informações acerca do trabalho sobre StrAli-BPM (KPI2BLA) para a disciplina SIN5009 - Gestão Computacional de Processos de Negócio

Integrante 1:

Integrante 2:

\section{Parte 1 - Desenvolvimento do Trabalho}

1. Como foi feita a divisão para realização do trabalho:

( ) a. Ambos os integrantes da dupla fizeram o trabalho \{ Nesse caso, ambos os integrante devem responder o restante do questionário\}

( ) b. Apenas um dos integrantes fez o trabalho \{Nesse caso, apenas o integrante que fez deve responder o restante do questionário. Nenhuma penalidade será dada a dupla pelo fato de apenas um ter feito trabalho\}

\section{Parte 2 - Identificação de formação/experiência}

(Quando apropriado, marque todas as alternativas que se aplicarem)

1. Possui experiência profissional?

[ ] Não

[ ] Estágio (quantos anos?

[ ] Emprego (quantos anos?

2. Se possui experiência profissional, em que função?

[ ] Engenheiro de software e similares (qual especificamente?

[ ] Analista de TI/suporte e similares (qual especificamente?

[ ] Professor (que curso?

[ ] Outro (qual?

3. Qual seu nível de escolaridade?

[ ] aluno de graduação

[ ] aluno de pós-graduação

4. Se aluno de graduação:

4.1. Qual seu semestre no curso?

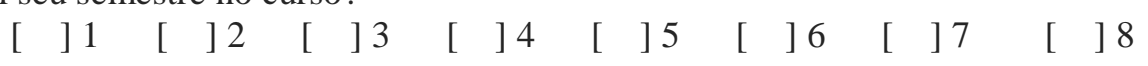

4.2. Quais dessas disciplinas já cursou?

[ ] Introdução à Administração para Computação

[ ] Prática e Gestão de Projetos

[ ] Economia para Computação

[ ] Empreendedorismo em Informática

[ ] Contabilidade para Computação

5. Se aluno de pós-graduação, qual sua graduação?

[ ] Sistemas de Informação

[ ] Ciência da Computação

[ ] Engenharia da Computação

[ ] Tecnologia na área de computação (qual?

[ ] Outros (qual? 


\section{Parte 3 - Identificação de Conhecimento Prévio}

(Responda às questões abaixo usando a escala de 1 a 5, sendo 1 o nível mais baixo e 5, o mais alto)

1. Conceitue sua experiência prévia (ou seja, antes da realização deste trabalho) em relação a processos de negócio e gestão de processos de negócio (BPM) em geral:

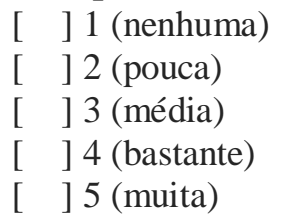

2. Conceitue sua experiência prévia (ou seja, antes da realização deste trabalho) em relação à notação BPMN:
[ ] 1 (nenhuma)
[ ] 2 (pouca)
[ ] 3 (média)
[ ] 4 (bastante)
[ ] 5 (muita)

3. Conceitue sua experiência prévia (ou seja, antes da realização deste trabalho) em relação a requisitos não funcionais:

[ ] 1 (nenhuma)

[ ] 2 (pouca)

[ ] 3 (média)

[ ] 4 (bastante)

[ ] 5 (muita)

4. Conceitue sua experiência prévia (ou seja, antes da realização deste trabalho) em relação a SLA (Service Level Agreement) e QoS (Quality of Service):
[ ] 1 (nenhuma)
[ ] 2 (pouca)
[ ] 3 (média)
[ ] 4 (bastante)
[ ] 5 (muita)

5. Conceitue sua experiência prévia (ou seja, antes da realização deste trabalho) em relação a planejamento/plano estratégico e metas estratégicas organizacionais:
[ ] 1 (nenhuma)
[ ] 2 (pouca)
[ ] 3 (média)
[ ] 4 (bastante)
[ ] 5 (muita)

6. Conceitue sua experiência prévia (ou seja, antes da realização deste trabalho) em relação a KPI (Key Performance Indicator):
[ ] 1 (nenhuma)
[ ] 2 (pouca)
[ ] 3 (média)
[ ] 4 (bastante)
[ ] 5 (muita) 


\section{Parte 4 - Avaliação da abordagem usada para realização do trabalho}

1. Qual abordagem foi usada pela sua dupla?

[ ] Ad hoc

[ ] KPI2BLA

2. Quão fácil você achou modelar o BLA com base no KPI informado seguindo a abordagem usada por você? [facilidade: quando não existem dificuldades ou obstáculos para realização de uma tarefa]

[ ] 1 (muito difícil)

[ ] 2 (difícil)

[ ] 3 (nem fácil, nem difícil)

[ ] 4 (fácil)

[ ] 5 (muito fácil)

3. Quão viável você acha que seja modelar BLAs com base em KPIs seguindo a abordagem usada por você? [viabilidade: quando há condições para se realizar uma tarefa]

[ ] 1 (muito inviável)

[ ] 2 (inviável)

[ ] 3 (nem viável, nem inviável)

[ ] 4 (viável)

[ ] 5 (muito viável)

4. Quão benéfico você acha que seja modelar BLAs com base em KPIs seguindo a abordagem usada por você? [benefício: quando há vantagens associada a realização de uma tarefa]

[ ] 1 (muito maléfico)

[ ] 2 (maléfico)

[ ] 3 (nem maléfico, nem benéfico)

[ ] 4 (benéfico)

[ ] 5 (muito benéfico)

5. Você recomendaria a alguém a abordagem usada por você para modelar BLAs com base em KPIs?

[ ] 1 (certamente não recomendaria)

[ ] 2 (provavelmente não recomendaria)

[ ] 3 (poderia tanto recomendar quanto não recomendar)

[ ] 4 (provavelmente recomendaria)

[ ] 5 (certamente recomendaria)

6. Use as linhas abaixo caso queira fazer algum comentário adicional sobre a abordagem usada por você para modelar BLAs com base em KPIs? 
Apêndice C 


\title{
Informações sobre o protótipo de ferramenta computacional usado para auxiliar no processo de avaliação da abordagem KPI2BLA
}

\begin{abstract}
A ferramenta foi desenvolvida na plataforma da Microsoft para aplicações Web usando a linguagem de programação C\# e banco de dados SQL Server 2014. O ambiente usado para hospedagem da ferramenta e do banco de dados foi o Windows Azure, que é uma plataforma da Microsoft para aplicações na nuvem (cloud computing).
\end{abstract}

\section{Primeiro acesso}

Com intuito de evitar interferência no processo de execução da tarefa submetida aos alunos, foi necessário a criação de um controle de acesso para evitar que os alunos não tivessem acesso aos resultados da tarefa de outros alunos. Então no primeiro acesso é necessário efetuar um cadastro para criar um usuário de acesso. 


\section{Tela de login}

De pose das credencias de acesso (nome de usuário e senha) é possível efetuar o login na ferramenta.

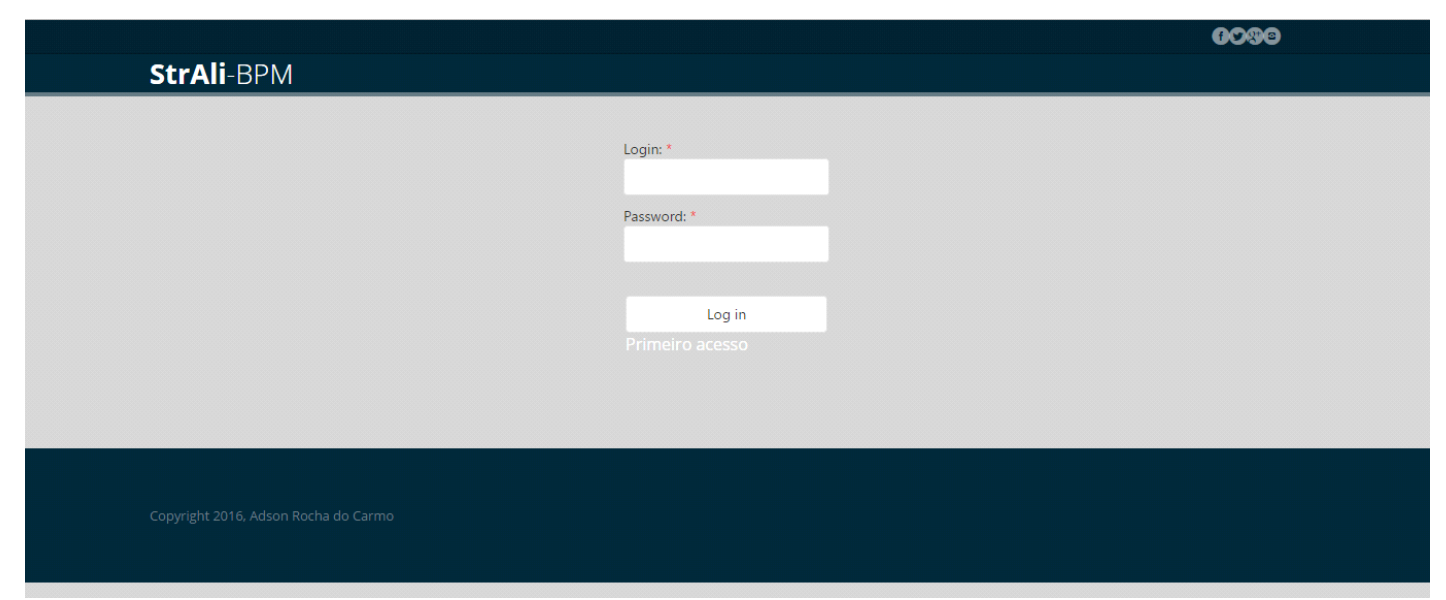

\section{Tela de apresentação das principais features da ferramenta}

Nesta tela é feita uma breve apresentação dos principais conceitos usados pela ferramenta e também é disponibilizado os links para acessá-las.

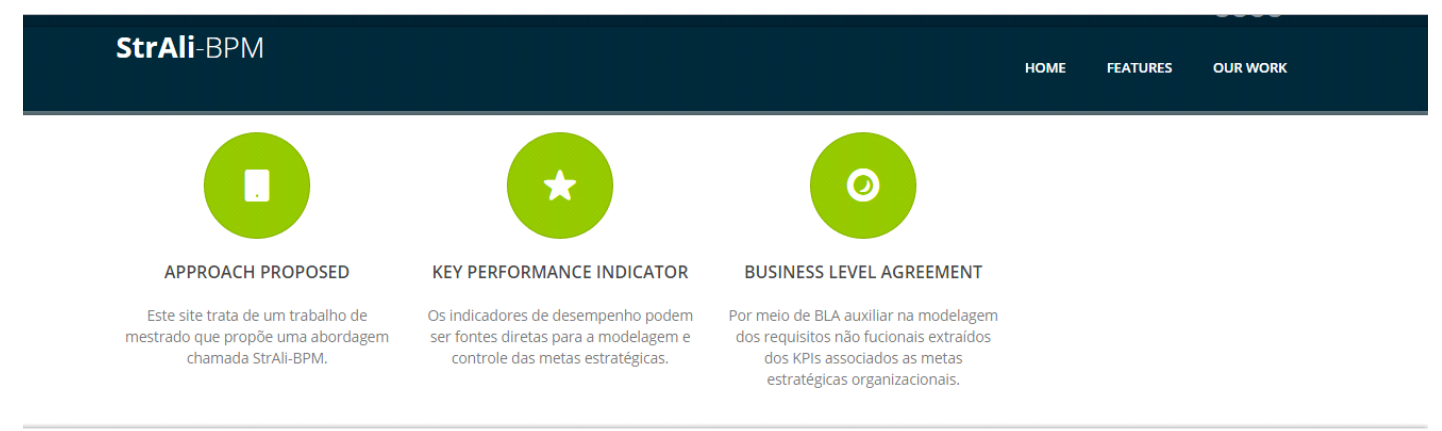




\section{Proposed template}
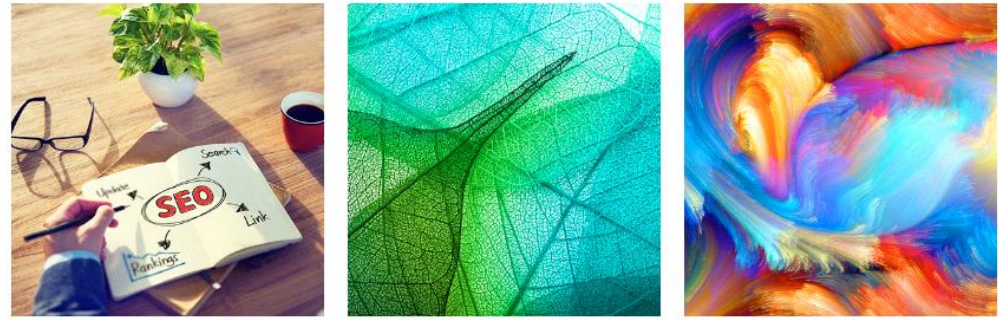

\section{A primeira tela de inicio do processo é a tela de criação da meta estratégica organizacional}

Informações como o texto descrevendo a meta estratégica organizacional e o período de desejado para alcançá-la.

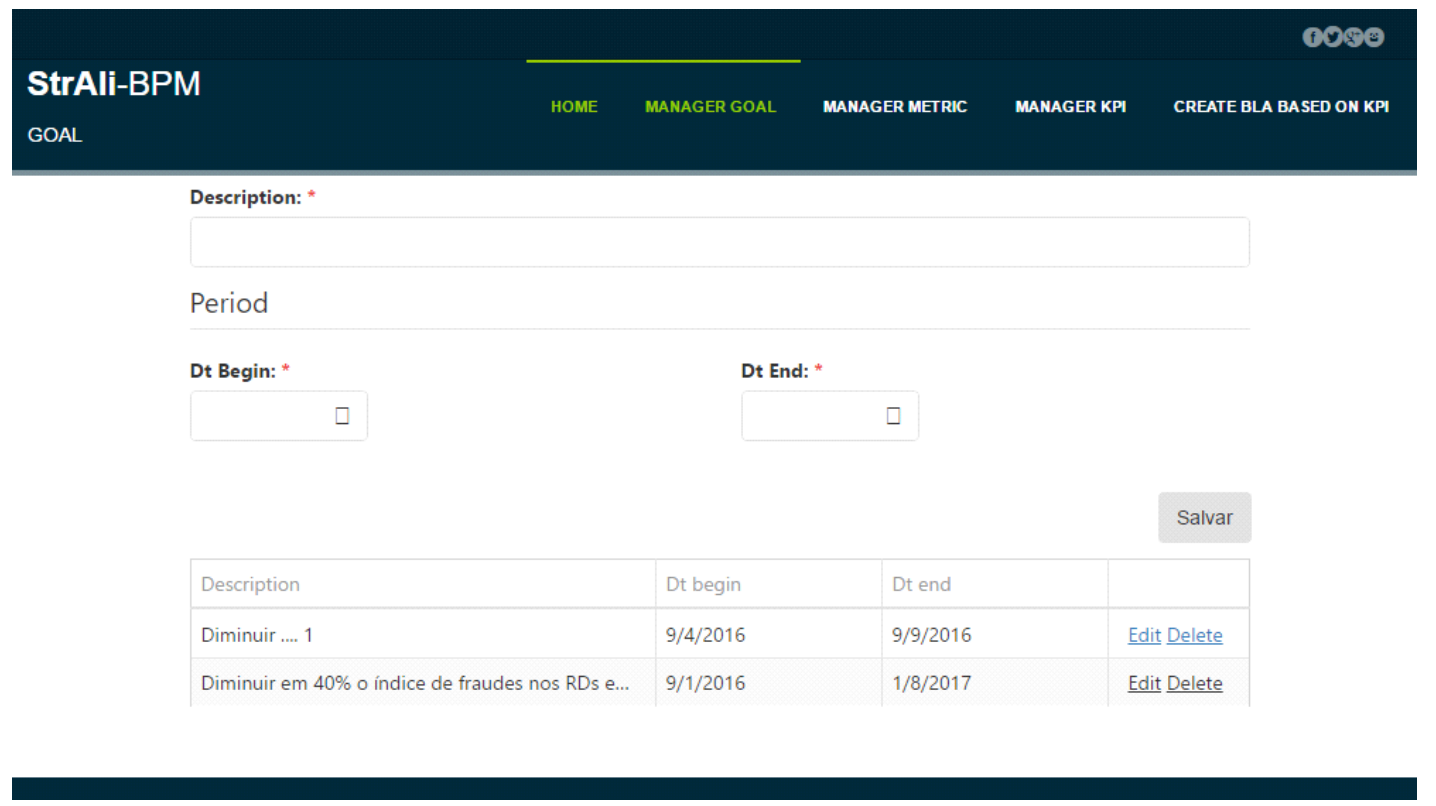




\section{A tela de criação da métrica}

O primeiro passo é selecionar a meta estratégica organizacional que a métrica será associada. Em continuidade informações como: calculo da métrica, atributo de desempenho e tipo da métrica devem ser preenchidas. Logo abaixo do formulário é listado as métricas já criadas.

\section{StrAli-BPM}

METRIC

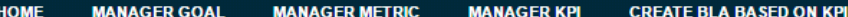

\begin{tabular}{|c|c|c|c|c|c|}
\hline \multicolumn{6}{|l|}{ Goal: } \\
\hline \multicolumn{6}{|c|}{ Diminuir em $40 \%$ o índice de fraudes nos RDs em seis meses. } \\
\hline \multicolumn{3}{|l|}{ Name: * } & \multicolumn{3}{|l|}{ Description: * } \\
\hline \multicolumn{6}{|l|}{ Calculation: * } \\
\hline \multicolumn{3}{|l|}{ Atributo Performance Name: * } & \multicolumn{3}{|c|}{ Metric Type Name: * } \\
\hline \multicolumn{3}{|l|}{ Select... } & \multicolumn{2}{|l|}{ Select... } & fi \\
\hline & & & & & Salvar \\
\hline Name & Calculati... & AtributoPerfor... & Goal & Creation date & \\
\hline Teste Up & onono & Maintainability & Diminuir em $4 \ldots$ & 9/9/2016 & Edit Delete \\
\hline Teste $><$ & da & Interoperability & Diminuir em $4 \ldots$ & $9 / 9 / 2016$ & Edit Delete \\
\hline Percentual de RDs recusados & NumRDs... & Effectiveness & Diminuir em $4 \ldots$ & $9 / 6 / 2016$ & Edit Delete \\
\hline Metrica & $A>B$ & Interoperability & Diminuir .... 1 & $9 / 5 / 2016$ & Edit Delete \\
\hline
\end{tabular}




\section{Tela de criação do KPI}

A tela seguinte é a mais importante, pois é o cerne do template proposto e representa o KPI. Na tela de criação do KPI, o primeiro passo deve ser escolher a meta que motiva a criação do BLA, em seguida deve ser selecionado uma das métricas disponíveis que estão relacionadas a meta selecionada anteriormente. Ao selecionar a métrica, é exibida uma visualização resumida da métrica (chamada na ferramente de Metric detail), com proposito de ajudar o usuário a lembrar os detalhes da métrica. Os detalhes da métrica exibida ao ser selecionada são dispostos de uma forma a ajudar na leitura da métrica, como ilustrado na figura abaixo.

\section{StrAli-BPM}

KPI

Goal:

Diminuir em $40 \%$ o índice de fraudes nos RDs em seis meses.

Select metric

Percentual de RDs recusados

Metric details:

A métrica a ser aplicada é o percentual de RDs recusados

Effectiveness: Percentual de RDs recusados $=($ NumRDsRecusados $/$ TotalRDsEnviado $)$ Down

General data

Name: *

Description: *

Dt Begin: * Dt End:

$\square \square$ 
7. Ainda na tela de criação de KPI, outra feature é apresentada no preenchimento das informações de bonificação e penalidade. Na parte inferior da tela, a ferramenta exibe um resumo das informações do KPI relacionadas a bonificação e a penalização de acordo com preenchimento do formulário. Este resumo, além da bonificação e da penalização, usa informações da métrica, criando uma expressão que envolve lógica e as informações preenchidas pelo usuário. A expressão exibida como resumo pode ser vista na figura abaixo e são intituladas de "Bonus details e Penality details".

Penality
Description: *
Departamento
Coin: *
Real
Comparation: *

Source: *
Departamento pessoal
Value: *
3000.00
Limiar Value: *
20

Bonus details:

'if' Percentual de RDs recusados (NumRDsRecusados / TotalRDsEnviado ) < ' then ' Departamento financeiro

' must earn ' 1500.00 Real

Penality details:

'if' Percentual de RDs recusados (NumRDsRecusados / TotalRDsEnviado ) > ' then ' Departamento pessoal

' must pay ' 3000.00 Real 


\section{Tela de edição e exportação (em XML), do BLA criado a partir do KPI}

Após a criação do KPI ele será listado em outra tela. É nesta tela que ocorre a conversão das informações do KPI para BLA. Quando um KPI é criado no protótipo ele fica armazenado e a qualquer momento o usuário pode gerar um BLA a partir do KPI, para isso, basta clicar no KPI criado e o protótipo exibe o BLA e suas informações em campos abertos para edição, como ilustrado na figura abaixo. Isto é possível porquê um dos intuitos da abordagem é permitir autonomia ao usuário no momento da criação do BLA.

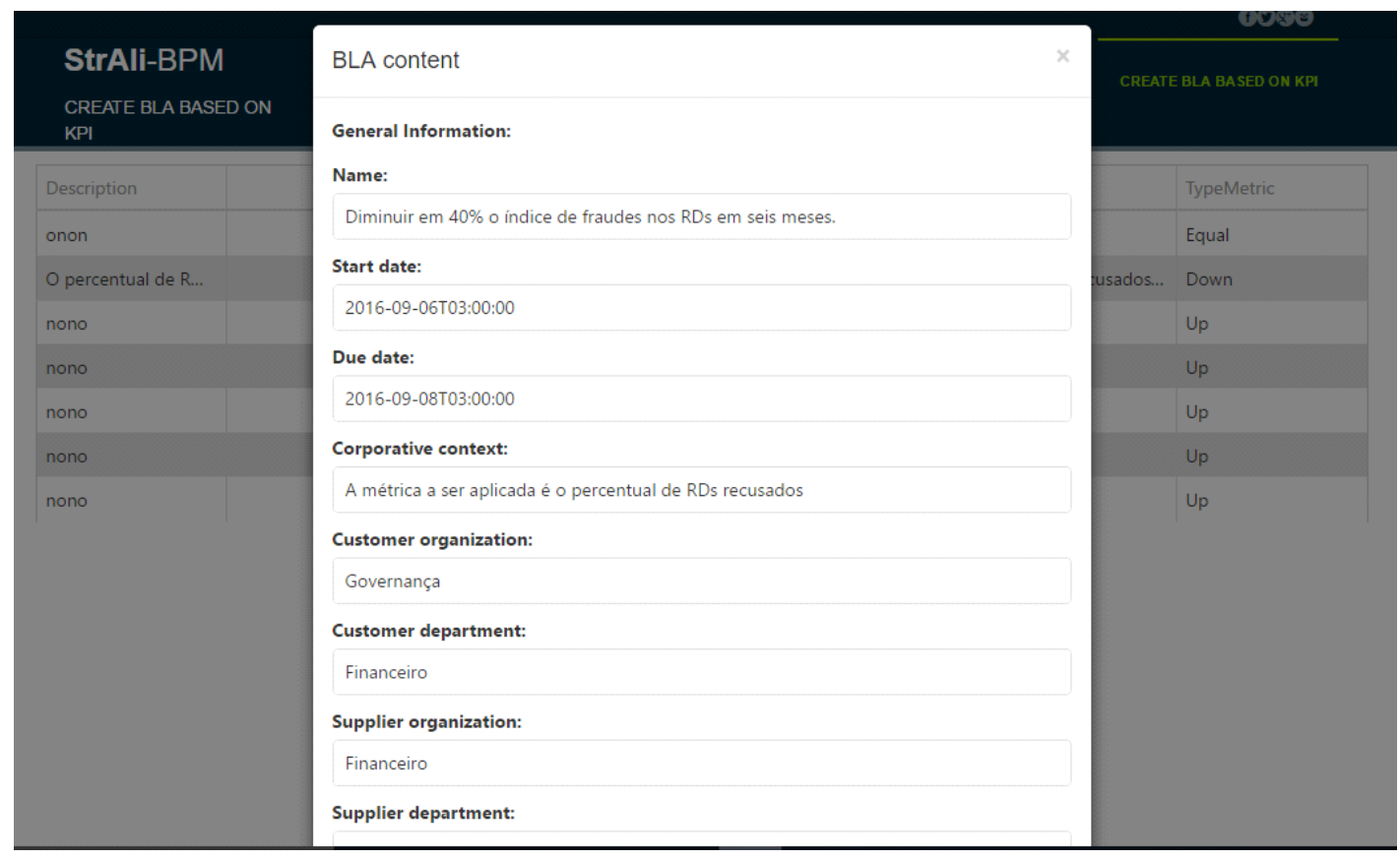


9. Ao concluir a edição dos campos do BLA ou simplemente concordar com o BLA sugerido, o usuário pode gerar um XML por meio do botão, "View as XML", disponível no final da tela BLA content.

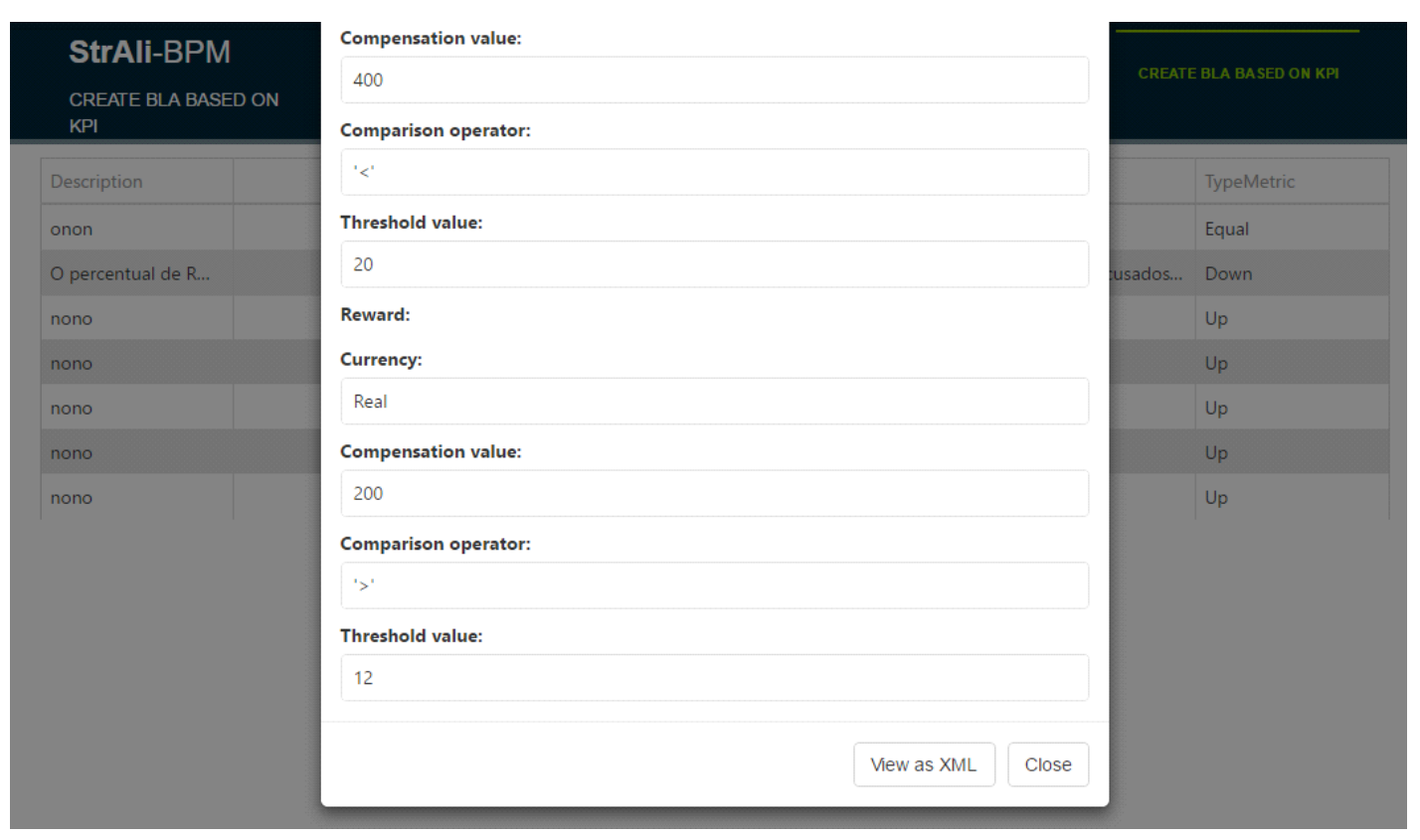




\section{Ao clicar no botão "View as XML" a ferramenta disponibiliza o XML na tela para que o usuário possa copiá-lo e salvar como .txt. Este XML servirá como entrada para a versão anterior do framework StrAli-BPM.}

$<$ BLA $><$ Name $>$ Melhorar em $40 \%$ a qualidade do atendimento dos pacientes com doenças crônicas não transmissiveis nos próximos três anos.</Name> <DtBegin >2016-09-28T03:00:00</DtBegin ><DtEnd >2016-10-28T02:00:00</DtEnd $>$ $<$ CorporativeContext $>$ Aumentar em $20 \%$ as consultas dos pacientes com status participating $<$ /CorporativeContext $><$ CustomerOrganization $>$ Departamento multidisciplinar $<$ /CustomerOrganization $><$ CustomerDepartment $>$ Diretoria hospitalar $<$ /CustomerDepartment $><$ SupplierOrganization $>$ Diretoria hospitalar $<$ SSupplierOrganization $><$ SupplieDepartment $/><\mathrm{kpi}>$ Controle do percentual de consultas dos pacientes $</ \mathrm{kpi}>$ $<$ ComparisonOperator>TotalConsultasPacientesCronicosParticipating / TotalConsultasPacientesCronicos $</$ ComparisonOperator $>$ $<$ TargetValue $>80<$ TargetValue $><$ Unit $>\%</$ Unit $><$ CheckOnBLADueDate $/>$ $<$ CurrencyPenalty $>$ reais $</$ CurrencyPenalty $>$ $<$ CompensationValuePenalty $>4000</$ CompensationValuePenalty $>$ $<$ ComparisonOperatorPenalty $>$ '\&lt;' $</$ ComparisonOperatorPenalty $>$ $<$ ThresholdValuePenalty $>65</$ ThresholdValuePenalty $>$ $<$ CurrencyBonus $>$ reais $<$ /CurrencyBonus $>$ $<$ CompensationValueBonus $>3500</$ CompensationValueBonus $>$ $<$ ComparisonOperatorBonus $>$ '\&gt,'</ComparisonOperatorBonus $>$ $<$ ThresholdValueBonus $>75</$ ThresholdValueBonus $><$ BLA $>$ 